\title{
Pipe-to-Pipe Impact Program
}

J. M. Alzheimer

M. C. C. Bampton

J. R. Friley

F. A. Simonen

June 1984

Prepared for

the U.S. Nuclear Regulatory Commission under Contract DE-AC06-76RLO 1830

NRC FIN B2383

Pacific Northwest Laboratory Operated for the U.S. Department of Energy by Battelle Memorial Institute 


\title{
DISCLAIMER
}

This report was prepared as an account of work sponsored by an agency of the United States Government. Neither the United States Government nor any agency thereof, nor any of their employees, makes any warranty, express or implied, or assumes any legal liability or responsibility for the accuracy, completeness, or usefulness of any information, apparatus, product, or process disclosed, or represents that its use would not infringe privately owned rights. Reference herein to any specific commercial product, process, or service by trade name, trademark, manufacturer, or otherwise, does not necessarily constitute or imply its endorsement, recommendation, or favoring by the United States Government or any agency thereof. The views and opinions of authors expressed herein do not necessarily state or reflect those of the United States Government or any agency thereof.

\author{
PACIFIC NORTHWEST LABORATORY \\ operated by \\ BATTELLE \\ for the \\ UNITED STATES DEPARTMENT OF ENERGY \\ under Contract DE-AC06-76RLO 1830
}


Interim Report

PIPE-TO-PIPE IMPACT PROGRAM

J. M. Alzhe imer

M. C. C. Bampton

J. R. Friley

F. A. Simonen

June 1984

Prepared for

the U.S. Nuclear Regulatory Commission under Contract DE-AC06-76RLO 1830

NRC FIN B2383

Pacific Northwest Laboratory

Richland, Washington 99352 


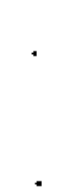




\section{ABSTRACT}

This report documents the tests and analyses performed as part of the Pipe-to-Pipe Impact (PTPI) Program at the Pacific Northwest Laboratory. The PTPI Program is sponsored by the Mechanical and Structural Engineering Branch, Reactor Safety Research Division of the U.S. Nuclear Regulatory Commission (NRC). Dr. G. H. Weidenhamer is the NRC Project Manager. This work was performed to assist the NRC in making licensing decisions regarding pipe-topipe impact events following postulated breaks in high energy fluid system piping. The report scope encompasses work conducted from the program's start through the completion of the initial hot oil tests. The test equipment, procedures, and results are described, as are analytic studies of faiture potential and data correlation. Because the PTPI Program is only partialiy completed, the total significance of the current test results cannot yet be accurately assessed. Therefore, although trends in the data are discussed, final conclusions and recommendations will be possible only after the completion of the program, which is scheduled to end in FY 1984. 


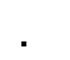

. . . . 
ABSTRACT • . . . . . . . . . . . . . . .

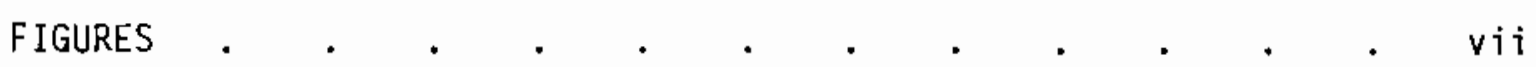

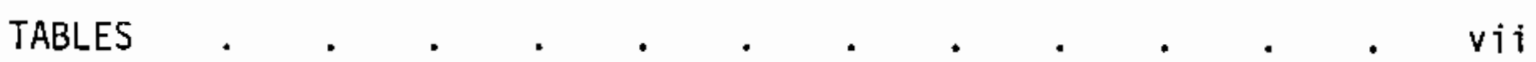

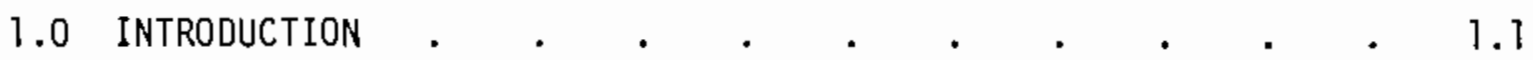

2.0 PIPE-TO-PIPE IMPACT TESTS. $\quad . \quad$. . . . . . 2.1

2.1 TEST MATRIX $. \quad . \quad . \quad . \quad . \quad . \quad . \quad . \quad . \quad$. 2.1

2.2 TEST EQUIPMENT . . . . . . . . . . . . . . . 2.3

2.2.1 Pipe Catapult. . . . . . . . 2.3

2.2 .2 Pipe Supports . . . . . . . . 2.5

2.2.3 Heating/Pressurizing System . . . . . 2.5

2.2 .4 Instrumentation . . . . . . . . 2.7

2.3 TEST RESULTS . . . . . . . . . . . . . . . . 2.9

2.3.1 Unheated, Unpressurized Pipe Tests . . . 2.9

2.3.2 Pressurized Hot 0il Tests . . . . . 2.12

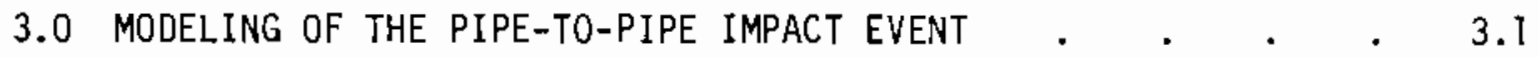

3.1 EQUATIONS OF MOTION . . . . . . . . . . . . 3.3

3.2 ALLOCATION OF CRUSHING ENERGY . • . • . . . . 3.6

3.3 APPLICATION OF DIMENSIONAL ANALYSIS. $. \quad . \quad . \quad$. 3.7

3.4 CORRELATION RESULTS . . . . . . . . . . . 3.12

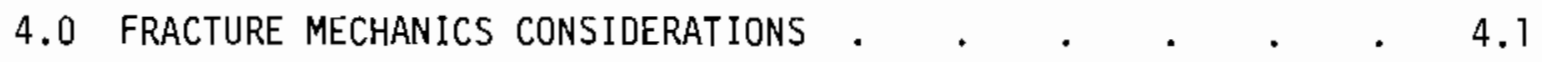

4.1 FRACTURE PROPERTIES . . . . . . . . . . . . 4.1

4.2 FLAW SENSITIVITY CALCULATIONS . . . . . . . . 4.4

4.3 PLASTIC STRAIN LIMITS . . . . . . . . . 4.6

4.4 RUPTURE PROBABILITY FOR FLAWED PIPE. . . . . 4.10

4.5 RUPTURE PROBABILITY FOR UNFLAWED PIPE . . . . . . 4.13

5.0 CONCLUSIONS AND RECOMMENDATIONS $. \quad . \quad . \quad . \quad . \quad . \quad . \quad 5.1$

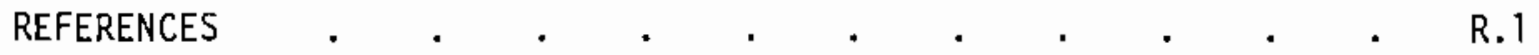
APPENDIX A - CALCULATION OF PLASTIC BENDING MOMENTS FOR

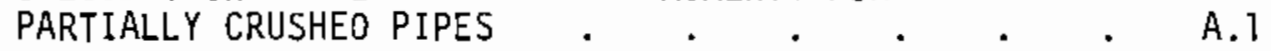
APPENDIX B - DERIVATION OF TARGET PIPE VOLUMETRIC COMPLIANCE. . B. 1 


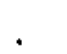

. 


\section{FIGURES}

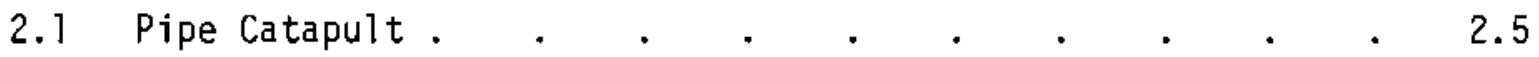

2.2 Surface Cracks on Impacted Pipe, Group 1 Tests . . . 2.10

2.3 Surface Cracks in Target Pipe Wal1, Group 1 Tests . . 2.11

2.4 Bend Angle Results for Hot 0il Tests . . . . . 2.13

2.5 Diameter Change Results for Hot 0 il Tests . . . . 2.13

2.6 Impacted Pjpe - Group 2, Test 2.1 . . . . . . . . 2.15

2.7 Impacted Pipe - Group 2, Test 2.2 . . . . . . . . 2.15

2.8 Impacted Pipe - Group 2, Test 2.3 . . . . . . . . . . . . . . . . .

2.9 Impacted Pipe - Group 3, Test 3.2 . . . . . . . 2.17

2.10 Impacted Pipe - Group 3, Test 3.1. . . . . . 2.18

2.11 Impacted Pipe - Group 3, Test 3.3. . . . . . . 2.18

2.12 Impacted Pipe - Group 3, Test 3.4 . . . . . . . . 2.19

2.13 Impacted Pipe - Group 4a, Test 4a.1 . . . . . . 2.20

2.14 Impacted Pipe - Group 4b, Test 4b.1 . . . . . 2.22

2.15 Impacted Pipe - Group 4b, Test 4b.2 . . . . . . 2.22

2.16 Impacted Pipe - Group 4b, Test 4b.3 . . . . . . 2.23

2.17 Impacted Pipe - Group 4b, Test 4b.4 . . . . . . 2.23

2.18 Side View of Ruptured Pipe . . . . . . . . . . 2.24

2.19 Detail of Through-Wall Crack. . . . . . . . 2.24

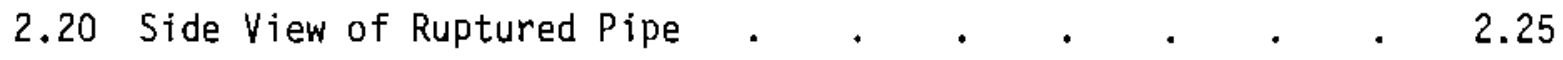

2.21 Detail of Through-Wall Crack . . . . . . . . 2.25

2.22 Impacted Pipe - Group 5a, Test $5 \mathrm{a} .1 \quad$ • . . . . . 2.27

2.23 Impacted Pipe - Group 5a, Test 5a.2 . . . . . . 2.27

2.24 Impacted Pipe - Group 5b, Test 5b.1 . . . . . 2.29

2.25 Impacted Pipe - Group 5b, Test 5b.2 . . . . . 2.29

2.26 Impacted Pipe - Group 5b, Test 5b.3 . . . . . . 2.30

3.1 Nomenclature for the Impact Model . . . . . . . 3.1

3.2 Generalized Velocity Plots for Pipe Response
in the Flexure Phase . . . . . . . . . . . . 3.6

3.3 Crush Energy Allocation Method . . . . . . . . . 3.7

3.4 Crush Data for 6-Inch Schedule 40 Pipes . . . . 3.10 
3.5 Crush Data for 6-Inch Schedule 80 Pipes . . . . 3.10

4.1 Dynamic Fracture Toughness for Al06 Grade B Pipe . . . 4.2

4.2 Plastic Fracture Solution for Applied J $\quad$ • $\quad$ • . . 4.5

4.3 Al06 Plastic Fracture Prediction . . . . . . . . . 4.6

4.4 Strain Limits for Unflawed A106 Predicted by Metal

4.5 Measured Strains for PNL Pipe Impact Test 5b . . . . 4.9

4.6 Reference Geometry for Rupture Probability Estimate . . 4.11

4.7 Summary of Failure Probability Estimates . . . . . 4.12

4.8 Configuration Used to Estimate Velocity/Energy

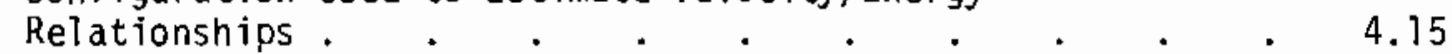

4.9 Estimated Velocities From Sample Calculation . . . 4.16

A.l Assumed Elliptical Ovalization Geometry for Crushed Pipe Sections . . . . . . . . . . A.l

B.1 Geometry and Terminology for Volumetric Compliance Anatysis. B.2

\section{TABLES}

2.1 Pipe-to-Pipe Impact Test Matrix $\quad . \quad$. $\quad . \quad$. $\quad$. 2.2

3.1 Data Used in Scale Model Crush Tests . . . . . . . . 3.8

3.2 Preliminary Results for Impact Model . . . . . . 3.12

4.1 Typical Fracture Properties of Al06 Class C Steel . . . 4.3 


\subsection{INTRODUCTION}

The U.S. Nuclear Regulatory Commission (NRC) has authorized the Pacific Northwest Laboratory (PNL) to investigate the behavior of piping during postulated pipe-to-pipe impact events. The laboratory research Pipe-to-Pipe Impact (PTPI) Program is sponsored by the Mechanical and Structural Engineering Branch, Reactor Safety Research Division of the NRC.

Justification for the PTPI Program stems from a need for data upon which to base licensing decisions. The current licensing criteria, as contained in Standard Review Plan (SRP) Section 3.6.2, are stated as follows:

"An unrestrained whipping pipe should be considered capable of causing circumferential and longitudinal breaks, individually, in impacted pipes of smaller nominal pipe size, and developing through-wall cracks in equal or larger nominal pipe sizes with thinner wall thickness, except where analytical or experimental, or both, data for the expected range of impact energies demonstrates the capability to withstand the impact without rupture."

The current criteria define a readily usable set of conditions under which pipe-to-pipe impact events can be permitted or should be prevented. However, the criteria do not specifically address the available energies, piping arrangements, or other potentially significant parameters. Because data to validate the criteria are lacking, the conservatism cannot be assessed. Under certain circumstances the current criteria may not be conservative. On the other hand, they may be overly conservative, thus adding unneeded restraints to power plants. The intent of the PTPI Program is to determine the range of parameters associated with postulated pipe-to-pipe impact events in typical nuclear power plants, conduct impact tests within the range of interest, evaluate current criteria in light of the test results, and, if appropriate, propose more realistic criteria. 
The pipe-to-pipe impact test methodology, equipment, and results are detailed in Section 2.0 of this report. Section 3.0 presents a description of the analytical method formulated to model the impact event. Fracture mechanisms related to pipe wall failure are discussed in Section 4.0. The conclusions and recommendations based on results obtained to date are presented in Section 5.0 of this report. 


\subsection{PIPE-TO-PIPE IMPACT TESTS}

This section describes the methodology and equipment used in conducting the impact tests. Results obtained are presented and discussed.

\subsection{TEST MATRIX}

Because the purpose of the PTPI Program was to investigate the current pipe-to-pipe impact criteria, the initial test matrix was developed to reflect the parameters of the current criteria. The current criteria, as contained in Standard Review Plan Section 3.6.2, "Determination of Break Locations and Dynamic Effects Associated with Postulated Rupture of Piping", consider nominal pipe diameters and relative wall thicknesses as the important parameters in determining if impacted pipes will break or leak. The rationale behind developing the matrix was to test various combinations of diameters and wall thicknesses. Some tests were performed on swinging and target pipes of equal diameters and equal wa1l thicknesses. Some tests were conducted using pipes of equal diameters but with different wall thicknesses. Other tests were performed on pipes with equal wall thicknesses but different diameters. The initial test matrix is shown in Table 2.1. For each group in the test matrix, three or four tests at different velocities were planned.

All pipe specimens were manufactured of A106 Grade B carbon steel. Al06 Grade $B$ was selected because it is the most typical carbon steel pipe in nuclear power plants and carbon steel was felt to be more likely to rupture than stainless steel. In addition, this carbon steel costs less than stainless steel and, therefore, allowed more testing for the same funding. All piping used in test specimens was supplied with material certifications listing the chemical composition, the yield and tensile strengths, and the elongation to failure. For the initial test matrix, all pipes of a given size (diameter and wail thickness) were from the same heat.

It was assumed that 6-inch diameter pipes would provide the average size for representative distributions. The potential effect of normaliy occurring, microscopic flaws in the piping material on the failure modes was 
TABLE 2.1. Pipe-to-Pipe Impact Test Matrix

\begin{tabular}{|c|c|c|c|c|}
\hline Group & Swinging Pipe & Target Pipe & $\begin{array}{l}\text { Wall Thickness } \\
\text { Relationship }\end{array}$ & $\begin{array}{c}\text { Diameter } \\
\text { Relationship }\end{array}$ \\
\hline$j^{(a)}$ & $6-i n$. Sch 40 & 6 -in. Sch 40 & $t_{1}=t_{2}$ & $D_{1}=D_{2}$ \\
\hline 2 & 6 -in. Sch 40 & 6 -in. Sch 40 & $t_{1}=t_{2}$ & $D_{1}=D_{2}$ \\
\hline 3 & 6 -in. Sch 80 & $6-$ in. Sch 80 & $t_{1}=t_{2}$ & $D_{1}=D_{2}$ \\
\hline $4 a$ & 6-in. Sch 40 & 6 -in. Sch 80 & $t_{1}<t_{2}$ & $D_{1}=D_{2}$ \\
\hline $4 b$ & 6 -in. Sch 80 & 6 -in. Sch 40 & $t_{1}>t_{2}$ & $D_{1}=D_{2}$ \\
\hline $5 a$ & 6 -in. Sch 120 & 12-in. Sch 60 & $t_{1}=t_{2}$ & $D_{1}<D_{2}$ \\
\hline $5 b$ & 6 -in. Sch 80 & 3 -in. Sch 160 & $t_{1}=t_{2}$ & $D_{1}>D_{2}$ \\
\hline
\end{tabular}

(a) The pipes in the Group 1 tests were unheated and unpressurized. In all other tests, the impacted (target) pipes were subjected to temperatures of approximately $550^{\circ} \mathrm{F}$ and pressures ranging between 2000 and 2300 psi. All swinging pipes were unpressurized and at ambient temperature when tested.

unknown. Therefore, very small pipe diameters were not used due to the concern for relative flaw size. Six inches was selected as the maximum nominal diameter of the swinging pipes for the tests although much larger pipes are currently in service. The energy requirements of swinging larger pipes was a primary consideration. The 6-inch diameter was assumed to be large enough to represent relative flaw size. Tests were to be performed on pipe without artificially induced flaws. In addition, impact would not be near welds. Al1 test specimens were 10 feet long because this length is economically obtainable from the standard 20- to 21-foot length of pipe. It is also a practical length with which to work. The 10-foot length was not intended to represent an expected break-to-hinge length or a nornal spacing distribution, although for some situations this length may be typical. All tests had the impact point at the mid-span of the impacted pipe and near the center of percussion of the swinging pipe. The two pipes were perpendicular at impact to represent the worst-impact condition. Except for a limited 
number of Group 1 tests, all impacted pipes were simply supported with a 9-foot span. Except for those tested in Group 1, a11 impacted pipes were pressurized to 2000 to 2300 psi and heated to approximately $550^{\circ} \mathrm{F}$. A11 swinging pipes were unpressurized and at ambient temperature.

\subsection{TEST EQUIPMENT}

After the test matrix was developed, the equipment necessary for conducting the tests had to be assembled. The major components required were the pipe-swinging device, the target pipe supports, a heating and pressurizing system, and the instrumentation system.

\subsubsection{Pipe Catapult}

The most unique piece of equipment needed for the pipe-to-pipe impact tests was the device to swing the pipes. Based upon the largest pipe sizes in the test matrix (Group 5a), the energy requirements to cause failure were estimated. Because it was not possible to readily assess the energy requirements to break the pipe, another mode of failure was examined. Failure of the impacted pipe could be considered as its loss of functional capability. For some systems this failure could correspond to the loss of the cross-sectional flow area. With this in mind, the energy required to completely flatten a 1-diameter length of both the swinging and target pipe in Group 5a was estimated. The flattening energy was used to estimate the energy required of the pipe-swinging device.

Several alternatives were examined for swinging the pipes. One concept for obtaining the same energy level did so with a very large mass falling at a slow speed. This concept was dismissed for strain rate effect reasons among others. In another concept, the swinging pipe would be filled with saturated water at an elevated temperature. A rupture disk would be broken, allowing the steam to exit around an elbow, creating a thrust very similar to an actual pipe break event. This concept was dismissed for safety reasons. Many other concepts were also examined. 
The concept finally adopted was a pneumatically-powered catapult. This catapult is shown in Figure 2.1. Major components of the catapult are the large pneumatic cylinder, catapult arm, connecting link, latch mechanism, pipe carriage, front and rear stanchions, and base. Energy to accelerate the pipe is stored in compressed gas in the rod end of the large cylinder. This actuator has a 20-inch diameter piston and a 36-inch stroke, and is rated to 500 psig. The pressure acts on the piston supplying a force to the piston rod. The piston rod is connected by a link to the catapult arm and thereby supplies a torque to the catapult arm. The catapult arm is released by actuating the small pneumatic cylinder. This allows the catapult arm, through the pipe carriage, to push against the pipe. The pipe is accelerated through an angle of up to 60 degrees, when the pressure of the gas trapped in the cap end of the large cylinder increases to greater than the pressure on the rod end. The catapult arm decelerates as the pipe continues on at a fairly constant velocity until it impacts the target pipe. After separating from the swinging pipe, the catapult arm is stabilized by the compression of the trapped volumes of gas on either side of the piston.

After the pneumatically-powered pipe catapult was conceptualized, its feasibility was studied. The feasibility study was followed by a preliminary design, which was subsequently refined. An analysis was performed and a computer program written to model the operation of the catapult so that the effects of various parameters could be assessed. This also allowed the determination of the dynamic loads applied to the various components. These loads were used in a stress analysis of the catapult. The catapult was then fabricated.

The catapult was used for all tests in the initial matrix as well as for numerous practice tests. The device performed very well with no significant problems, even though it was used at energy levels above those originally envisioned. Tests at these higher energy levels were accomplished without modifications because of the original margins of safety built into the design. 


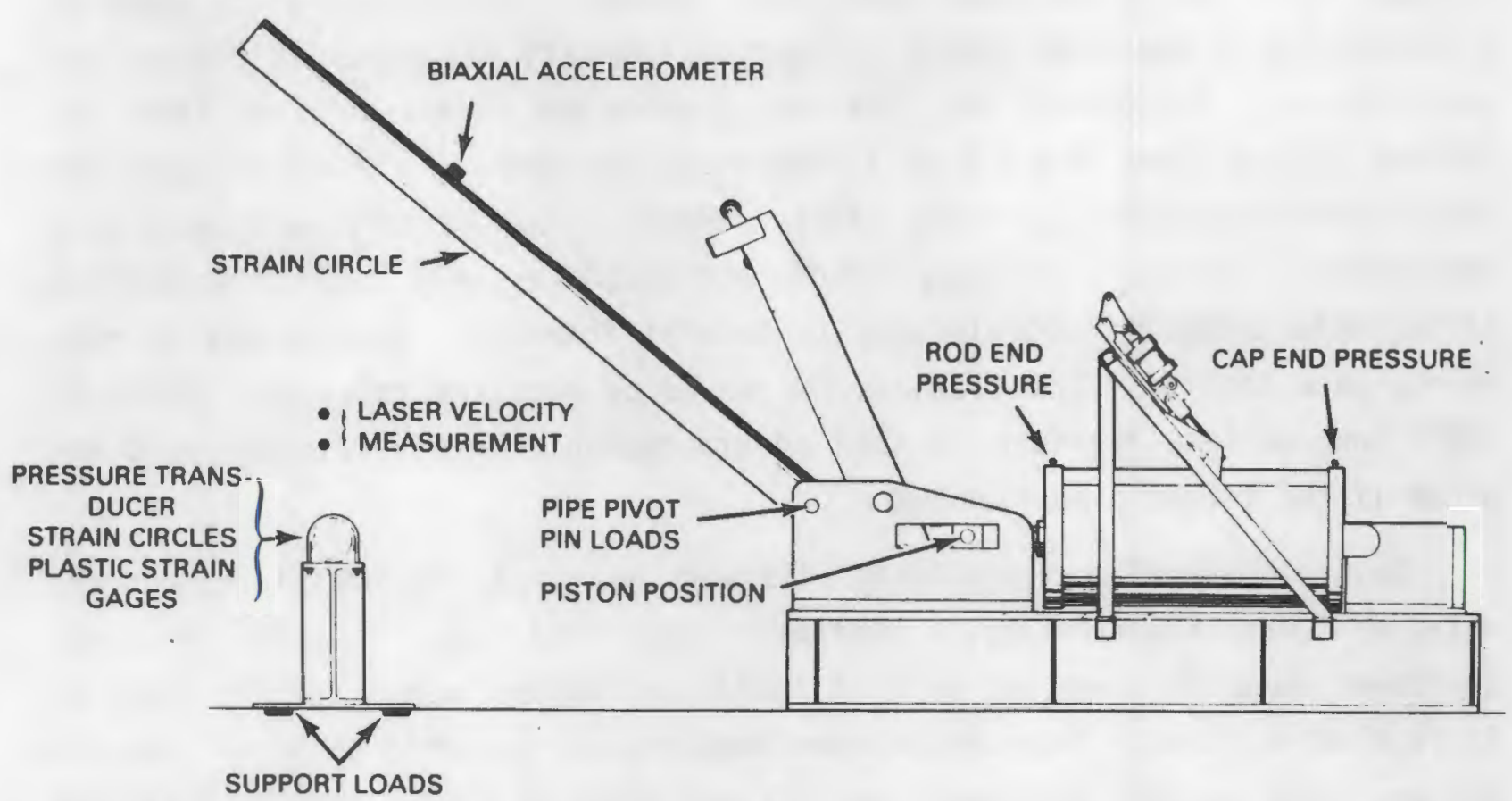

FIGURE 2.1. Pipe Catapult

\subsubsection{Pipe Supports}

The most severe support condition initially envisioned for the target pipe would be to rigidly support the pipe behind the point of impact. The other configuration considered at the program's outset was to simply support the pipe near the ends. During the preliminary tests conducted in Group 1, it was determined that the simply supported configuration was more severe because the pipe experienced a combined crush and bending deformation. Hence, all tests for the remainder of the test matrix used simpie supports.

\subsubsection{Heating/Pressurizing System}

To conduct the tests with the target pipes at $550^{\circ} \mathrm{F}$ and pressurized to 2000 to 2300 psi, a heating and pressurizing system was needed. Several media were considered for pressurizing the pipe. The most obvious choice was water 
because it is the fluid used in service. However, because of safety problems associated with the high energy content of water-filled pipes at pressurized water reactor (PWR) conditions, the use of water was rejected for at least the initial test matrix. The use of a compressed gas such as air or nitrogen was also unacceptable for the same safety reasons. Discussions were held with researchers in France, Germany, Canada, and Japan, as well as with scientists at Battelle Columbus Laboratories, to benefit from their experiences in high energy pipe testing. The fluid medium would be required to remain liquid at $550^{\circ} \mathrm{F}$ and ambient pressure so that an unacceptable energy release would not occur if the target pipe ruptured.

Several natural and synthetic oils were examined. An additional concern with oil was flammability. Sunflower seed oil was finally selected. Sunflower seed oil does not boil at $550^{\circ} \mathrm{F}$ and has a flash point above $550^{\circ} \mathrm{F}$. It is also relatively inexpensive when compared to synthetic oils. A comparison was made between sunflower seed $0 i 1$ and water at $550^{\circ} \mathrm{F}$ with the following results:

- state - At $550^{\circ} \mathrm{F}$ and 2000 psi, both water and sunflower seed oil are liquid. If the pipe were to rupture, the water would flash to steam while the oil would remain liquid.

- density - Over the range of available data ( 70 to $450^{\circ} \mathrm{F}$ ), the density of vegetable oil is 0.90 to 0.94 times that of saturated liquid water.

- compressibility - The compressibility of vegetable $0 i 1$ is about 0.005 volume percent per atmosphere at room temperature while that of water is 0.0046. Data on the compressibility of oil at high temperatures were not available.

- sonic velocity - The speed of sound in the two fluids was estimated to be within $10 \%$.

On the basis of these results, it was assumed that the use of oil would represent the actual behavior of water until the pipe ruptured. After the pipe rupture, the water would maintain the internal pressure at its saturation pressure while the oil would allow the pressure to drop rapidly. 
Electrical resistance heater tapes were used to heat the target pipe. The tapes were wrapped over the outside of the pipe except at the points of contact with the supports and at the center of the pipe for about 1 diameter either side of the impact point. The specimen was covered with fiber glass insulation while it was being heated. Just before an impact test the insulation was removed from the central region of impact.

The following procedures were used to heat and pressurize the target pipe: After the target pipe was secured to the supports, it was filled with the sunflower seed 0il. Care was taken to assure that no significant air space was left in the pipe. The heater tapes and insulation were added next. A pair of small-diameter, high pressure stainless steel lines was connected to the target pipe. One line permitted venting and bleed-off; the other line was used for pressurizing the target pipe. Next, the pressurizing line valve was closed and the vent line was opened. The heater tapes were connected to the power supply; as the specimen heated, the oil expanded faster than the pipe. The excess oil bled off through the vent line and was collected. When the specimen temperature, as monitored by a thermocouple, reached the desired test temperature, the vent line valve was closed. The valve in the pressurizing 1 ine was opened and the target pipe was pressurized from a nitrogen bottle. To prevent the nitrogen from dissolving in the oil, the nitrogen pressure was transferred to the $0 i 1$ by a piston in a small hydraulic cylinder. Just before the test the heater tapes were disconnected. When the test was completed, the pressurizing line was immediately closed and the target pipe vented.

\subsubsection{Instrumentation}

The most important information from each test was whether the impacted pipe ruptured. Also important were the diameter changes and the bend angles of both pipes. These data were augmented by various instruments that:

- established the test conditions and monitored the operation of the catapult

- monitored the target pipe during a test. 
The temperature and pressure of the target pipe and the velocity of the swinging pipe were controlled for each test. The temperature for the tests was specified to be $550^{\circ} \mathrm{F}$ but was somewhat higher for a few tests. The target pipe pressure for the tests was 2000 to 2300 psi and was usually determined by the pressure available from the nitrogen bottle. Precise control on the target pipe pressure was not maintained because the results were felt not to be highly dependent on the internal pressure. The velocity of the swinging pipe was controlled by varying the pressures on either side of the piston in the large pneumatic actuator. Using the computer program developed to model the kinematics and dynamics of the catapult, a combination of pressures was selected to achieve the desired velocity and to keep from overstressing the pneumatic cylinder. The temperature of the target pipe was monitored by a thermocouple attached to the pipe's outside surface under the insulation. The static target pipe pressure was set by the gage on the nitrogen bottle and checked by the pressure transducer in the end of the target pipe. The pressures on both sides of the piston were monitored with transducers before and during the test. The piston displacement was monitored by an extensometer.

For each test the target pipe was instrumented with strain gages, strain circles, and a transient pressure transducer. The load was measured at one support. For two initial tests, an accelerometer was placed on the swinging pipe. For these tests, the velocity of the swinging pipe just before impact was measured. After these two tests, the diameters of both pipes at the impact point were measured along with the bend angles. Two biaxial, plastic strain gages were placed on each target pipe at the circumference containing the initial point of impact. The strain gage signals indicated the gages failed after a very brief period. The initial strain rates were estimatable but, because of the obvious later failure of the gages, the data may be suspect. The strain circles were grids of circles electromarked onto the pipe surface. They did not indent or distort the pipe in any way. By knowing the initial diameter and measuring the deformed diameters of the strain circles, the local permanent strains could be assessed. The pressure transducers mounted in the end of the target pipe monitored the pressure transient inside 
the pipe during impact and the rate of depressurization if the pipe ruptured. Load cells were placed under one of the two supports to measure the load during impact. Because of the symmetrical impact, both support loads were assumed equal. The load cell under the support base measured the impact force. The use of accelerometers on the swinging pipe was discontinued after the first two tests because the data were not useful. A measure of the rigid body motion of the pipe had been sought. This part of the signal was swamped out by the high frequency ringing of the pipe wall, which overloaded the accelerometer. The velocity of the pipe was measured by a chronograph consisting of two parallel laser beams impinging on photocells and a timer to record the interval between the sequential interruption of the beams.

\subsection{TEST RESULTS}

As mentioned previously, the pipe-to-pipe impact tests outlined in Table 2.1 were conducted under two sets of temperature and pressure conditions. The target pipes studied in the Group 1 tests were filled with sunflower seed oil at ambient temperature and pressure. $0 i 1$ in the target pipes for test groups 2 through $5 \mathrm{~b}$ was heated to $550^{\circ} \mathrm{F}$ and pressurized to between 2000 and 2300 psi.

\subsubsection{Unheated, Unpressurized Pipe Tests}

The primary purpose of the tests conducted at ambient temperature and pressure was to check out the overall test system components before introducing the elevated heat and pressure conditions.

\subsubsection{Group 1 Tests}

Group 1 tests were performed first. Both target and impactor pipes were 6-inch Sch 40, which have a 6.625-inch diameter and 0.280-inch wall thickness $\left(t_{1}=t_{2} ; D_{1}=D_{2}\right)$. All pipes were unpressurized and at ambient temperature.

The initial tests in Group 1 were conducted with rigidly backed target pipes. The rigidly backed target pipe was originally postulated to be the most conservative test condition. However, although the target pipe with this support condition was crushed significantly, the swinging pipe was deformed 
much more. It was felt that simply supporting the target pipe would be a more conservative test condition. When this arrangement was tested at the same energy level, the target pipe was deformed more. Hence, all subsequent tests, as well as all hot oil tests, were conducted with the target pipes simply supported.

After one of the Group 1 simply supported tests was conducted, examination of the target pipe revealed several cracks on the outside surface in areas of relatively high tensile strain. One of these cracks is shown in Figure 2.2. For reference, the diameter of the strain circles was 0.2 inch before impact.

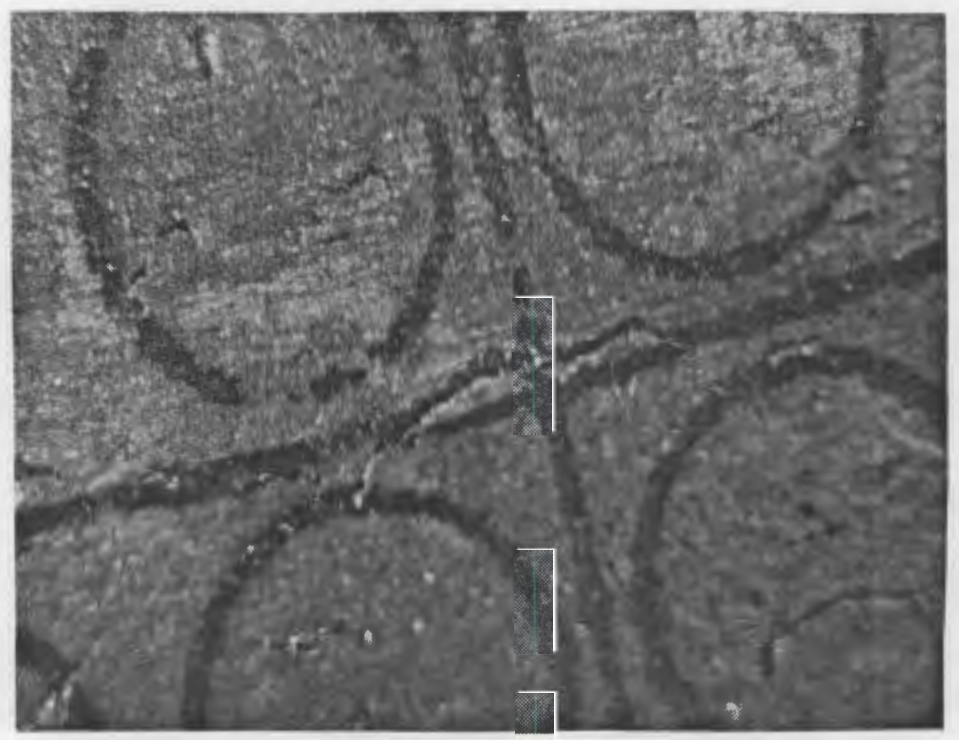

FIGURE 2.2. Surface Cracks on Impacted Pipe, Group 1 Tests

The extent of the through-wall penetration of these cracks was impossible to determine from a surface examination, so a portion of the pipe wall containing the most extensive crack was sectioned. Figure 2.3 shows microphotographs of the wall cross section. The distance along the crack was about 0.04 inch, but the maximum depth from the surface was only about 0.007 inch. There 

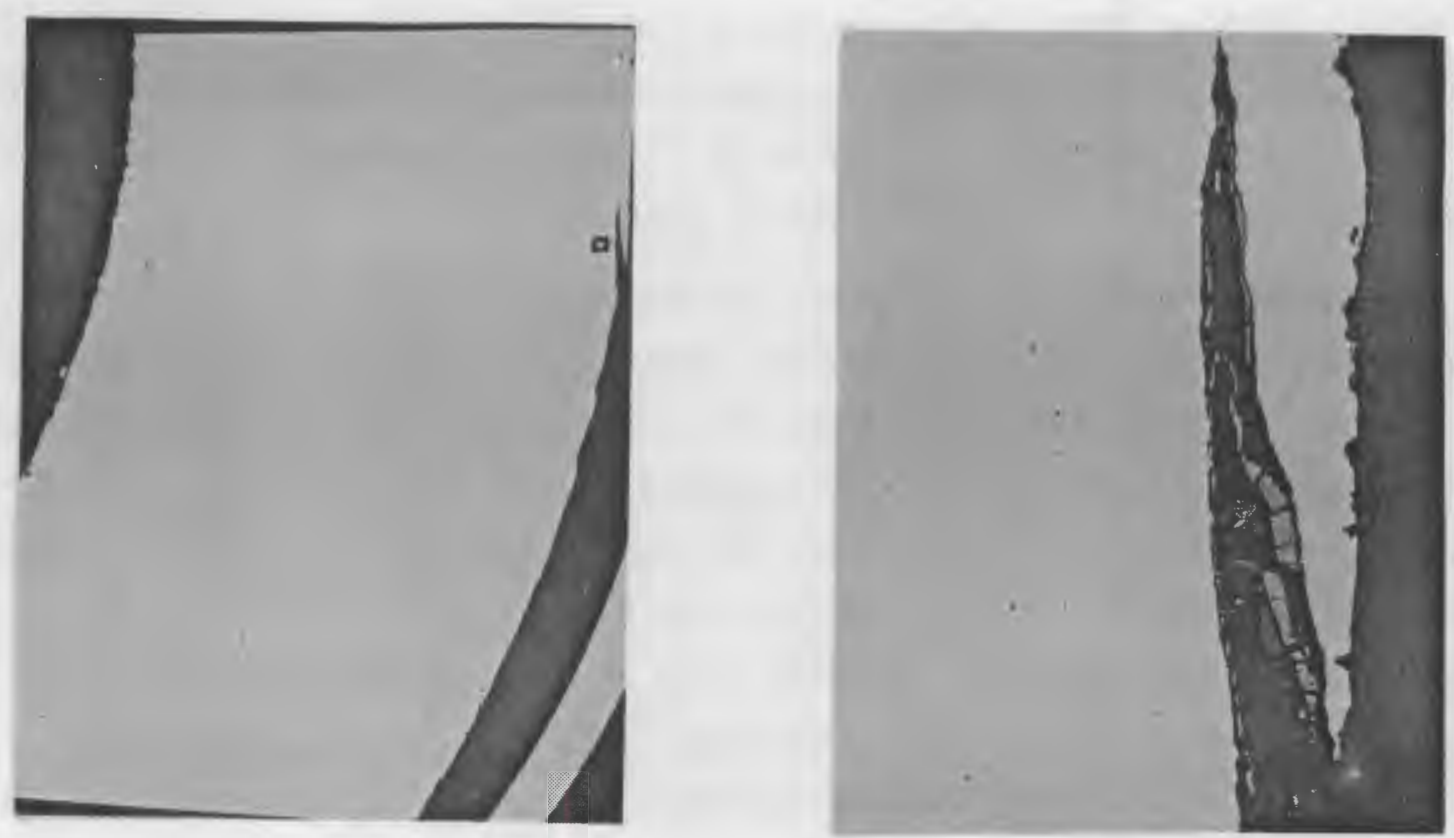

(a)

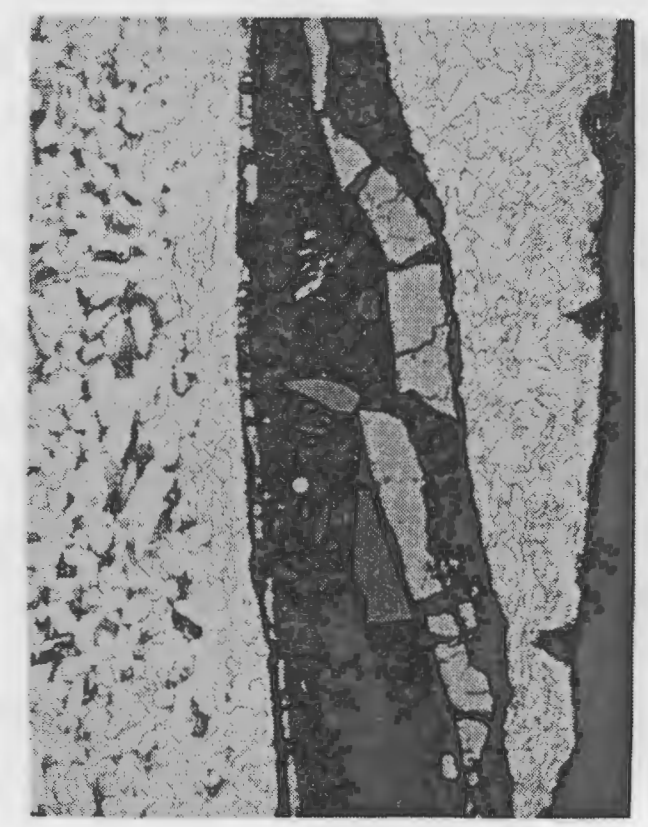

(a)

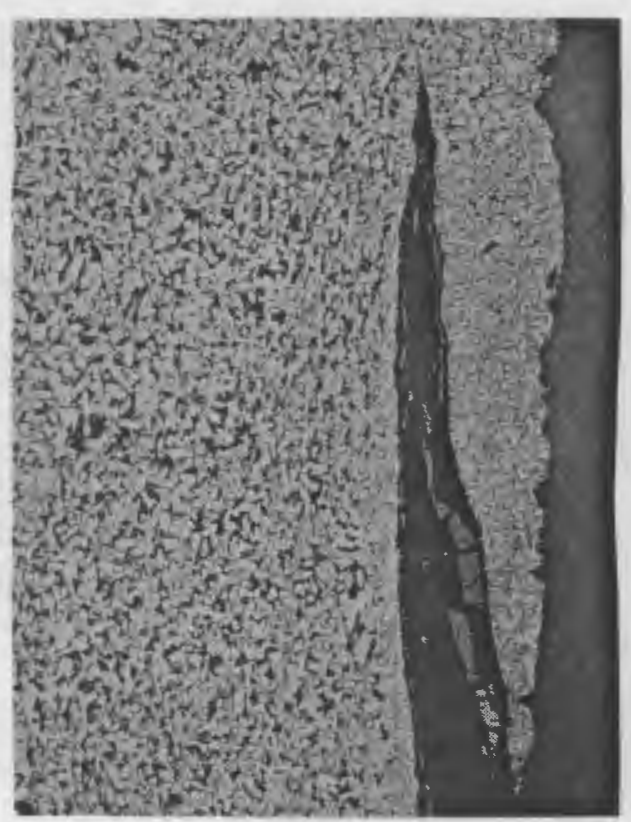

(a)

FIGURE 2.3. Surface Cracks in Target Pipe Wall, Group 1 Test 
was no indication that the crack would have penetrated the wall even if more pipe deformation had occurred. The cause of the cracks appears to be related to the way in which the pipe was made. The grain structure of the metal is noticeably different on either side of the crack.

To determine whether the pipes contained any significant flaws that could affect the test results, all target pipes were examined by ultrasonic (UT) inspection in an 8-inch zone about the centerline. The UT inspection showed all except three of the 12-inch diameter pipes to be free of detectable defects. The three defective pipes had several cracks on the OD surface. The cracks were sized for depth using an electrical resistivity gage (ERG). The crack with the largest UT response also had the largest ERG reading, which estimated the crack to be 0.05 inch deep. All indications were marked on the pipes so that the pipes could be oriented in such a way that the indications would not be in the highly strained region. None of the cracks showed any visible change as a result of the tests. Several of the pipes were inspected with magnetic particles; except for the cracks in the 12-inch pipe, no defect indications were found.

\subsubsection{Pressurized Hot 0il Tests}

The hot oil tests constitute all except Group 1 of the test matrix. For each group the pipe size combinations are compared to the current SRP Section 3.6.2 criteria. The results of the tests are presented and comparisons are made between the various groups. Photographs of the impacted pipes show the deformation near the contact point. Results of all hot oil tests are shown in Figures 2.4 and 2.5. The data have been normalized to aid in comparison. The kinetic energies available at impact were normalized by dividing by the product of $\mathrm{Pi}$ multiplied by the yield stress multiplied by the diameter of the target pipe multiplied by the diameter of the swinging pipe multiplied by the sum of the two pipe wall thicknesses. The diameter changes were normalized by dividing the sum of the diameter reductions by the sum of the original diameters. The bend angles were normalized by dividing the sum of the bend angles by 90 degrees. 


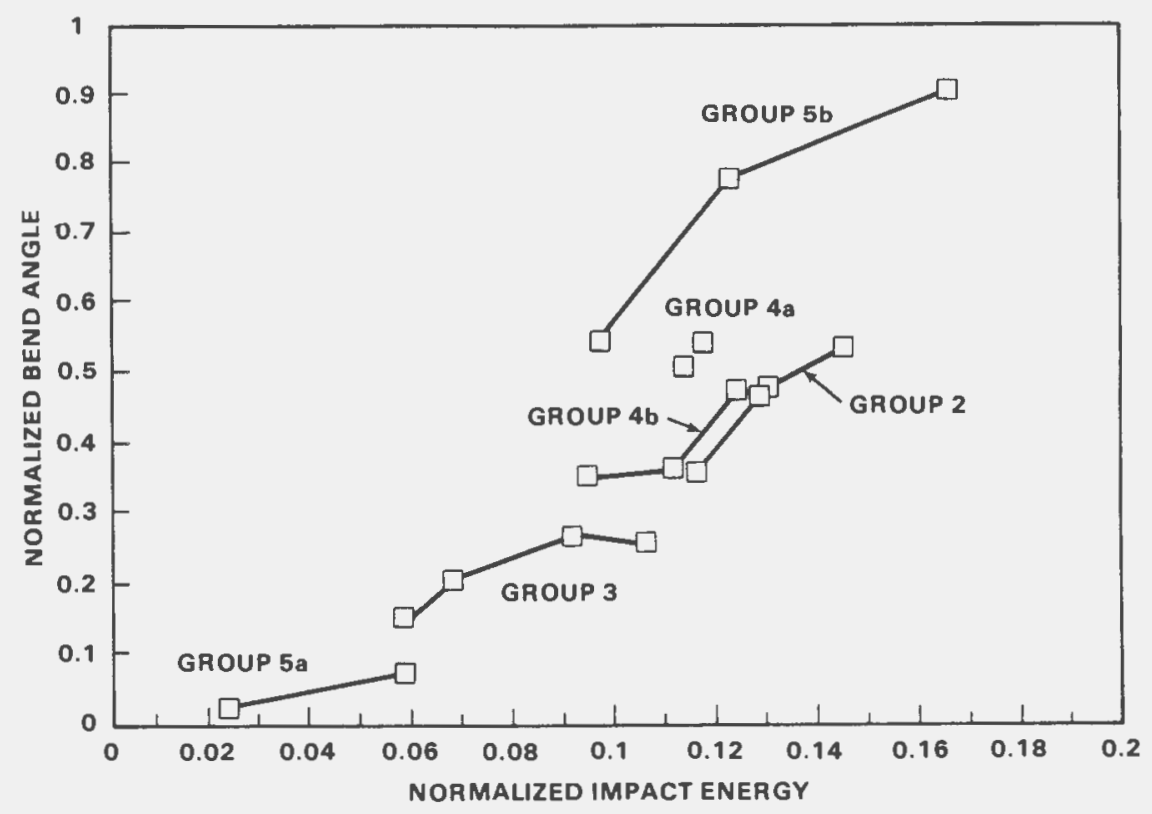

FIGURE 2.4. Bend Angle Results for Hot 0 il Tests

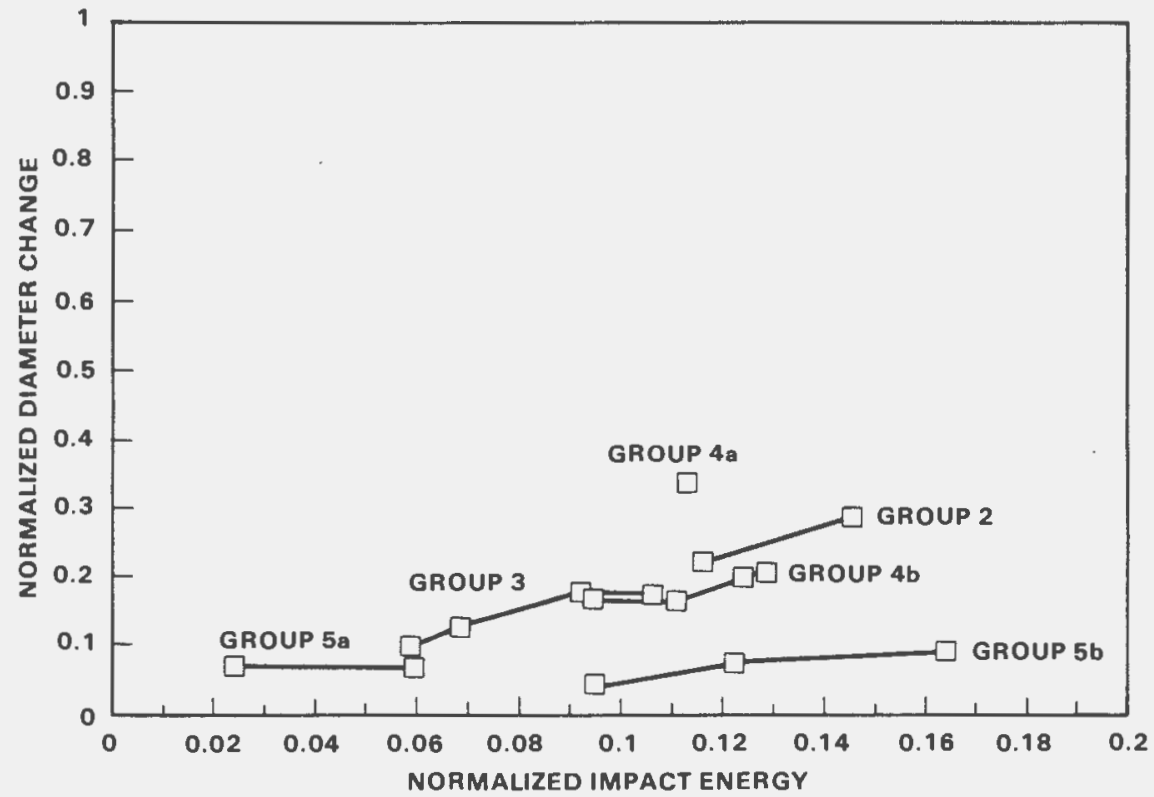

FIGURE 2.5. Diameter Change Results for Hot Oil Tests 


\subsubsection{Group 2 Tests}

Pipes tested in Group 2 were 6-inch Sch 40 impacting 6 -inch Sch 40; $t_{1}=$ $t_{2} ; D_{1}=D_{2}$. Actual pipe diameters were 6.625 inches and wall thicknesses were 0.280 inches. The Group 2 target pipes were heated to approximately $550^{\circ} \mathrm{F}$ and pressurized to over $2000 \mathrm{psi}$. Under the current criteria, the target pipe was postulated to not rupture.

Three tests were conducted in Group 2. One of these tests was at the highest velocity obtained by any of the swinging pipes in the entire test matrix. This is the highest velocity the catapult could achieve with a 6 -inch Sch 40 pipe, given the pressure 1 imits imposed for safety considerations.

None of the target pipes tested in Group 2 ruptured. The bend angle and diameter change data are shown in Figures 2.4 and 2.5. As expected, an increase in both bend angles was associated with an increase in impact energy. Over the range of energies tested, the diameter changes of the impactor pipes were fairly constant while the diameter changes of the target pipes were more a function of the impact energy. The maximum axial and hoop strains measured from the strain circles were -1 to $+7 \%$ and -2 to $+8 \%$, respectively. As with all strain circle readings, these values may not represent the maximum strain on the surface of the pipe because the strain circles are only at a finite number of points and they also average the strain over about 0.20 inch.

Figures 2.6 through 2.8 show details of the target pipes near the point of impact. All photographs of target pipes in this section were taken perpendicular to the target pipe along a line parallel to the longitudinal axis of the impactor pipe unless otherwise noted. Figure 2.6 shows a modest amount of bending in the pipe and minor indentations on the upper surface of the pipe either side of the initial contact point. The target pipe in Figure 2.7 shows more bending. This pipe has a nonsymmetric characteristic. One side of the contact region is indented noticeably more than the other. This was attributed to nonuniformity in the material or wall thickness of one of the pipes. Figure 2.8 shows even more bending. Two regions of indentation are evident on either edge of this pipe's contact area. These regions were 


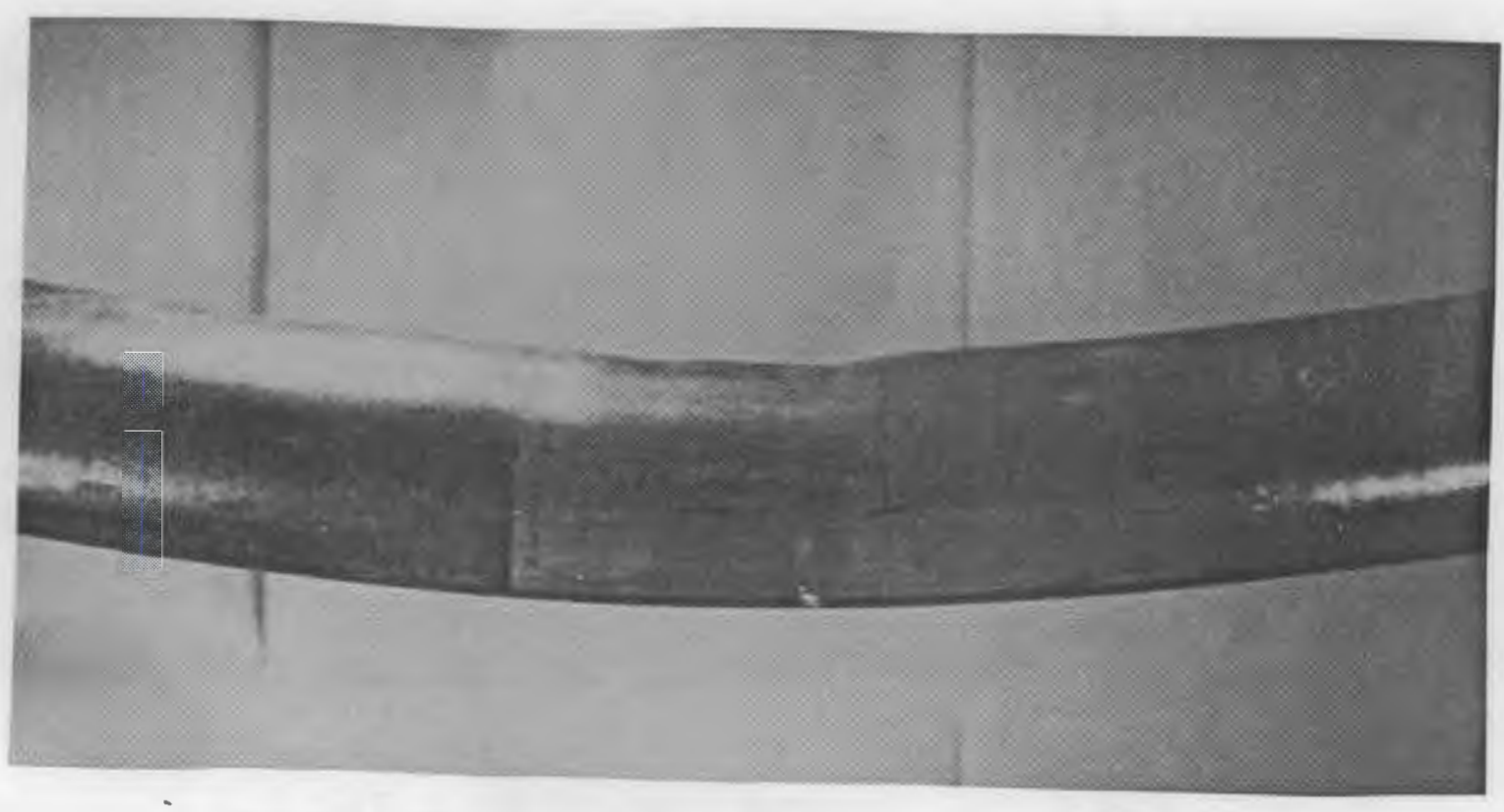

FIGURE 2.6. Impacted Pipe - Group 2, Test 2.1

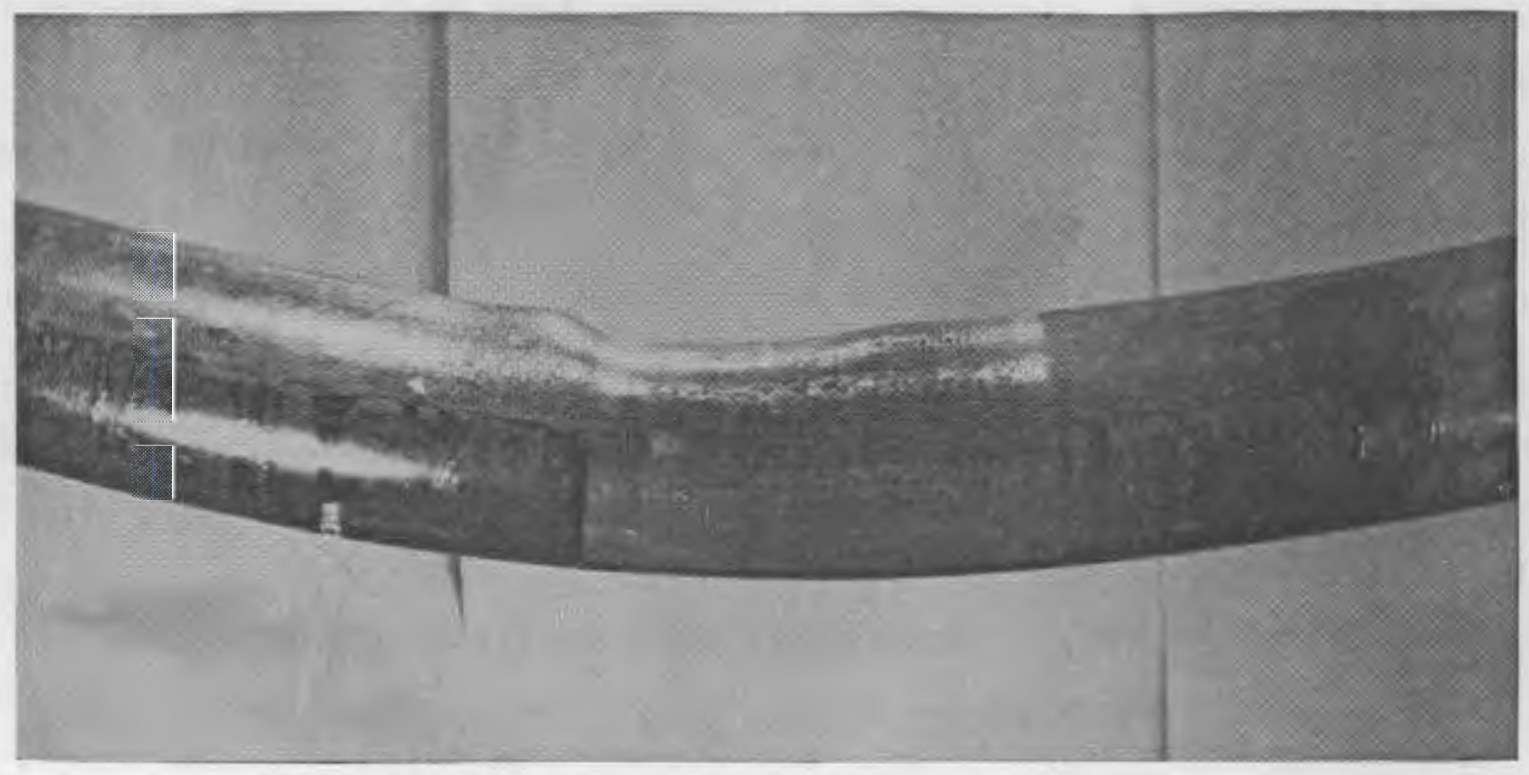

FIGURE 2.7. Impacted Pipe - Group 2, Test 2.2 


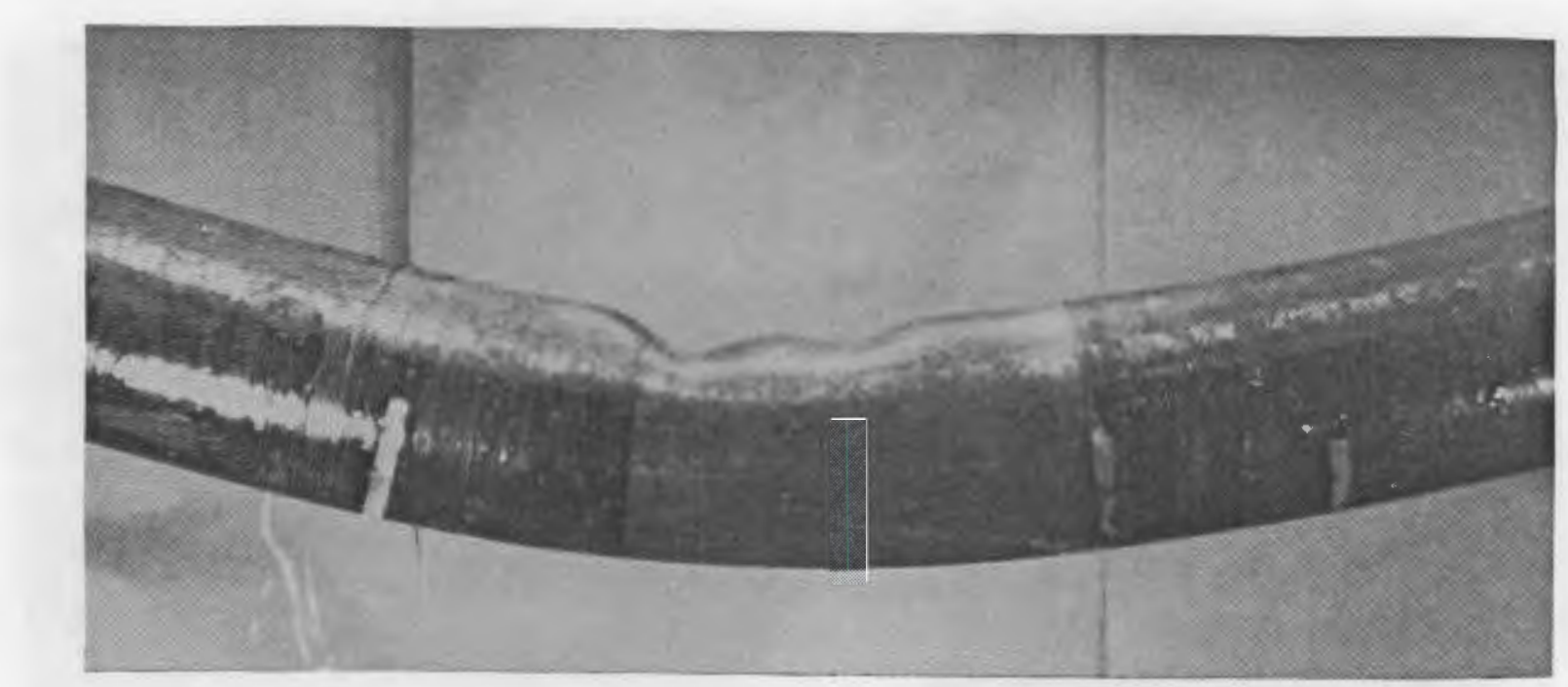

FIGURE 2.8. Impacted Pipe - Group 2, Test 2.3

approximately in line with the outside edge of the impactor pipe. This deformation pattern is noticeably different from that observed in the other groups tested.

The ability of the target pipes to maintain flow under the conditions imposed by this test group is apparent.

\subsubsection{Group 3 Tests}

Group 3 tests were similar to those in Group 2 in that impactor and target pipes were the same size. While all pipes in Group 2 were 6 -inch Sch 40, all pipes in Group 3 were 6 -inch Sch 80 . Actual pipe diameters were 6.625 inches; wall thicknesses were 0.432 inches $\left(t_{1}=t_{2} ; D_{1}=D_{2}\right)$. Using the current criteria, Group 3 target pipes would be postulated to not rupture.

Four tests were conducted in this group. While the highest velocity from this group was lower than that for Group 2, the kinetic energy was higher due to the thicker pipe wall. This test represents the catapult's highest safe velocity with 6 -inch Sch 80 pipe. 
None of the target pipes from Group 3 ruptured. Bend angles and diameter change data are shown in Figures 2.4 and 2.5. Figures 2.9 through 2.12 show the target pipes from Group 3. The increase in both bend angle and diameter change is evident with increasing energy.

Maximum strains as measured by the strain circles were -11 to $+5 \%$ axial and -7 to $+10 \%$ hoop. These are larger than those reported for the Group 2 tests. However, the strain levels are still fairly small. Accuracy of the measurements is probably within a few percent even for small strains.

\subsubsection{Group 4a Test}

For Group 4a, 6-inch Sch 40 struck 6-inch Sch 80 . Based upon the test results of Groups 2 and 3 , it was felt very unlikely that a rupture would occur for this combination. The diameter of both pipes was 6.625 inches $\left(D_{1}=\right.$ $D_{2}$ ). The wall thickness of the impactor pipe was 0.280 inches and that of the target pipe was 0.432 inches $\left(t_{1}<t_{2}\right)$.

Only one test was conducted for Group 4a. The angular velocity was the maximum velocity of the catapult for this size pipe.

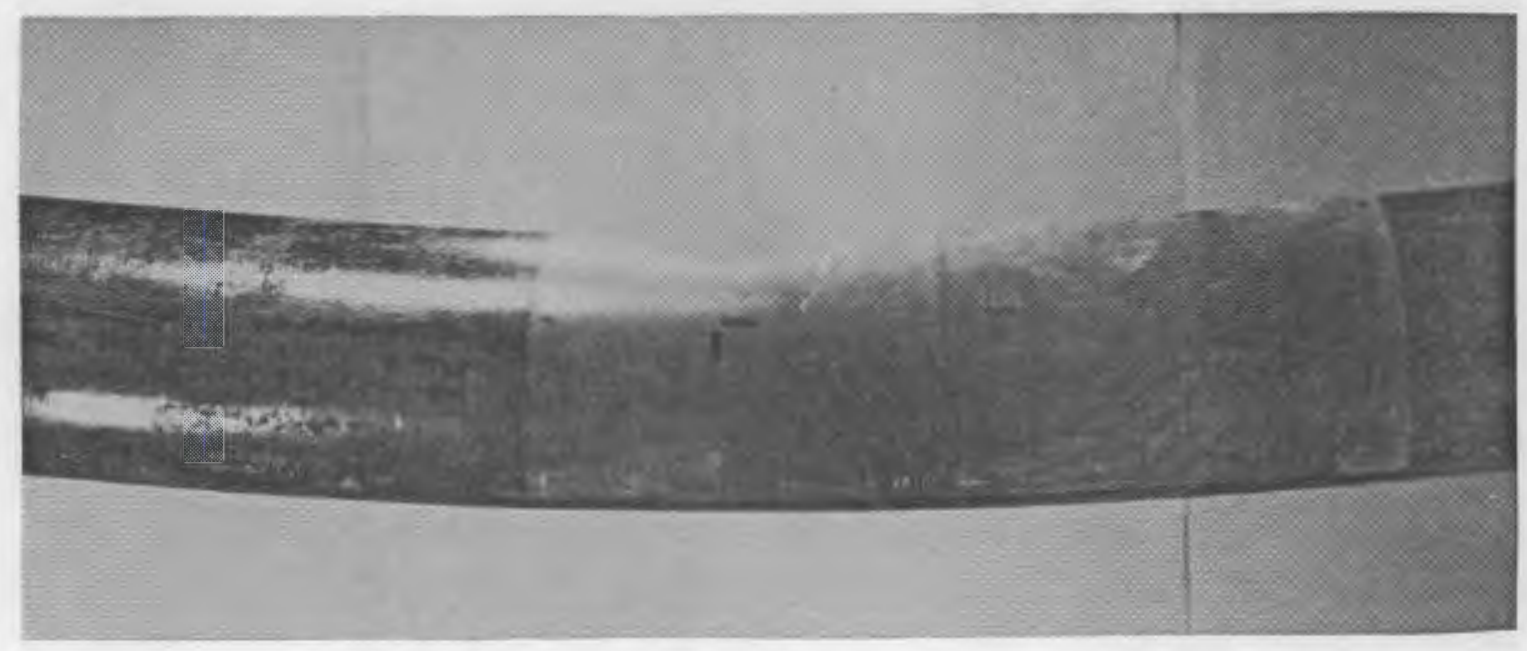

FIGURE 2.9. Impacted Pipe - Group 3, Test 3.1 


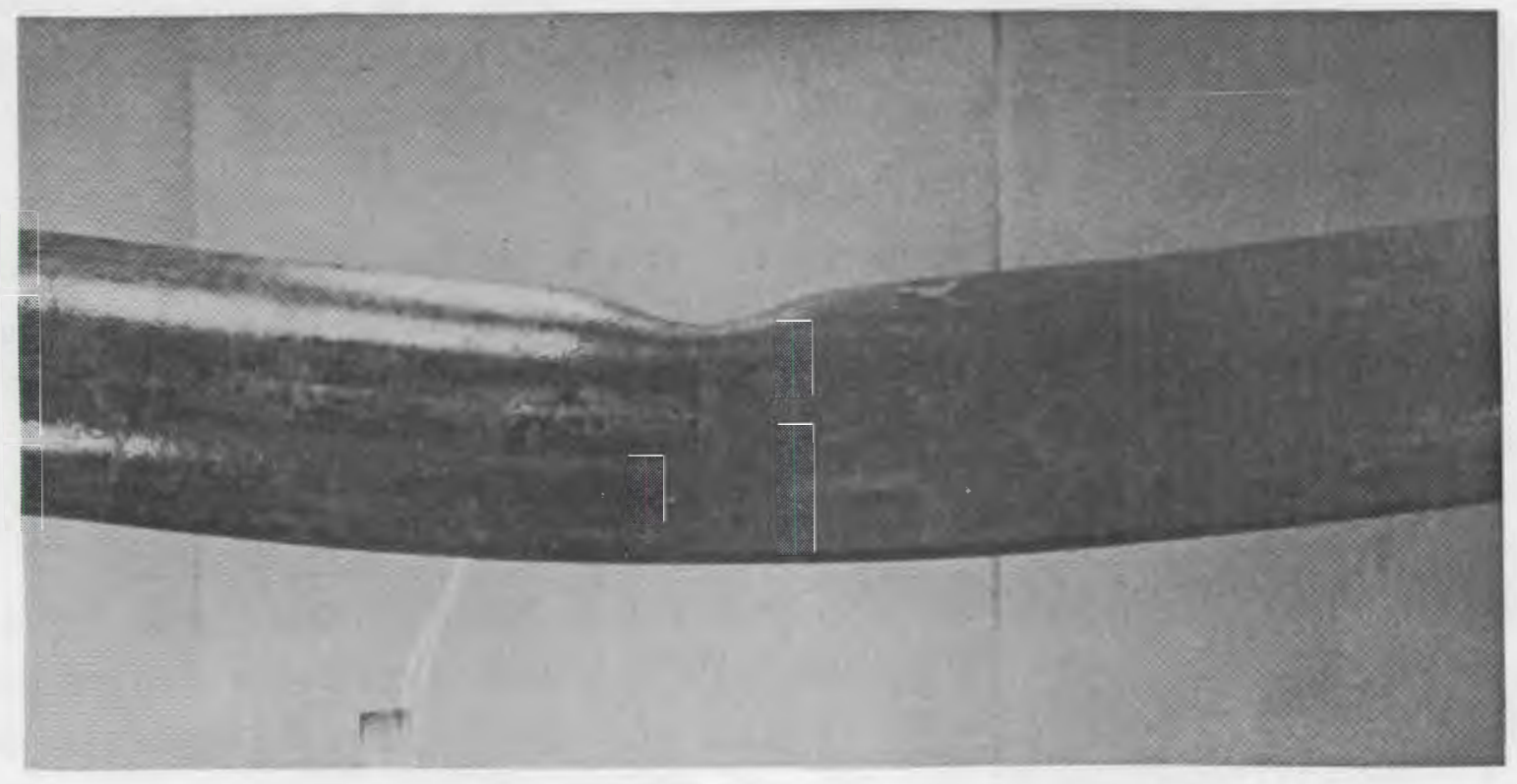

FIGURE 2.10. Impacted Pipe - Group 3, Test 3.2

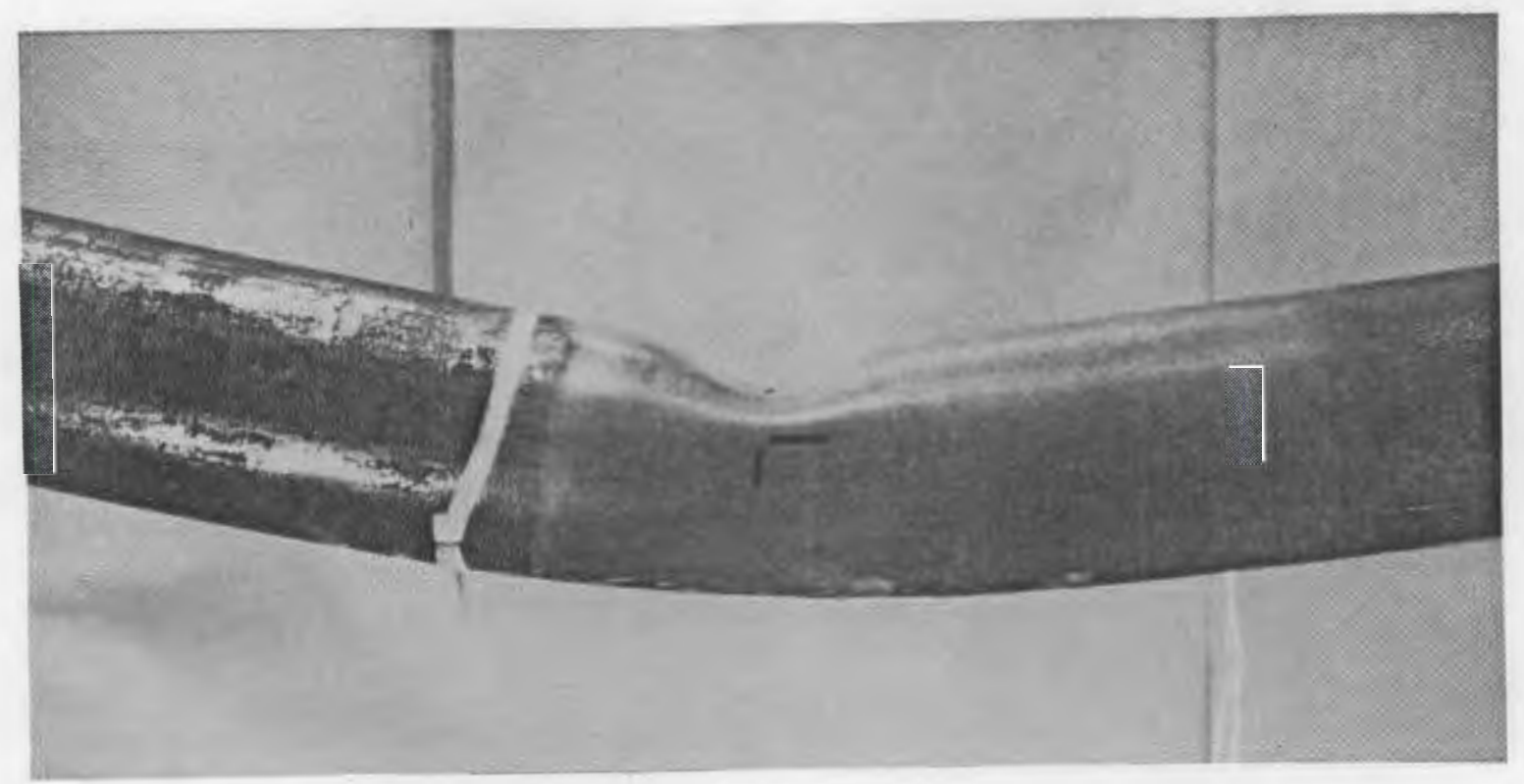

FIGURE 2.11. Impacted Pipe - Group 3, Test 3.3 


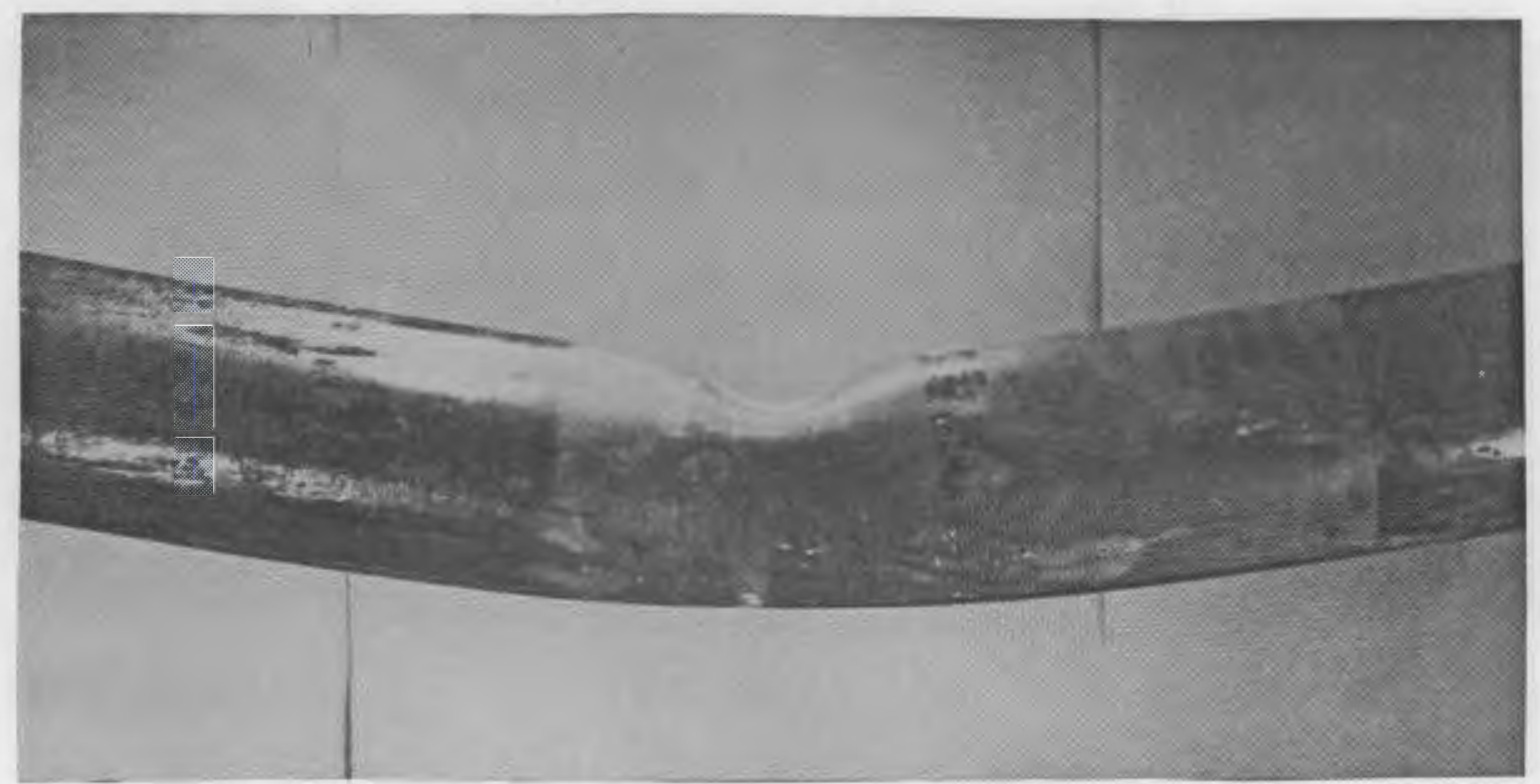

FIGURE 2.12. Impacted Pipe - Group 3, Test 3.4

The target pipe did not rupture. In fact, very little deformation of the target pipe occurred, as shown in Figure 2.13. On the other hand, the impactor pipe was deformed more than any other pipe in the entire test matrix. The results for the test are shown in Figures 2.4 and 2.5. The effect of the impact on the functional capability of the pipe is insignificant.

Strains as measured by the strain circles ranged from 3 to $5 \%$ axial and 4 to $6 \%$ hoop.

It is obvious from the one test in Group $4 a$ that, for pipes of equal diameter, the effect of different wall thicknesses is very important in determining the impact response.

\subsubsection{Group 4b Tests}

For Group 4b, 6-inch Sch 80 pipes struck 6-inch Sch 40 pipes. The outside diameter of all pipes was 6.625 inches $\left(D_{1}=D_{2}\right)$. Wall thickness of 


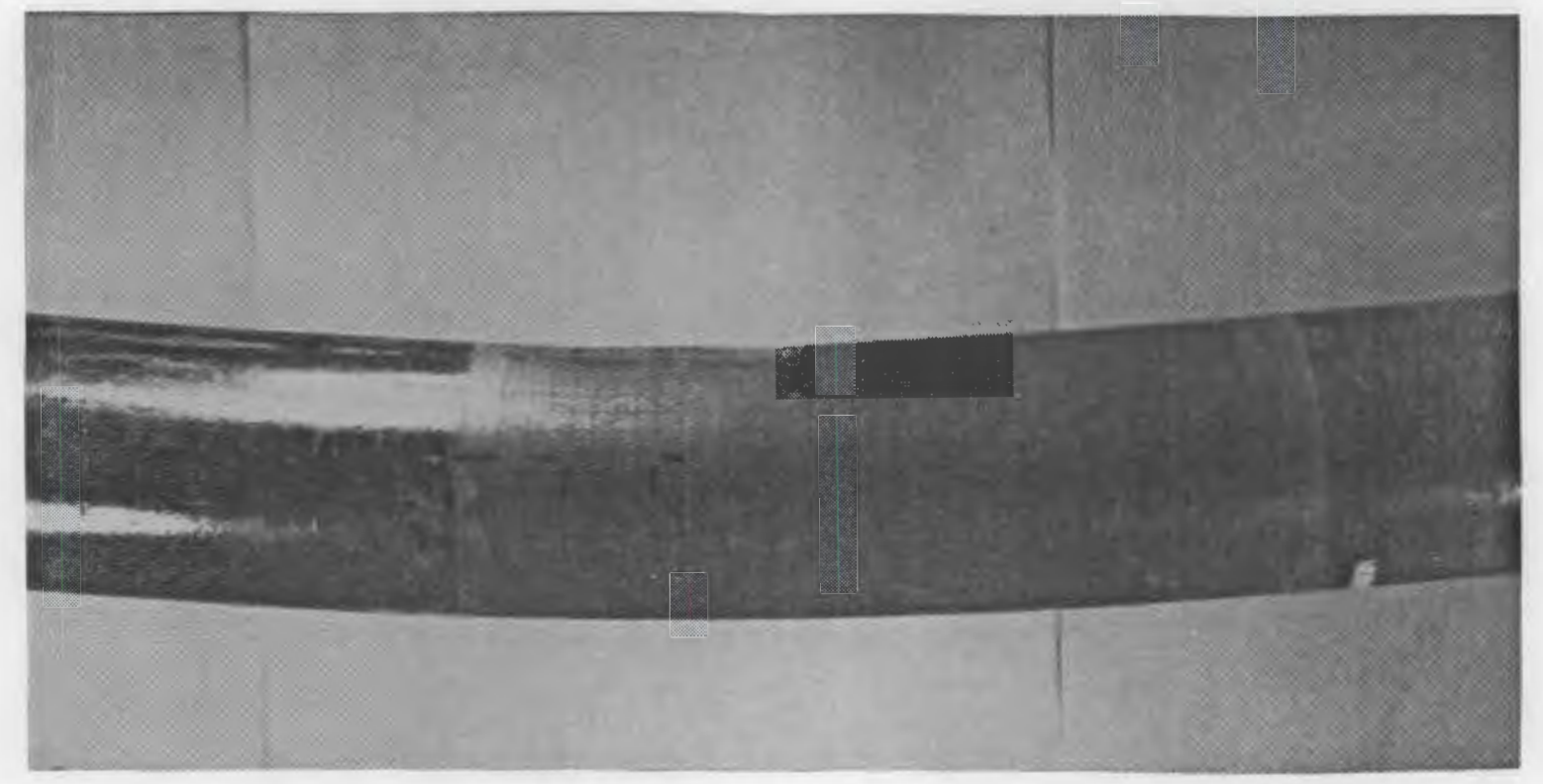

FIGURE 2.13. Impacted Pipe - Group 4a, Test 4a.1

the impactor pipes was 0.432 inch and that of the target pipes was 0.280 inch $\left(t_{1}>t_{2}\right)$. In terms of wall thickness, the pipes in this group are the reverse of those in Group 4a. Under the current SRP 3.6 .2 criteria, rupture of the target pipes would have been postulated. Based upon the results of tests for Groups 2, 3, and $4 a$, this group was felt likely to be the one in which a pipe rupture would occur.

Four tests were conducted in Group $4 \mathrm{~b}$, with angular velocities up to the highest obtainable from the catapult for this size pipe.

Two of the pipes ruptured. The ruptures occurred in the target pipes impacted at the highest and third highest velocities. The target pipe impacted at the second highest velocity did not rupture but was deformed in a manner similar to that of the two pipes that did rupture.

Bend angle and diameter change data are shown in Figures 2.4 and 2.5. Photographs of the target pipes in the vicinity of the impact area are shown 
in Figures 2.14 through 2.17. The deformation is similar to that occurring in Group 3 pipes except that both the bend angles and cross-sectional reduction are greater.

The most severely deformed strain circles from all Group 4b tests had axial strains of from -30 to $-34 \%$ and hoop strains of from +5 to $+24 \%$.

Figures 2.18 through 2.21 show some details of the cracks in one of the pipes that ruptured. Although two tests in Group $4 \mathrm{~b}$ were conducted at higher velocities, one of the pipes did not rupture and the other had less severe cracks. The pipe shown in Figures 2.18 through 2.21 developed cracks on either side of the impact region. The other pipe, which ruptured upon initial impact, had a through-wall crack on only one side. The pipe shown did not rupture on initial impact. Rather, the impactor pipe rebounded a short distance and fell on the target pipe. This secondary impact initiated the rupture. Very little energy was associated with this second impact. Because another pipe, tested under essentially the same conditions except for a higher energy level, did not rupture, it was concluded that definite variations exist in the threshold energy required to rupture the pipes. Variations in material properties may be important. Because all of the pipes of each size came from the same heat, attempts had been made to maintain similar material properties. Even greater variations in rupture thresholds could be expected for piping in general.

Because the test pipes were filled with hot oil and not water at LWR conditions, the ruptures from the tests may not be as extensive as might have occurred in a power plant. After the pipes ruptured, the pressure dropped fairly rapidly. If the pipes had been water-filled, the pressure would not have dropped below the saturation pressure of water. This may have caused the cracks to extend farther, perhaps leading to a complete severance of the pipe. This, however, is only a possibility and has not been demonstrated. The test-induced ruptures would be classified as leakage cracks. 


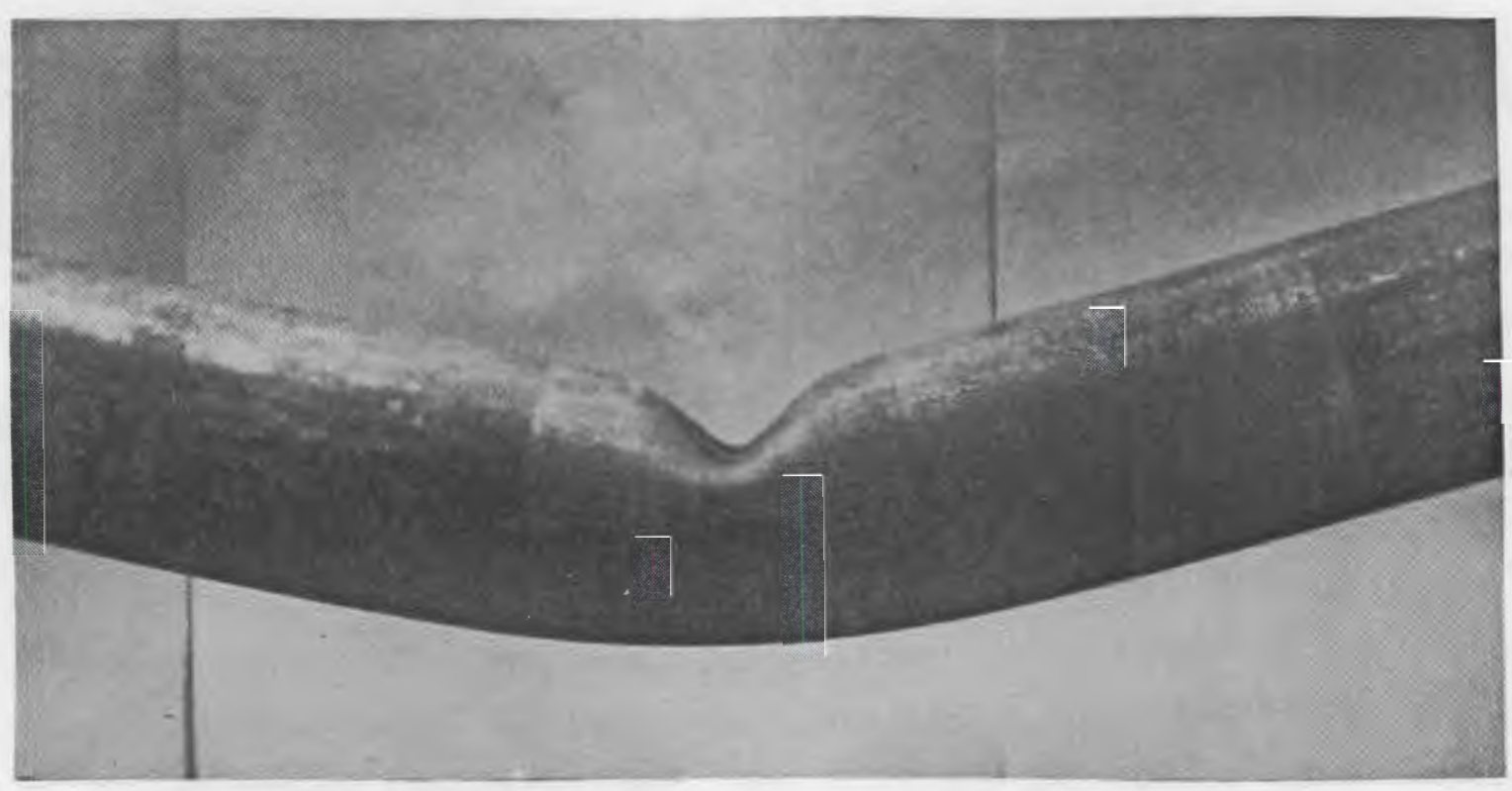

FIGURE 2.14. Impacted Pipe - Group 4b, Test 4b.I

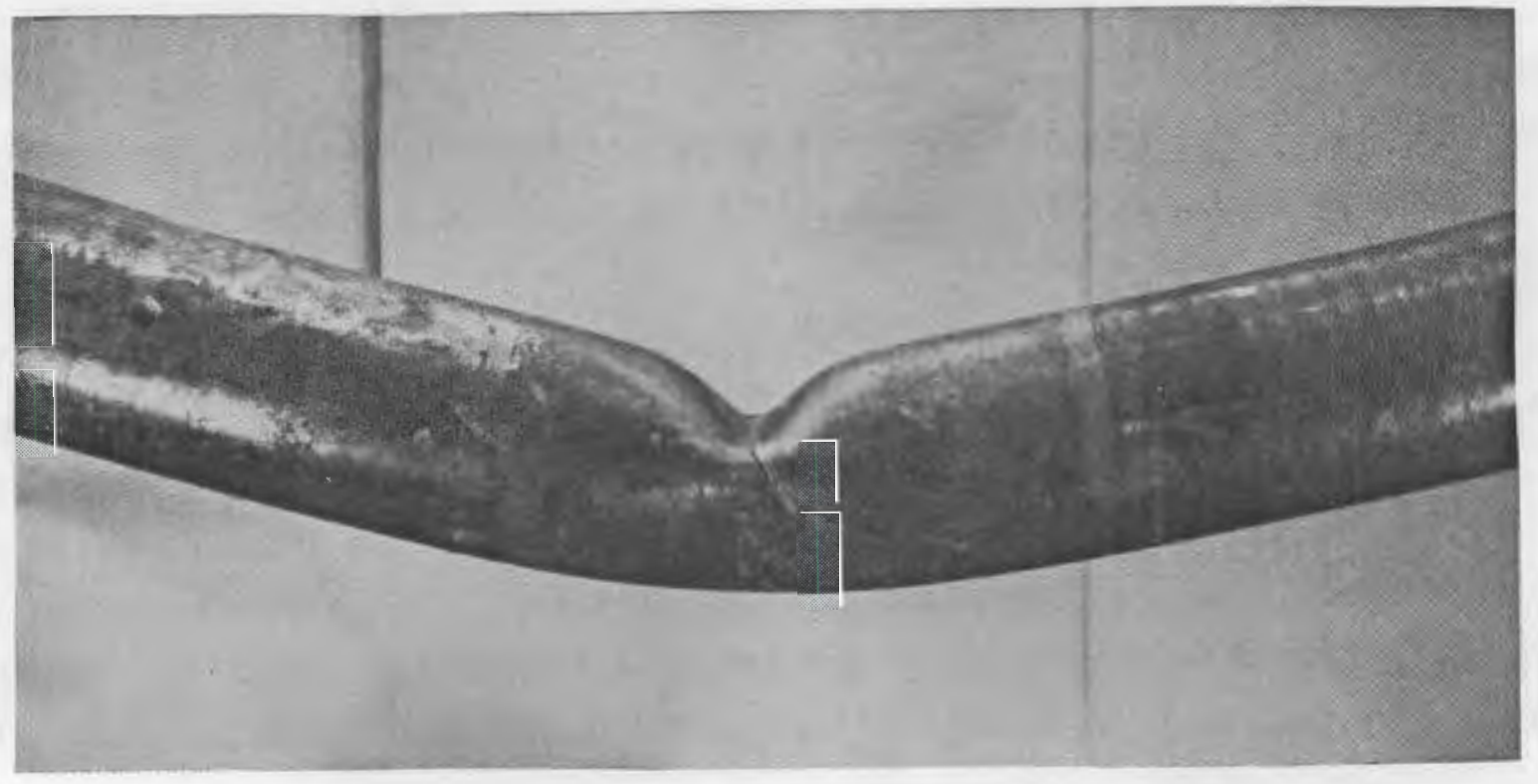

FIGURE 2.15. Impacted Pipe - Group 4b, Test 4b.2 


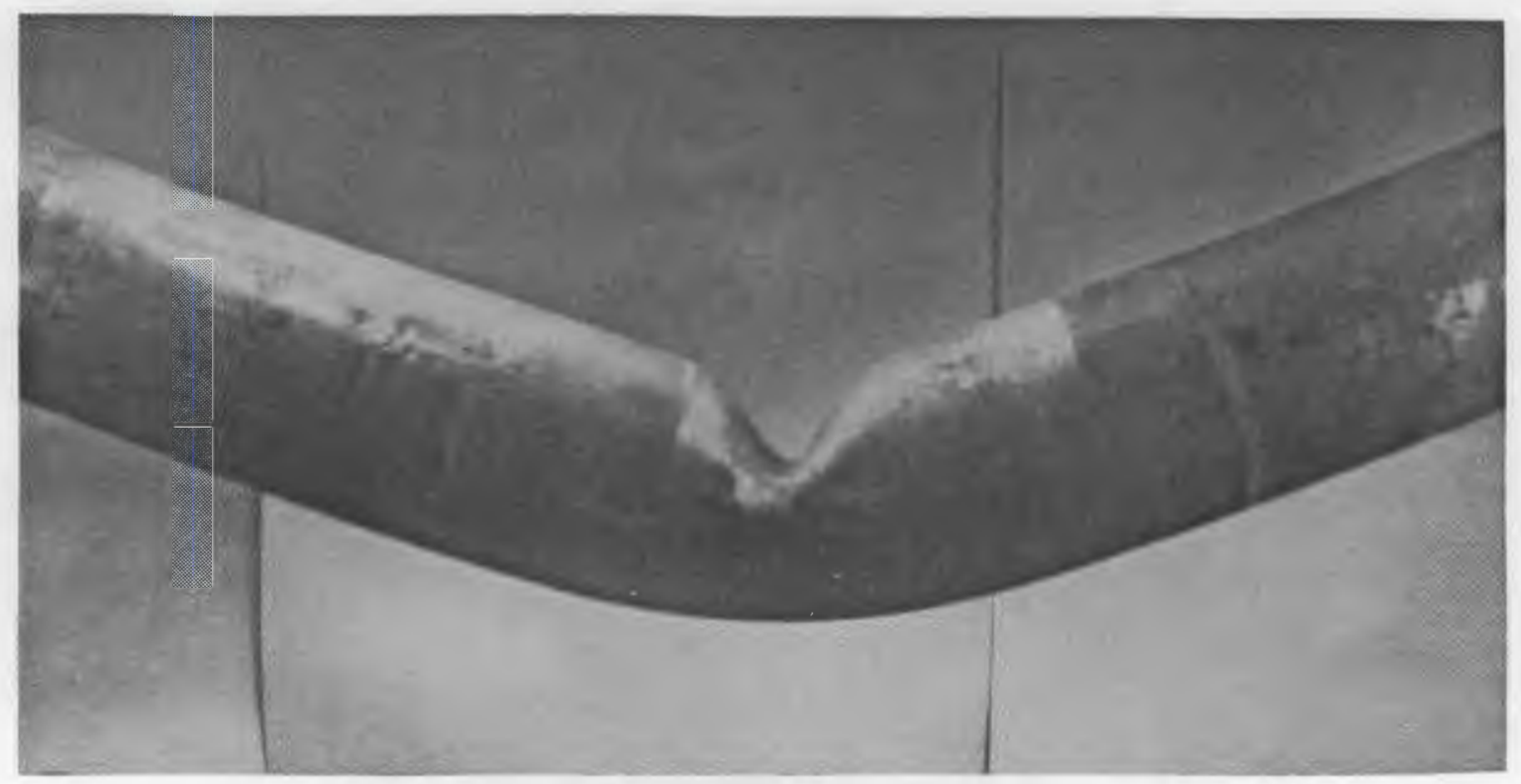

FIGURE 2.16. Impacted Pipe - Group 4b, Test 4b.3

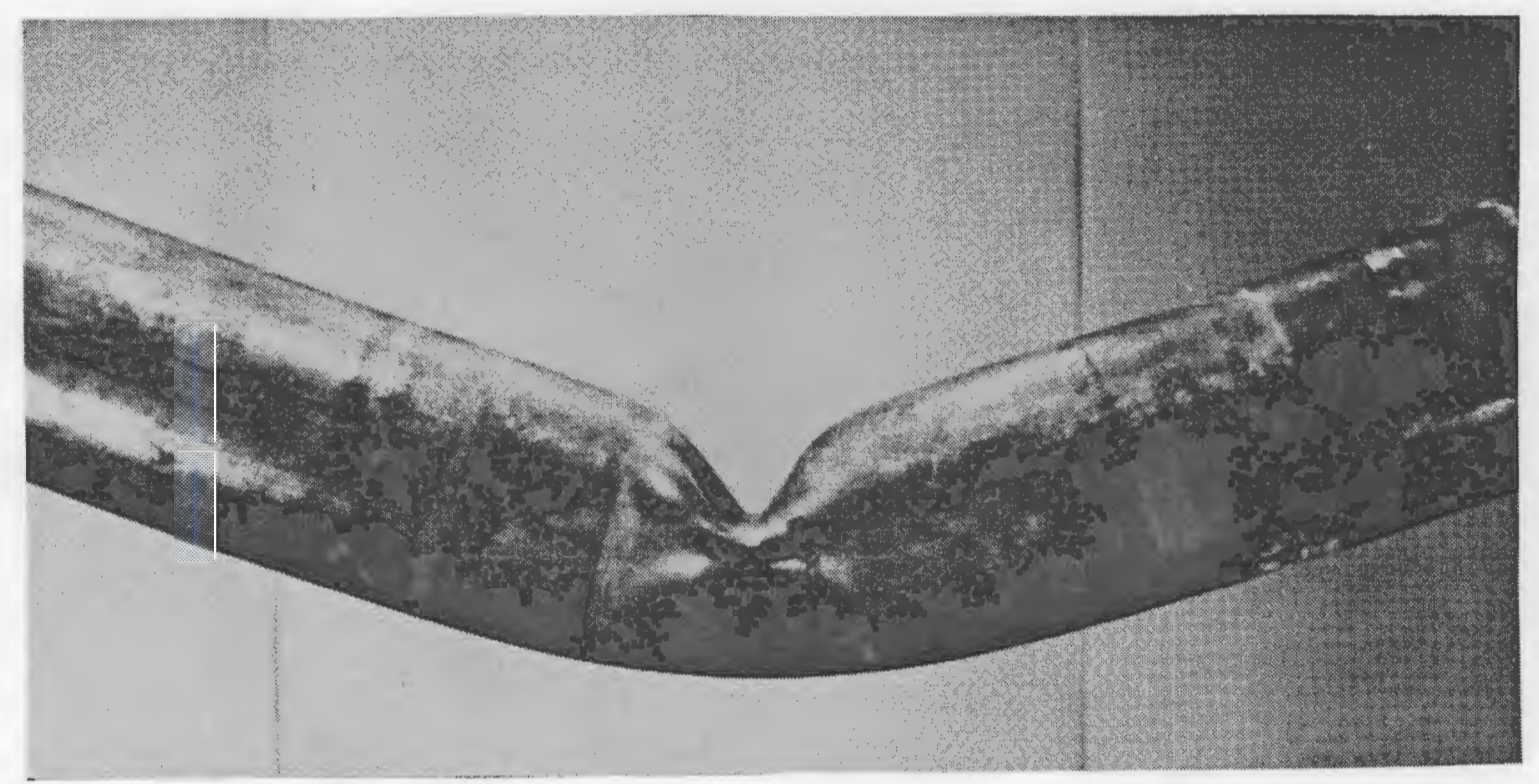

FIGURE 2.17. Impacted Pipe - Group 4b, Test 4b.4 


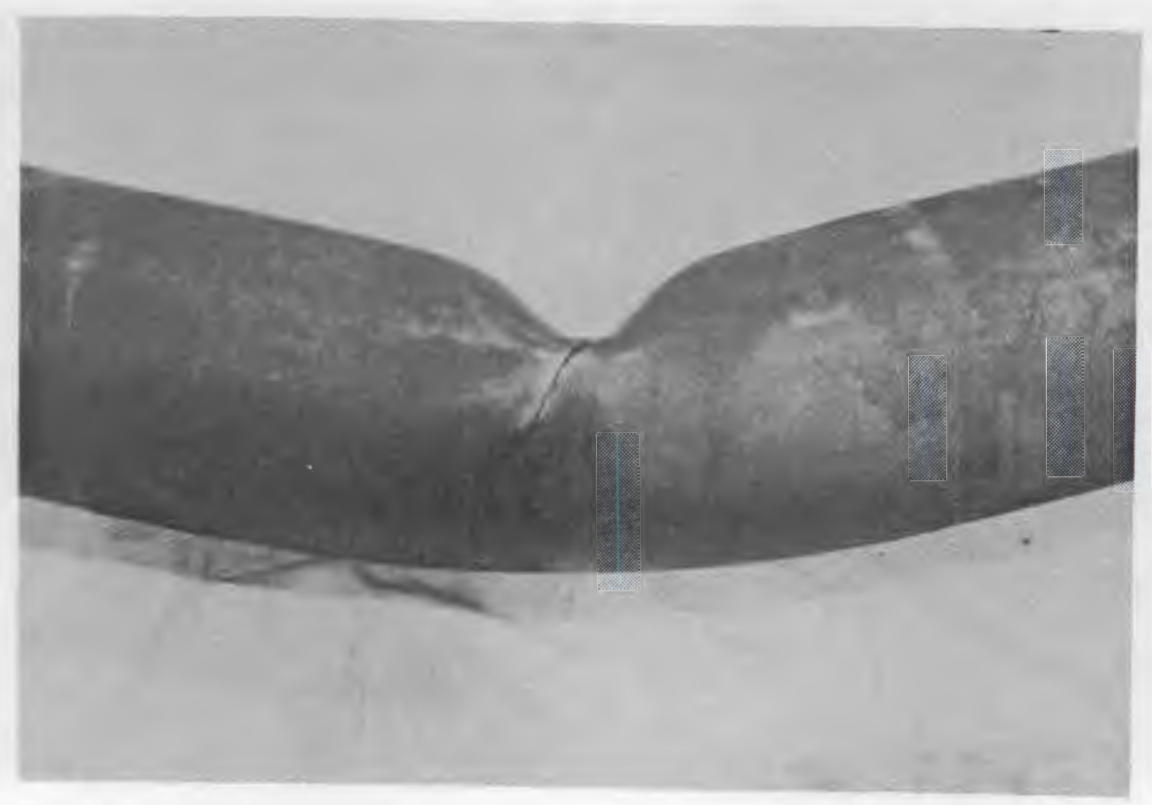

FIGURE 2.18. Side View of Ruptured Pipe

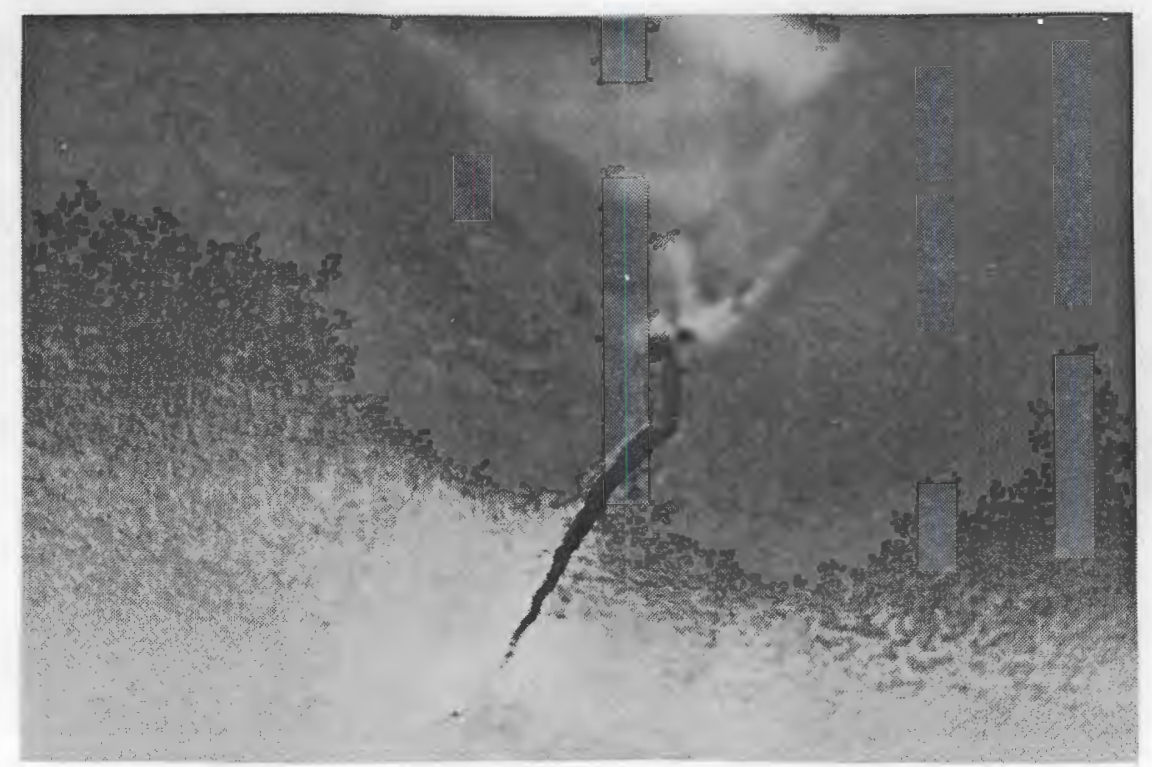

FIGURE 2.19. Detail of Through-Wall Crack 


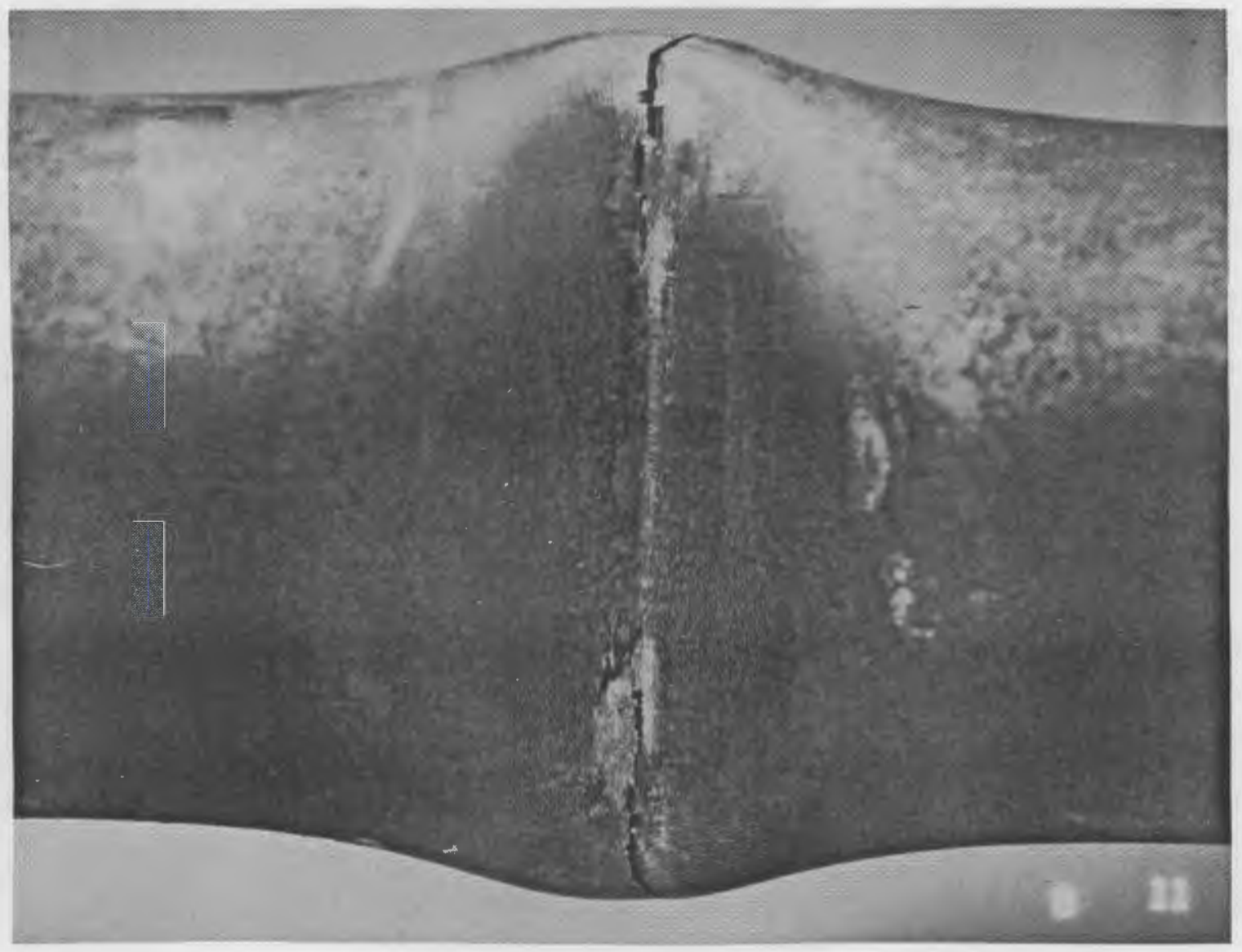

FIGURE 2.20. Side View of Ruptured Pipe

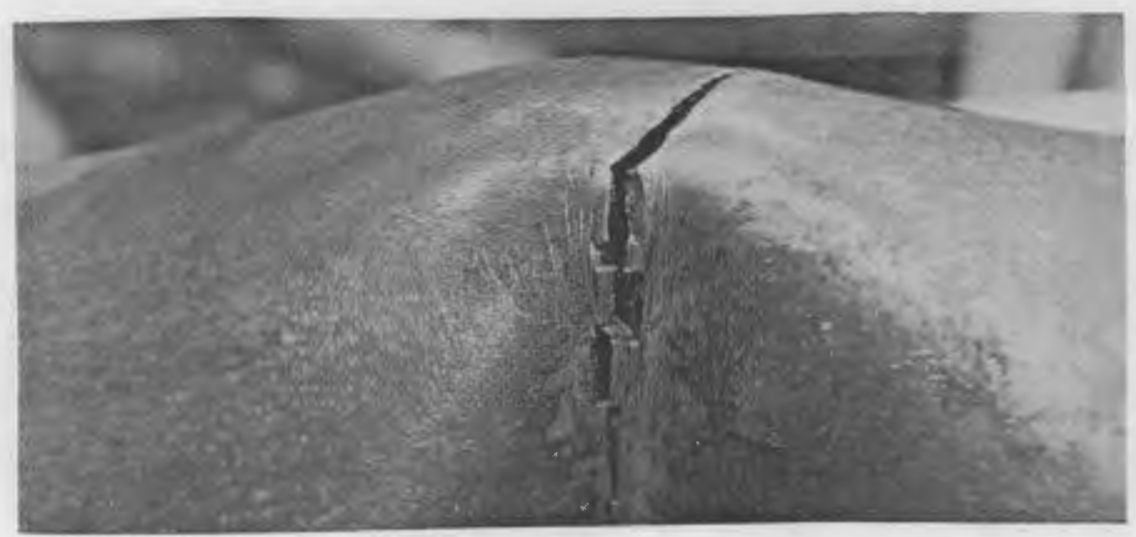

FIGURE 2.21. Detail of Through-Wall Crack 


\subsubsection{Group 5a Tests}

In the Group 5a tests, 6-inch Sch 120 pipe struck 12-inch Sch 60 pipe. Outside diameters of the pipes were 6.625 and 12.75 inches, respectively $\left(D_{1}<D_{2}\right)$. Both pipes had a wall thickness of 0.562 inch $\left(t_{1}=t_{2}\right)$. Under the current criteria, no rupture of the target pipes would be postulated; however, through-wall cracks must be postulated.

Two tests at different velocities were conducted using pipes from this group. The low velocity was selected to uncover any unexpected behavior for this pipe size combination. When nothing unusual happened, the higher velocity was used. This was the highest energy level test performed in the matrix.

Neither test from this group resulted in a rupture. In fact, the target pipes were barely deformed. The data are shown in Figures 2.4 and 2.5 . Because of the relatively larger sizes of the two pipes from this group, very little deformation of either pipe was achieved, even though the largest kinetic energy for any test in the matrix was used. It appears that energy density or the amount of kinetic energy per unit volume of pipe metal is an important parameter in pipe-to-pipe impact behavior.

The 12-inch target pipes are shown photographically in Figures 2.22 and 2.23. Very little deformation is noted. Maximum strain circle measurements were -1 to $+5 \%$ axial and +2 to $+7 \%$ hoop.

\subsubsection{Group 5b Tests}

The pipes tested in Group 5b were similar to those of Group 5a in that the impactor pipes and the target pipes had almost the same wall thickness. However, for this group the impactor pipes were of larger diameter than the target pipes $\left(D_{1}>D_{2}\right)$. The impactor pipes were 6-inch Sch 80 and the target pipes were 3 -inch Sch 160 . Their respective diameters were 6.625 inches and 3.5 inches. The wall thickness of the impactor pipe was 0.432 inch; that of the target pipe was 0.438 inch $\left(t_{1} \simeq t_{2}\right)$. Under the current criteria, the target pipes would be postulated to rupture.

Three tests at different velocities were conducted in this group. Because of the large bend angle of the target pipe during the first test, the 


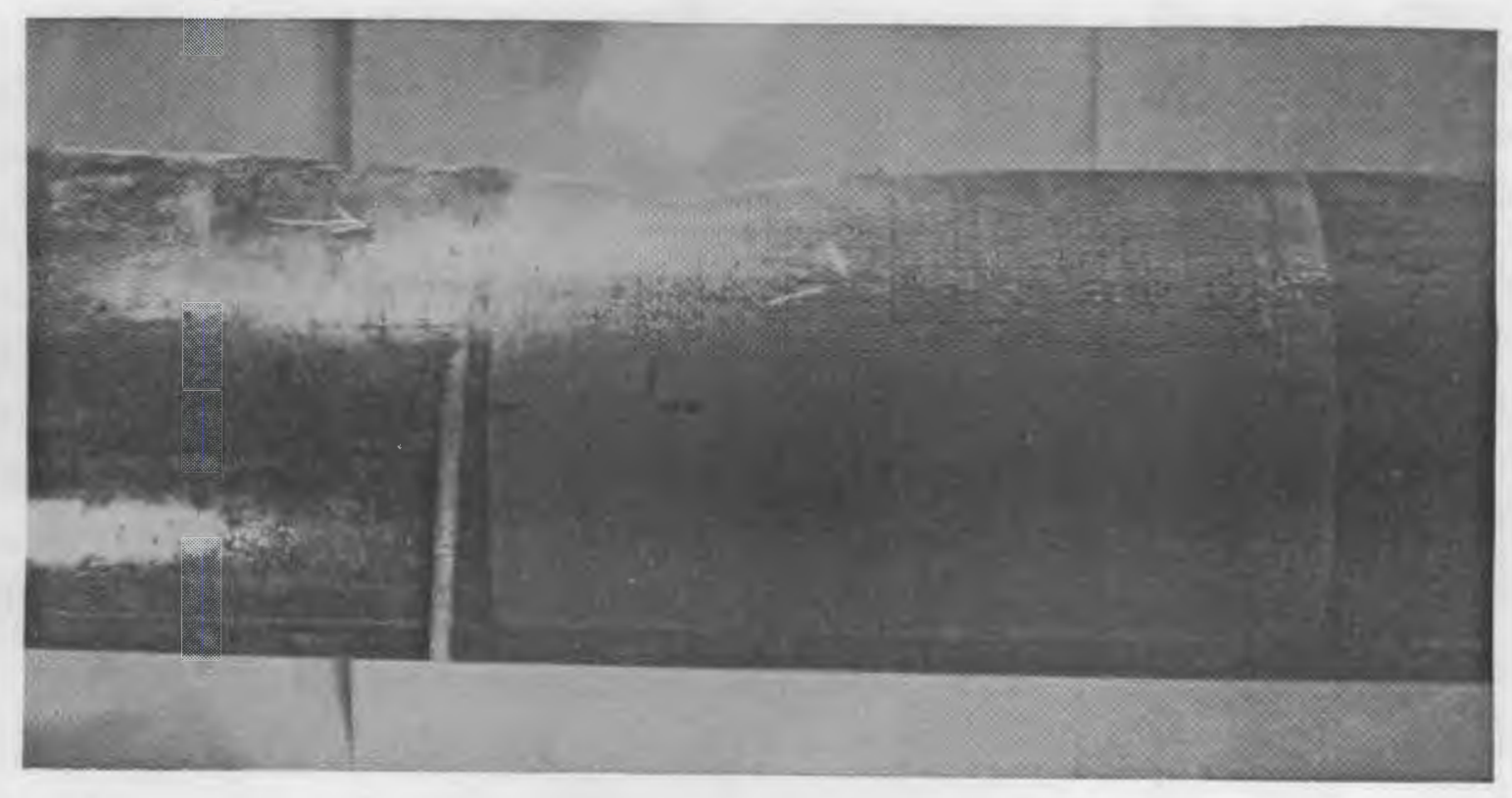

FIGURE 2.22. Impacted Pipe - Group 5a, Test 5a.1

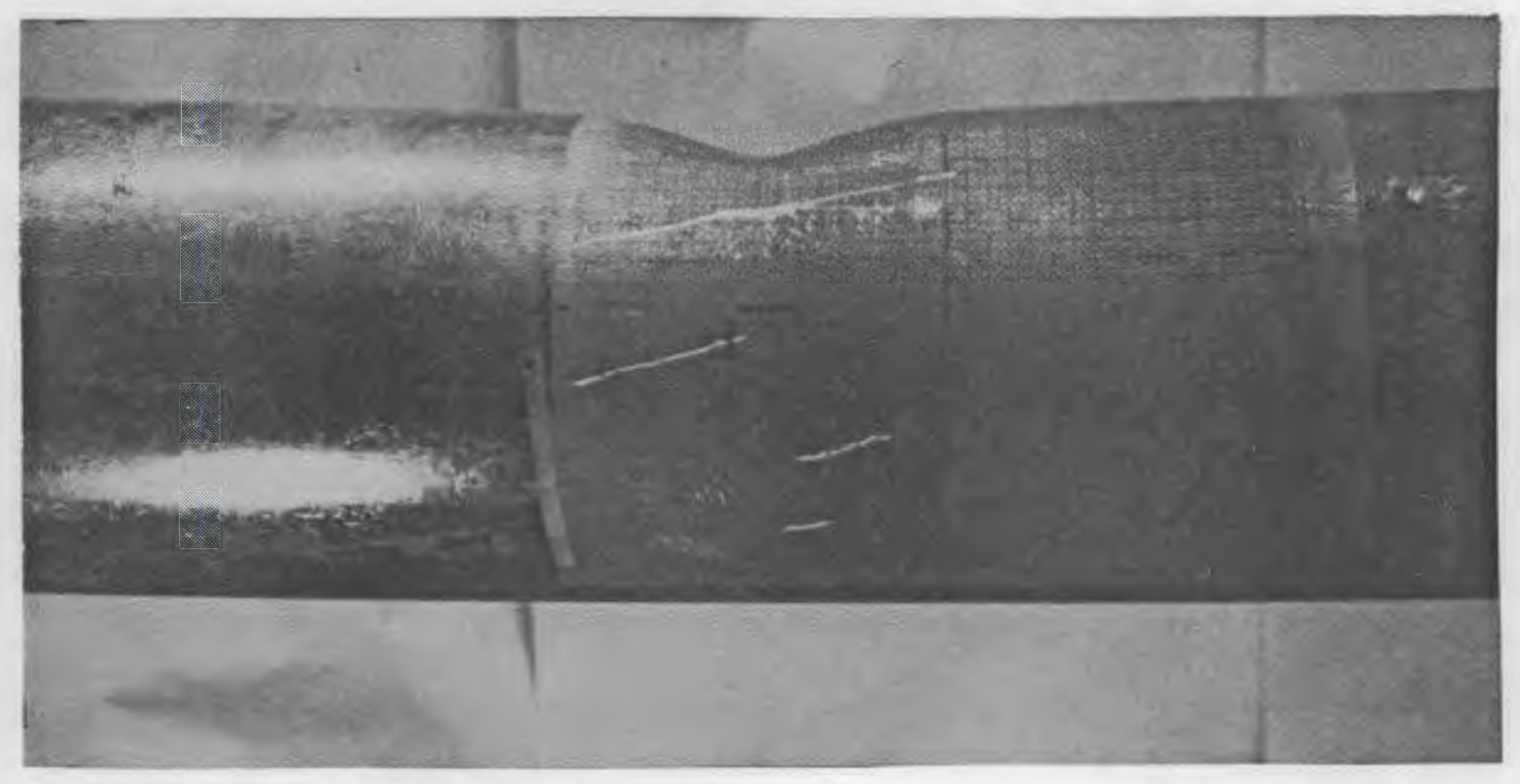

FIGURE 2.23. Impacted Pipe - Group 5a, Test 5a.2

\subsection{7}


supports were moved from a spacing of 108 inches to 84 inches to keep the tip of the impactor pipe from striking the ground at the next higher velocity. For the same reason the supports for the third test were moved to 42 inches apart.

None of the target pipes ruptured. The impactor pipe was not noticeably deformed for any of the tests from this group. In fact, the same impactor pipe was used for all three tests. The target pipes had reductions in diameters of about 11,21 and $26 \%$ at the impact point. For the last test, the pipe bent at each support as well as in the center. This additional bending was due to the inertial load on the $3-1 / 4 \mathrm{ft}$ free length of pipes beyond the support points.

Bend angle and diameter change data for Group $5 \mathrm{~b}$ tests are given in Figures 2.4 and 2.5. Photographs of the target pipes are shown in Figures 2.24 through 2.26 .

Strain circle measurements from the most severely deformed circles ranged from -14 to $+29 \%$ axial and from -13 to $+12 \%$ hoop.

Group $5 \mathrm{~b}$ tests and Group 4b tests were similar in that pipes with higher sectional moduli were impacting target pipes of smaller sectional moduli. Both sets of impacted pipes showed significant deformation of the pipe at the impact point. The pipes in Group 4b had more diameter change but less bending than those in Group 5b. 


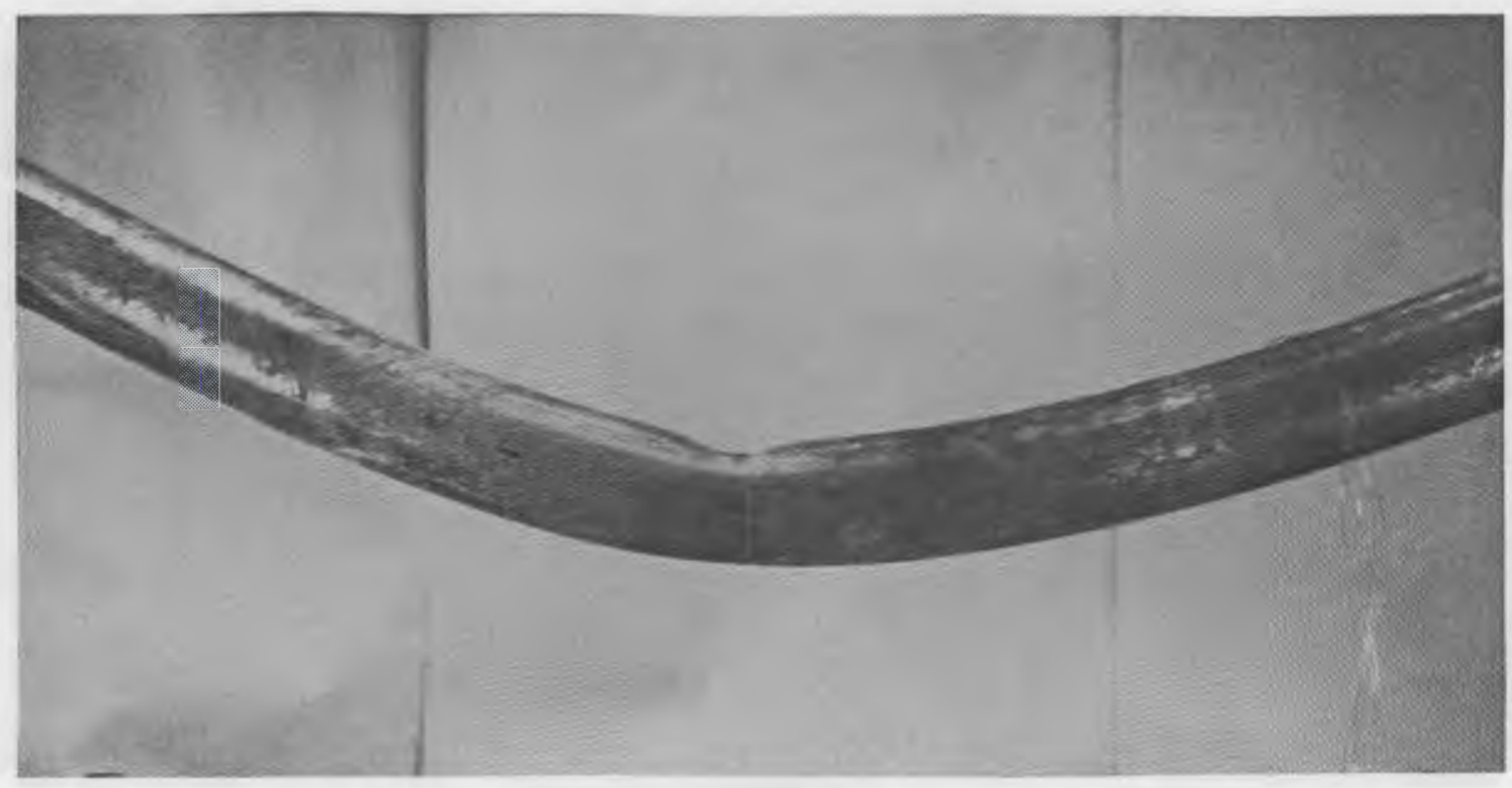

FIGURE 2.24. Impacted Pipe - Group 5b, Test 5b.1

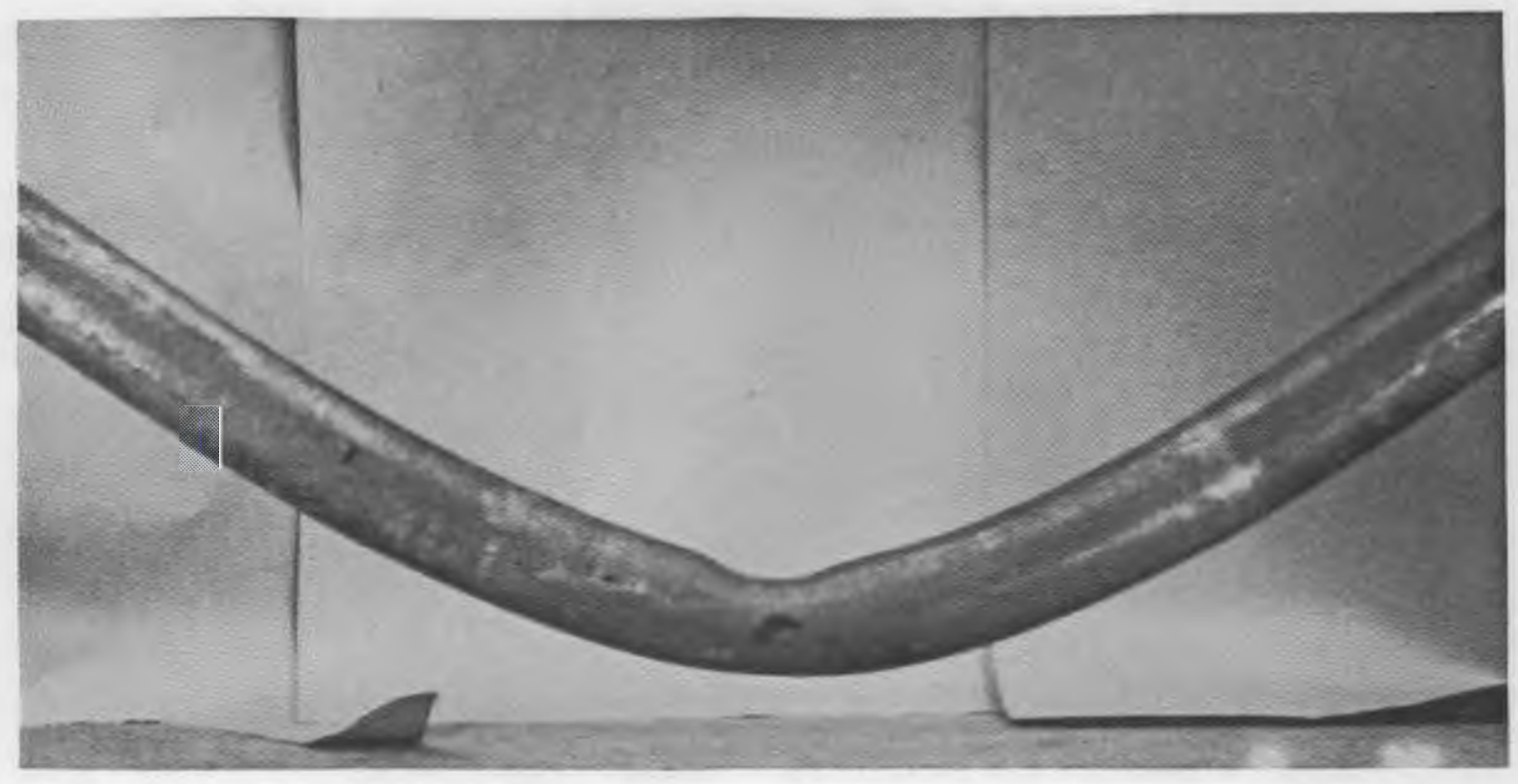

FIGURE 2.25. Impacted Pipe - Group 5b, Test 5b.2 


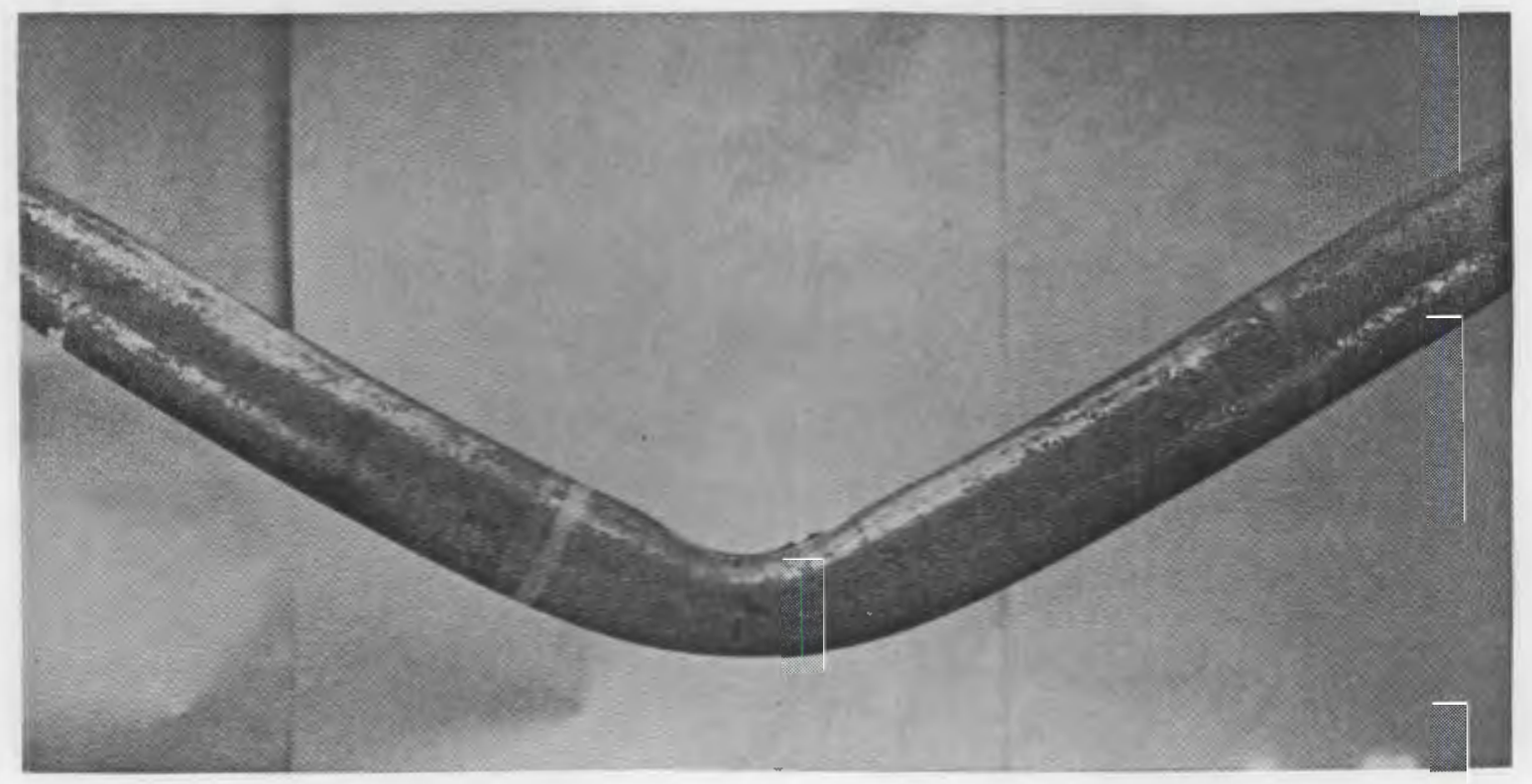

FIGURE 2.26. Impacted Pipe - Group 5b, Test 5b.3 


\subsection{MODELING OF THE PIPE-TO-PIPE IMPACT EVENT}

An analytical method was formulated to model pipe-to-pipe impact events. The model consists of a set of algebraic expressions relating impact behavior to input parameters. In this section, the derivation of the model will be briefly presented, and the results from the model will be compared to pipe impact experimental data.

Figure 3.1 depicts side and end views of the type of pipe impact configurations for which the model is applicable. All supports are assumed to be hinged, and the impacted or target pipe is assumed to be struck at the center. Four modes of deformation are assumed for the model. These consist of local ovalization (vertical diameter change) for each pipe at the impact point and plastic bend angles as indicated. Sections of pipe on either side of the impact point are assumed to remain straight.

The assumption precluding the existence of plastic hinges except at the point of impact should not be taken lightly. For impact configurations for which $\ell_{b}$ is small compared to $\ell_{a}$ (see Figure 3.1), hinge development in the impacting pipe between the pivot point and the point of impact is possible.

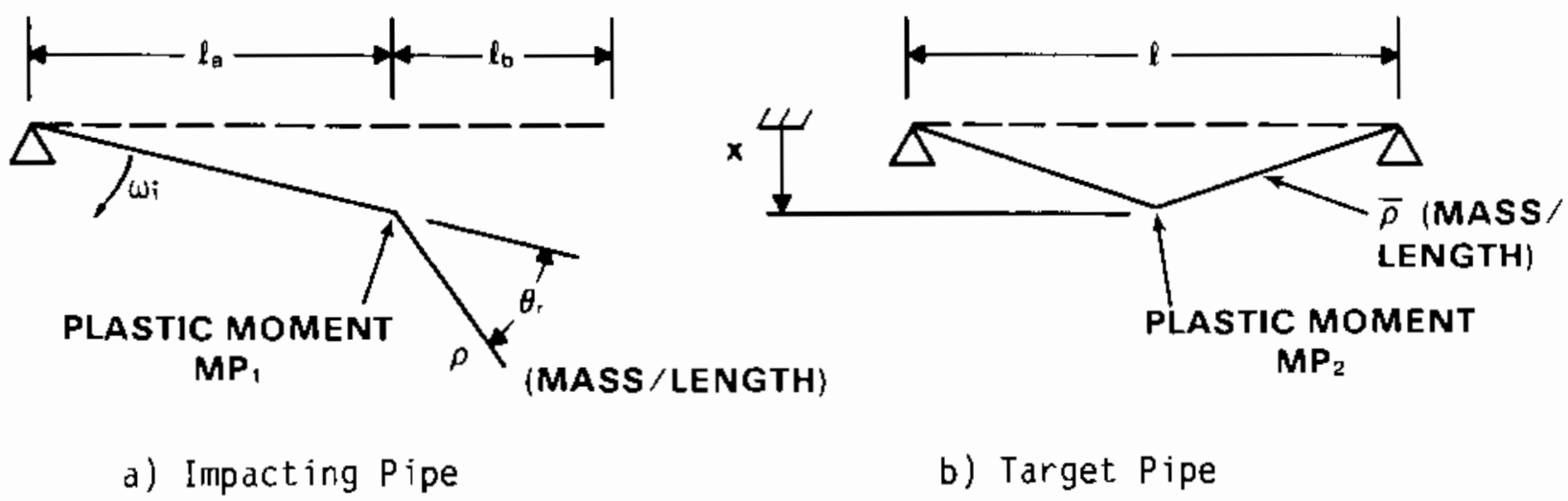

FIGURE 3.1. Nomenclature for the Impact Model 
It is assumed that all of the initial kinetic energy of the impacting pipe is absorbed by the four modes of deformation (ovalization and plastic flexure of both pipes). Thus, the model does not allow for any rebound kinetic energy. Experimental observations of pipe tests performed to date confirm the validity of this assumption. Rebound energies typically are substantially less than $5 \%$ of the initial kinetic energy.

For modeling purposes, the impact event was divided into two phases: an impulse or crushing phase of short duration, in which the pipes crush and achieve a common velocity at the impact location, and a flexure phase in which the bend angles form. The deformation phases were assumed to be mutually exclusive; i.e., no flexure occurs during the crush phase and no crushing occurs during the flexure phase.

A finite amount of the initial kinetic energy is lost during the impulse or crush phase. This energy can be determined if the velocity distribution is known after the crush phase and before the flexure phase. During the crush phase, both pipes were assumed to be hinged at the impacted sections. By applying equal and opposite impulses to the two pipes at the corresponding impact locations, it can be shown that the impulse required to cause the two final velocities to be equal results in the following generalized velocities for the two-degree-of-freedom system:

$$
\begin{aligned}
\dot{x}(D) & =\frac{\ell_{a} A \omega_{j}}{A+B} \\
\dot{\theta}_{r}(0) & =\frac{B\left(1+3 l_{a} / 2 l_{b}\right)}{A+B} w_{i}
\end{aligned}
$$

where $A=3 \rho\left(4 l_{a}+3 l_{b}\right)$

$$
B=12 \bar{\rho} \bar{\ell}
$$


This results in a kinetic energy after the crush phase of energy after impulse, expressed as

$$
\begin{aligned}
& \frac{\omega_{i}^{2}}{(A+B)^{2}} \| \frac{\rho \ell_{a}^{3}}{6} A^{2}+\frac{\rho \ell_{b}}{2}\left[\left(\left(\ell_{a}+\frac{\ell_{b}}{2}\right)^{2}\left(A^{2}+B^{2}\right)\right.\right. \\
& \left.\quad-b \ell_{a} \bar{\ell} \bar{\rho}(A+B)\left(\ell_{a}+\frac{\ell_{b}}{2}\right)+9 \ell_{a}^{2} \bar{\ell}^{2} \bar{\rho}^{2}\right\} \\
& \left.\quad+\frac{1}{12}\left\{\ell_{b}^{2}(A+B)^{2}+36 \ell_{a} \bar{\ell} \bar{\rho} \ell_{b}(A+B)+18^{2} \ell_{a}^{2} \bar{l}^{2} \bar{\rho}^{2}\right\}\right] \\
& \quad+\frac{1}{6} \bar{\rho} \bar{\ell} \ell_{a}^{2} A^{2} \|
\end{aligned}
$$

Because the initial kinetic energy of the striking pipe is

$$
1 / 3 \rho\left(l_{a}+\ell_{b}\right)^{3} \omega_{i}^{2}
$$

the total energy consumed during the crushing phase can be computed as

$$
\text { Crush energy = initial energy - energy after impulse }
$$

It must be pointed out that this is the total crush energy for the two pipes. A method for approximating the individual crush energies of the two pipes and for determining the respective ovalizations will be described in Section 3.2.

\subsection{EQUATIONS OF MOTION}

Equations of motion for the flexure phase may be written by making use of Lagrange's equations (Meirovitch 1967). To do so, certain assumptions must be made about the loading due to the plastic hinges. The direction of the plastic moments is in a sense so as to oppose relative angular motion. 
The magnitude of the plastic moments for the two pipe sections is computed by allowing for geometrical changes in the respective cross sections resulting from crush. In addition, temperature and strain rate effects were considered in determining suitable values of yield stress to use in calculating values for plastic moments. Details concerning the technique used in determining plastic moment values are given in Appendix $A$.

The initial conditions for $\dot{x}$ and $\dot{\theta}_{r}$ are positive; hence, for the first part of the flexure phase, both hinges are known to be active. Using Lagrange's equations of motion, it can be shown that during this phase the equations of motion take the form:

$$
\begin{aligned}
& \ddot{x}=\frac{M P_{1} B_{1}-\frac{4 M P_{2}}{B_{2}} A_{1}-\overline{B_{1}} B_{2}}{\bar{A}_{2}} \\
& \ddot{\theta}_{r}=\frac{\frac{4 M P_{2}}{\bar{l}} A_{2}-M P_{1} A_{1}}{B_{2}} \frac{A_{1}-B_{1} A_{2}}{A_{2}} \\
& A_{1}=\frac{\rho \ell_{a}}{3}+\frac{2 \bar{\rho} \ell_{a}}{3}+\frac{\rho \ell_{b}}{\ell_{a}^{2}}\left(\ell_{a}+\frac{\ell_{b}}{2}\right)^{2}+\frac{1}{12} \frac{\rho \ell_{b}{ }^{3}}{\ell_{a}^{2}} \\
& A_{2}=B_{1}=\frac{\rho \ell_{b}^{2}}{2}-\left(l_{a}+\frac{\ell_{b}}{2}\right) \frac{l}{\ell_{a}}+\frac{1}{12} \frac{\rho \ell_{b}{ }^{3}}{\ell_{a}} \\
& B_{2}=\frac{\rho \ell_{b^{3}}}{3}
\end{aligned}
$$

The initial conditions are:

$$
\begin{aligned}
& x(0)=\theta_{r}(0)=0 \\
& \dot{x}(0)=\frac{l_{a} A \omega_{j}}{A+B}
\end{aligned}
$$




$$
\dot{\theta}_{r}(0)=\frac{B\left(1+3 \ell_{a} / 2 \ell_{b}\right)}{A+B} \omega_{i}
$$

The equations of motion are valid only so long as the hinges are active. The plastic moments are assumed to be active so long as their corresponding velocities are positive; $i . e .$, the $M P_{1}$ hinge is active until $\dot{\theta}_{r}$ goes to zero and the $\mathrm{MP}_{2}$ hinge is active until $\dot{x}$ goes to zero. Since plastic hinge moments are assumed to be constant, accelerations are constant. Because initial velocities are known and because accelerations are constant, determining which degree of freedom comes to rest first is easy.

Applying Lagrange's equation to the system with only one active degree of freedom yields:

$$
\text { For } \begin{aligned}
\dot{\theta} & =0 \\
\ddot{x} & =\frac{-4 \mathrm{MP}_{2}}{\bar{\ell} \mathrm{A}_{1}} \\
\text { For } \dot{x} & =0 \\
\ddot{\theta}_{r} & =\frac{-M P_{1}}{\mathrm{~B}_{2}}
\end{aligned}
$$

The appropriate equation from above is then used to determine when motion ceases. Initial conditions for the one-degree-of-freedom system are taken from the final displacement and velocity conditions for the two-degree-offreedom system.

Typical velocity versus time plots for a system in which $\theta_{r}$ reaches zero first are shown in Figure 3.2. Final displacements $\left(\theta_{r}\right.$ and $x$ ) cannot be calculated by determining the areas under the respective velocity curves. The angle of bend of the target pipe is calculated as

$$
\theta_{b}=2 \tan ^{-1} \frac{2 x}{\bar{l}}
$$




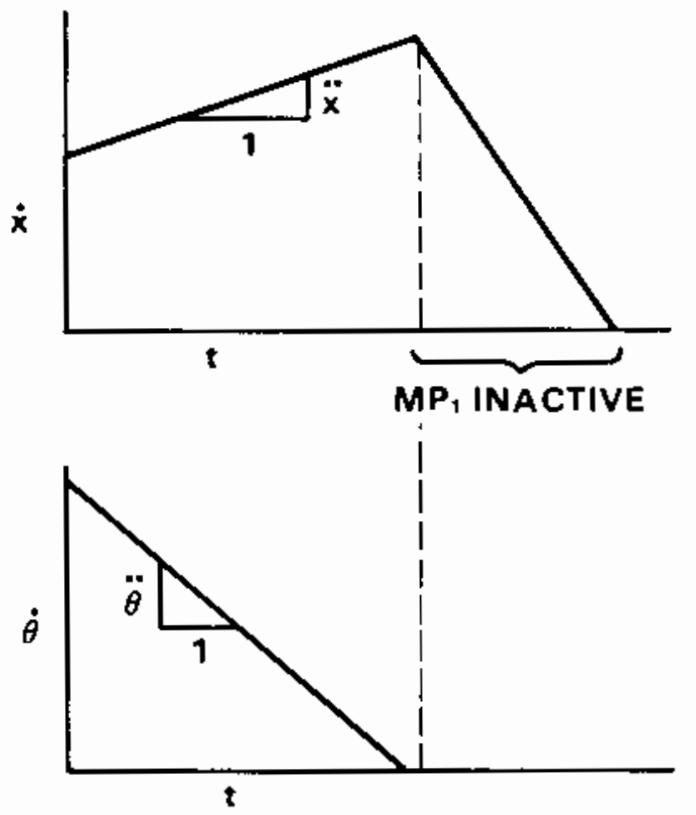

\section{ENERGY ABSORBED BY \\ PLASTIC HINGE \\ $M_{2} \propto$ THIS AREA}

ENERGY ABSORBED BY

PLASTIC HINGE MP,

PROPORTIONAL TO THIS

AREA

FIGURE 3.2. Generalized Velocity Plots for Pipe Response in the Flexure Phase

\subsection{ALLOCATION OF CRUSHING ENERGY}

Previously, it was shown that a certain fraction of initial kinetic energy was absorbed by crushing. The method for determining the allocation of this energy between the impacting and target pipes and the ovalization deformation of the respective pipes will now be described.

The dynamic load deflection characteristics of the two impacting pipes were assumed to be as shown in Figure 3.3. Because both pipes experience the same contact force at all times, the relative energy absorbed for a given load is proportional to the respective areas beneath the two curves. Crush ovalizations can be determined by conceptually increasing the load until the total energy absorbed is equal to that predicted by the impulse/momentum model.

It was further assumed that the dynamic load deflection characteristics of an empty pipe experiencing this type of loading could be determined from static testing. Although the dynamic crush situation involves a localized 


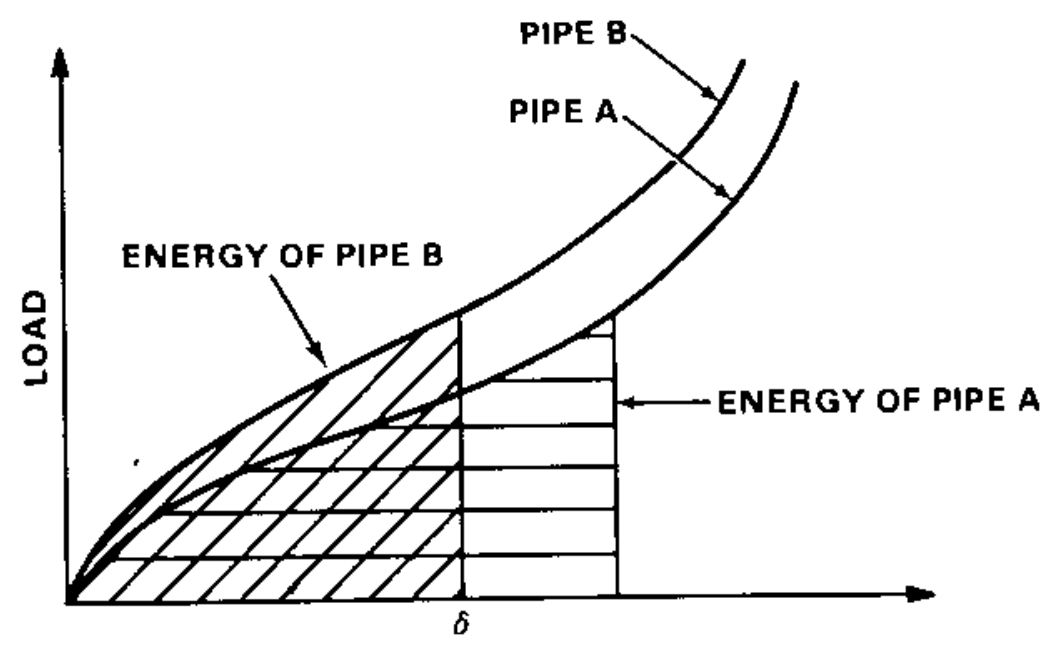

FIGURE 3.3. Crush Energy Allocation Method

contact load balanced by distributed body force inertial loading, it was assumed that the load deflection characteristic would be similar to that of a long piece of pipe (so that end effects would not enter in) supported by a rigid flat surface and loaded by a cylindrical platen of equal diameter. To compensate for dynamic material effects, the static results were scaled by using dynamic and static yield stress data ratios. In addition, temperature effects on crush stiffness were scaled from room temperature tests by using temperature-dependent yield stress values.

\subsection{APPLICATION OF DIMENSIONAL ANALYSIS}

Load deflection curves for empty 6-inch Sch 80 and 6-inch Sch 40 pipes were determined experimentally. Because full-scale tests (even static and at room temperature) would have been too costly, dimensional analysis was used so that small-scale tests could be substituted.

From techniques of dimensional analysis (Langhaar 1951), the following relationships can be made. 
Assuming that the load $P$ is a unique function of

D pipe outside diameter

$\sigma_{y}$ material yjeld stress

$t$ pipe wall thickness

$\delta \quad$ plastic deflection beneath load

then the following expressions are valid:

$$
\begin{aligned}
& \text { (Load) } P=\sigma_{y} t^{2} F\left(\frac{t}{D}, \frac{\delta}{0}\right) \\
& \text { (Energy) } E=\sigma_{y} t^{3} G\left(\frac{t}{0}, \frac{\delta}{0}\right)
\end{aligned}
$$

where $F$ and $G$ are two nondimensional functions of $t / D$ and $\delta / 0$. Thus, by using smaller pipes with $t / D$ ratios equivalent to 6 -inch Sch 80 and 6 -inch Sch 40 pipe, the desired load deflection data can be obtained for empty pipes. This was done using the data shown in Table 3.1.

TABLE 3.1. Data Used in Scale Model Crush Tests

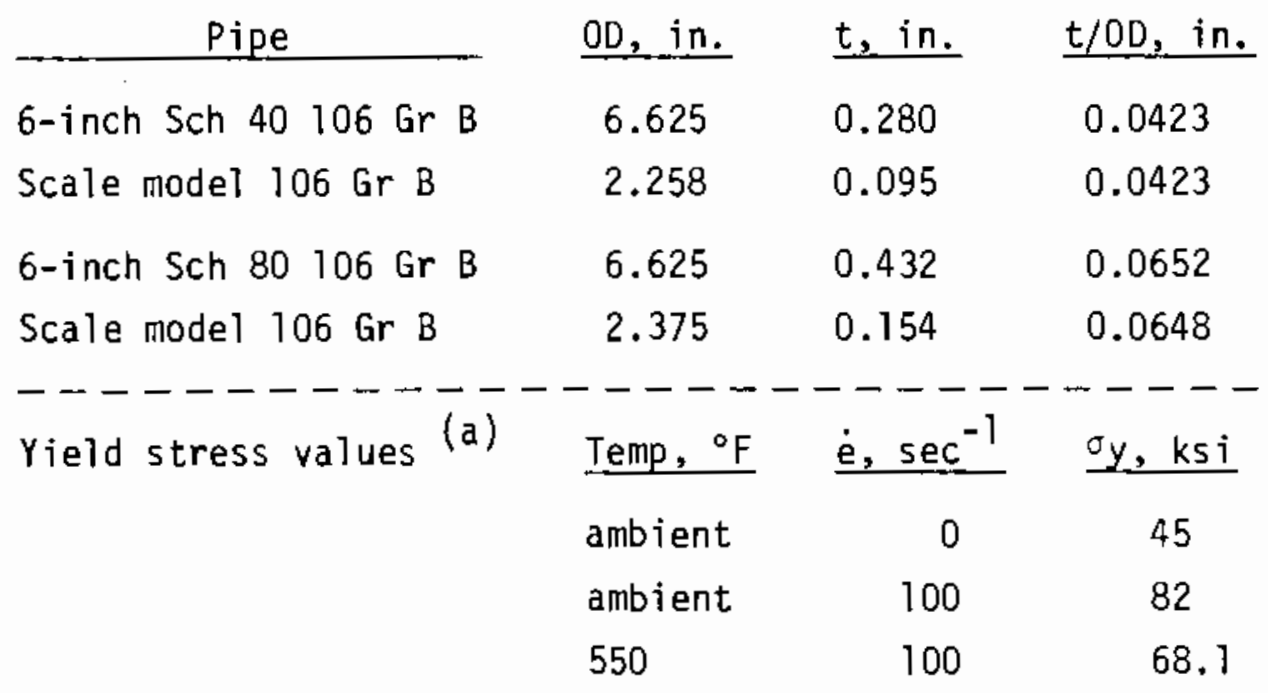

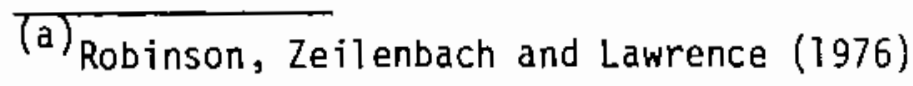


The impacting pipes for the current study were empty and at room temperature (RT). The target pipes, however, were full of oil. The liquid contents of the target pipe will tend to stiffen its load deflection curve (raise the corresponding curve in Figure 3.3). This stiffening effect should be more pronounced with thin-walled pipes. Note that this is the case for the analytical results shown in Figures 3.4 and 3.5.

One way to obtain the dynamic data for a fluid-filled pipe would be to perform static crush tests. However, this would add new variables to the dimensional analysis and greatly increase the amount of necessary experimental work.

An analytical procedure was devised to modify the data collected for empty crush tests so that it could be applied for the fluid-filled cases. It was assumed that the load for the fluid-filled pipe consists of two parts, i.e.,

$$
F_{\text {total }}(\delta)=F_{\text {empty }}(\delta)+F_{P}(\delta)
$$

where $\mathrm{F}_{\text {total }}=$ total load

$F_{\text {empty }}=$ load that would be required for the same deflection of an empty pipe

$F_{P}=$ increase in load for a given deflection due to fluid contents.

In addition, the following assumptions were made:

- The volume change in the vicinity of the impact point is a unique function of crush depth and is independent of pipe contents.

- Pressure is essentially uniform within the pipe.

- The pipe crushing is a quasi-static event.

Under these conditions, the additional force required as a result of pipe contents is 


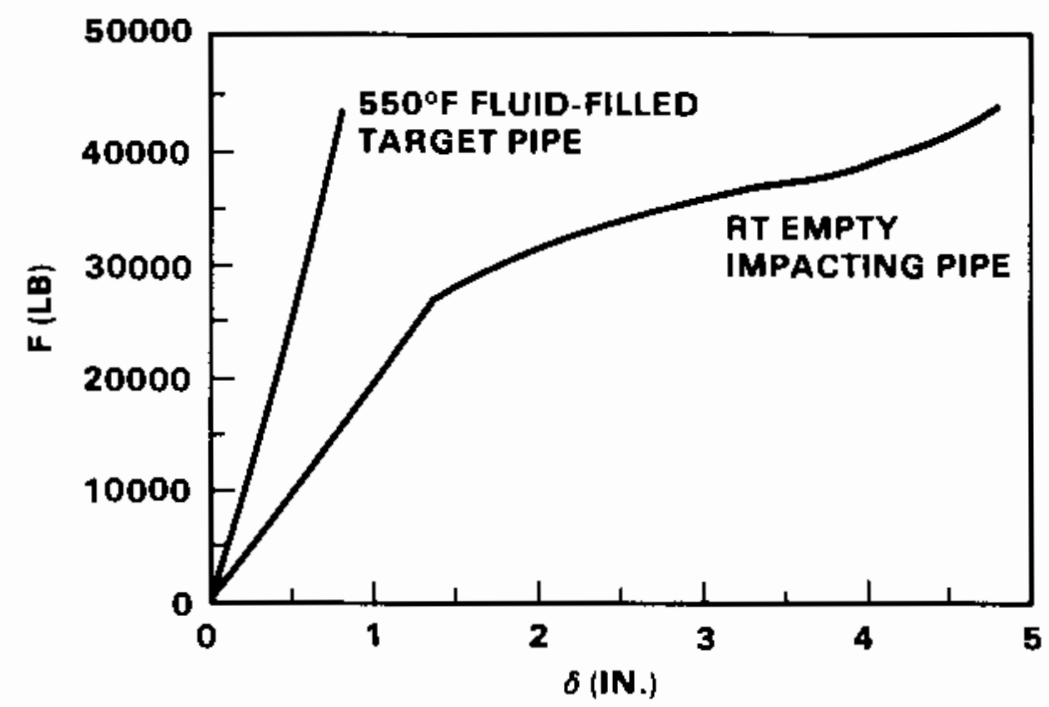

FIGURE 3.4. Crush Data for 6-Inch Schedule 40 Pipes

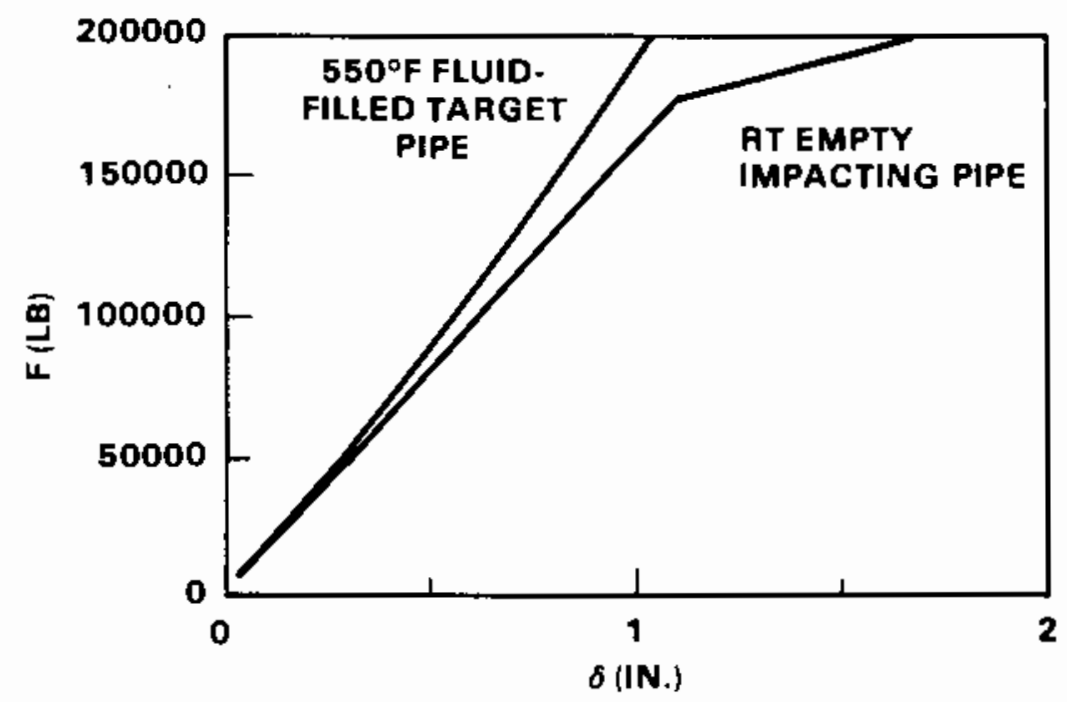

FIGURE 3.5. Crush Data for 6-Inch Schedule 80 Pipes 


$$
\begin{aligned}
F_{P} & =\left(P \frac{d V}{d \delta}\right) \\
F_{P} & =\left(P_{0}+\frac{V}{C}\right) \frac{d V}{d \delta}
\end{aligned}
$$

where P: total pressure

$V$ : localized decrease in pipe volume

$\delta$ : deformation of vertical diameter

$\mathrm{P}_{0}$ : initial pressure

C: pipe volumetric compliance (see Appendix B).

This expression is derived in Appendix B. The expression is valid only so long as the nonlocal behavior of the pipe remains elastic. When nonlocal yield occurs, the term $\left(P_{0}+V / C\right)$ should be replaced with

$$
P_{y i e l d}=\frac{2 \sigma_{y} t}{d}
$$

The quasi-static assumption made for this derivation should not be considered valid in all cases. If the crush phase is short, for example, compared to the time for a pressure pulse to propagate the pipe length, then the assumption becomes less valid. For very long pipes, this propagation distance might be considered as a substitute for the length of the target pipe. One last comment needs to be made regarding the limitation of this pressure correction term. If the crush volume is large and if the crush duration is short, then a likely deformation mode will be hoop yielding in the vicinity of the impact location accompanied by a pressure wave of decreasing magnitude as one moves away from the impact location. If this type of behavior occurs, then the expression for fluid stiffening of the target pipe will likely underpredict the true stiffness. Thus, ovalization of the target pipe will tend to be overpredicted.

Two pipe configurations were analyzed using the model described in this section. For each configuration, several impact velocities (w values) were used so as to correspond with impact velocities from the experimental program. 
The cases considered were the 6-inch Sch 80 impacting 6-inch Sch 80 tests and the 6-inch Sch 40 impacting 6-inch Sch 40 tests. Load deflection plots used for the crush phase of the impacts are shown in Figures 3.4 and 3.5 . The scaling data given in Table 3.1 were used in conjunction with small-scale test data in arriving at values corresponding to these figures.

\subsection{CORRELATION RESULTS}

Comparisons of the model predictions with the corresponding experimental data are shown in Table 3.2. All values are normalized in the same manner as described in Section 2. General trends of bend angles and crush ovalizations seem to be predicted adequately by the model in view of the following uncertainties:

- yield stress values used in the model - Yield stress values used were estimates. Twenty to thirty percent error could exist based on strain rate dependency alone. In addition, because strains are quite high, strain hardening effects could be substantial. Furthemore, the strain condition simulated was biaxial in nature, whereas yield stress values were for uniaxial conditions.

\section{TABLE 3.2. Preliminary Results for Impact Model}

\begin{tabular}{|c|c|c|c|c|c|}
\hline \multirow[b]{2}{*}{ Test } & \multirow{2}{*}{$\begin{array}{c}\text { Normalized } \\
\text { Energy } \\
\end{array}$} & \multicolumn{2}{|c|}{$\begin{array}{l}\text { Normalized } \\
\text { Bend Angle }\end{array}$} & \multicolumn{2}{|c|}{$\begin{array}{c}\text { Normal jzed } \\
\text { Diameter Change }\end{array}$} \\
\hline & & Exp. & Model & Exp. & Mode I \\
\hline 2.1 & 0.116 & 0.356 & 0.371 & 0.219 & 0.347 \\
\hline 2.2 & 0.129 & 0.472 & 0.439 & 0.250 & 0.365 \\
\hline 2.3 & 0.144 & 0.533 & 0.585 & 0.286 & 0.389 \\
\hline 3.1 & 0.059 & 0.144 & 0.159 & 0.096 & 0.106 \\
\hline 3.2 & 0.068 & 0.206 & 0.185 & 0.126 & 0.113 \\
\hline 3.3 & 0.091 & 0.272 & 0.252 & 0.178 & 0.131 \\
\hline 3.4 & 0.106 & 0.256 & 0.267 & 0.175 & 0.134 \\
\hline
\end{tabular}


- ovalization during the flexure phase - Experimental ovalization measurements were, of course, taken after the flexure deformation occurred. Ovalization deformations that occurred during the crush phase were possibly increased during the flexure phase.

- slight geometrical and material differences among the pipes

- assumptions made in formulating the model - These include:

- assuming an instantaneous impulse during the crush phase

- assuming an elliptical cross section for the crushed geometry used in plastic moment calculation

- all of the assumptions made for the calculation of pressure stiffening effects for the target pipes. 


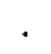




\subsection{FRACTURE MECHANICS CONSIDERATIONS}

Fracture mechanics evaluations were performed to guide the pipe impact test design and to interpret the test results. The specific objectives were

- to evaluate the consequences of flaws on the PNL test results

- to evaluate sensitivity requirements for pretest nondestructive examination of the pipe specimens

- to form a basis for placing margins on results of tests performed on unflawed pipe specimens.

In these evaluations, the methodology of elastic-plastic fracture mechanics was applied in predictions for flawed piping. For unflawed piping the concepts of strain limits from metal forming technology were applied to predict conditions for the initiation of cracking in plastically deformed piping.

\subsection{FRACTURE PROPERTIES}

Fracture properties for the A106 Grade B steel of the pipe specimens were both measured at PNL and estimated from published data. Tests at PNL were 1 imited to dynamic toughness measurements using precracked Charpy specimens.

Figure 4.1 shows typical trends of fracture toughness $\left(K_{I c}\right)$ as a function of temperature. As indicated, the longitudinal specimen exhibits both higher upper shelf toughness and lower ductile-brittle transition temperatures than the transverse specimens. Nevertheless, even the data for the transverse orientation clearly indicate that the temperatures of all the pipe impact tests were such that ductile upper shelf behavior rather than low temperature brittle fracture governed the outcome of the pipe impact tests.

Given that the tests were governed by upper shelf behavior, it was necessary to use elastic-plastic fracture mechanics to make quantitative predictions. The measurement of $\mathrm{J}_{\mathrm{IC}}$ and $\mathrm{J}$-resistance curves for $\mathrm{J}$ integral based fracture mechanics was beyond the scope of PNL's program. Rather, data generated by Gudas and Anderson (1981) in another NRC-sponsored research program were applied. These data for Al06 Class C piping steel are summarized 


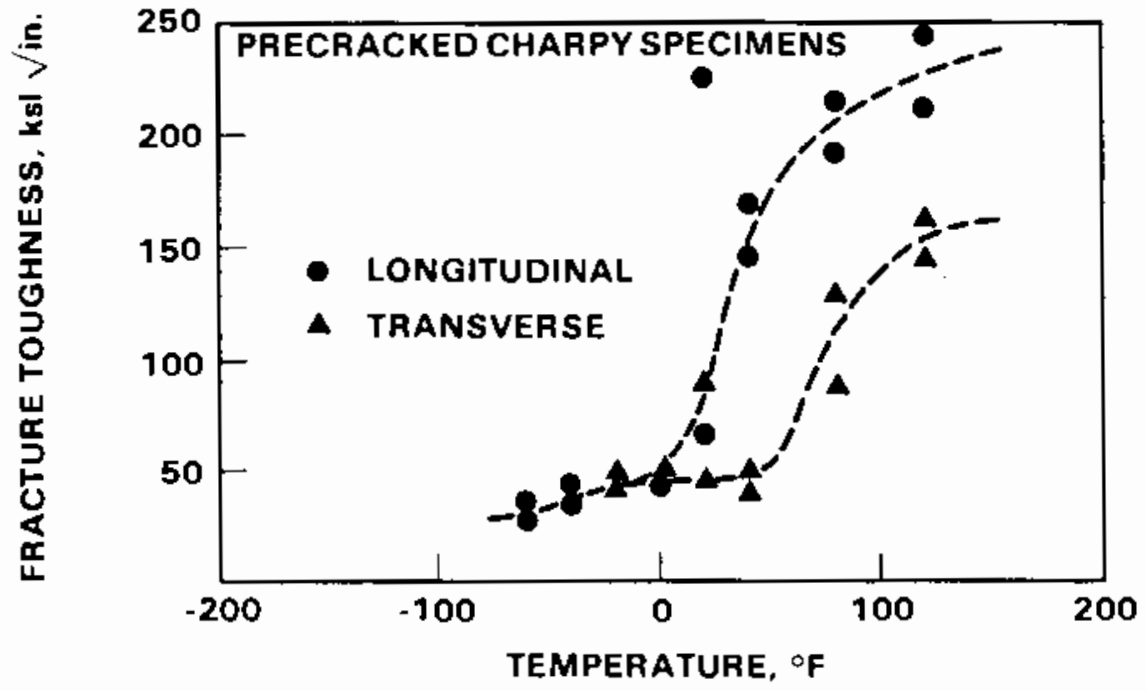

FIGURE 4.1. Dynamic Fracture Toughness for Al06 Grade B Pipe

in Table 4.1. The data indicate trends as a function of specimen orientation, test temperature, and typical specimen-to-specimen variations.

The C-L orientation is most relevant to the mode of cracking seen in the PNL pipe impact tests. The room temperature $J_{I c}$ values for prediction of the injtiation of crack growth were in the range of 1000 in.-1b/in. ${ }^{2}$. Typical resistance curves show that the applied value of $J$ approximately doubled for a crack extension of about 0.1 inch. No data for the elevated temperature condition $\left(550^{\circ} \mathrm{F}\right)$ of interest to the PNL impact tests were available for the $\mathrm{C}-\mathrm{L}$ orientation. However, the data for the $\mathrm{L}-\mathrm{C}$ orientation indicate that $\mathrm{J}$ IC is relatively insensitive to temperature, whereas the resistance curve seems to have a more "flat" characteristic at elevated temperatures (i.e., the value of $J$ does not increase as rapidly with respect to crack extension). Due to this more flat characteristic, it is expected that cracks may be driven through the wall more readily at $550^{\circ} \mathrm{F}$ than at room temperature.

One final observation is the relatively low toughness indicated in Table 4.1 for one L-C specimen reported by Gudas and Anderson (1981). These data 
IABLE 4.1. Typical Fracture Properties of Al06 Class

C Steel (Gudas and Anderson 1981)

C-L ORIENTATION

$$
\begin{aligned}
& \mathrm{J}_{\mathrm{IC}}=\text { range } 903 \text { to } 1034 \mathrm{in.}-1 \mathrm{~b} / \mathrm{in.}^{2} \text { ave. }=969 \mathrm{in.}-1 \mathrm{~b} / \mathrm{in}^{2} \\
& \text { Crack Extension (in.) Jvalue (in. }-1 b / \text { in. }{ }^{2} \text { ) } \\
& 0.020 \\
& 0.050 \\
& 1200 \\
& 1700 \\
& 0.200 \\
& 3200
\end{aligned}
$$

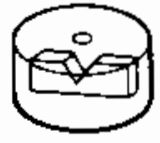

\section{L-C ORIENTATION}

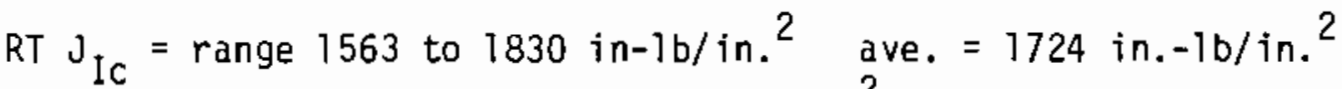

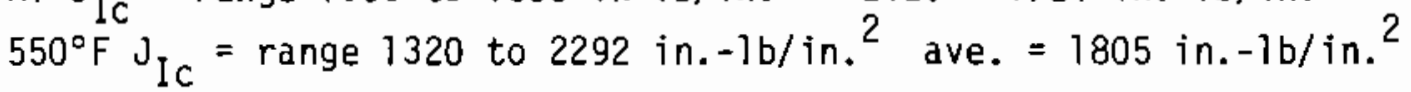

$$
\begin{aligned}
& \text { Crack Extension Room Temp. J Value } 550^{\circ} \mathrm{F} \mathrm{J} \text { Value } \\
& \text { (in.) } \\
& \text { (in.-1b/in.2) } \\
& \text { (in. }-1 b / \text { in. } 2) \\
& 0.020 \\
& 0.050 \\
& 1900 \\
& 0.200 \\
& 2900 \\
& 5600
\end{aligned}
$$

\section{WORST CASE}

One L-C specimen with slag inclusions gave

$$
\begin{aligned}
& J_{\text {Ic }}=386 \text { in. }-1 \mathrm{~b} / \text { in. }^{2} \\
& \frac{\text { Crack Extension (in.) }}{0.020}
\end{aligned}
$$

indicate the possibility that a low energy fracture could occur if a pipe impact should plastically deform such a location of poor toughness. Such isolated locations of low toughness may not, however, contribute significantly to piping failure probabilities for pipe-to-pipe impact events. In fact, the reported presence of slag inclusion in this worst-case specimen (Table 4.1) 
would often be treated in conservative fracture mechanics calculations as a flawed or cracked location in the pipe.

\subsection{FLAW SENSITIVITY CALCULATIONS}

Calculations were performed to estimate the sizes of the smallest flaws that would have the potential to affect the outcome of PNL's pipe-to-pipe impact tests. The intent in PNL's tests was to impact nominally unflawed piping, and not to test worst-case flawed piping.

Fracture mechanics solutions are not available or forthcoming for the complex patterns of plastic deformation seen in the PNL pipe-to-pipe impact tests. It was necessary, therefore, to perform greatly simplified analyses using handbook-type solutions from Kumar, German and Shih (1981). Results for the fully plastic values of the J-integral are displayed in Figure 4.2. In this case a small crack (one-eighth of the wall thickness) was assumed to be a region of otherwise uniform tensile strain. The calculated values of applied $J$ increase with both increasing levels of strain and increasing flaw depth; note that flaw depth increases with wall thickness for the postulated $t / 8$ flaw. In a simplistic manner, the remote strain axis of Figure 4.2 can be associated with the strains as measured on the surface of the impacted pipe using the grids of strain circles.

Figure 4.3 summarizes the results of the flaw sensitivity calculations. The focus is on the typical J Ic values indicated in Figure 4.3, rather than the worst-case, but low probability, values of $\mathrm{J}_{\mathrm{Ic}}$. A typical strain for PNL's tests would range from 20 to $30 \%$; a typical J ${ }_{\text {Ic }}$ value would be in the range of 1000 to $2000 \mathrm{in.-1b/in.}{ }^{2}$. In this case, for an adversely located and oriented crack, a flaw depth must be on the order of 0.02 inch for any flaw growth to occur. Much higher values of applied $J$ are required to sustain the flaw growth, so that the initial pre-test flaw must be substantially deeper than 0.020 inch before through-wa11 cracking would be expected.

In conclusion, only flaws of depths exceeding 0.02 inch are of sufficient size to have had a potential bearing on the outcome of PNL's pipe-to-pipe 


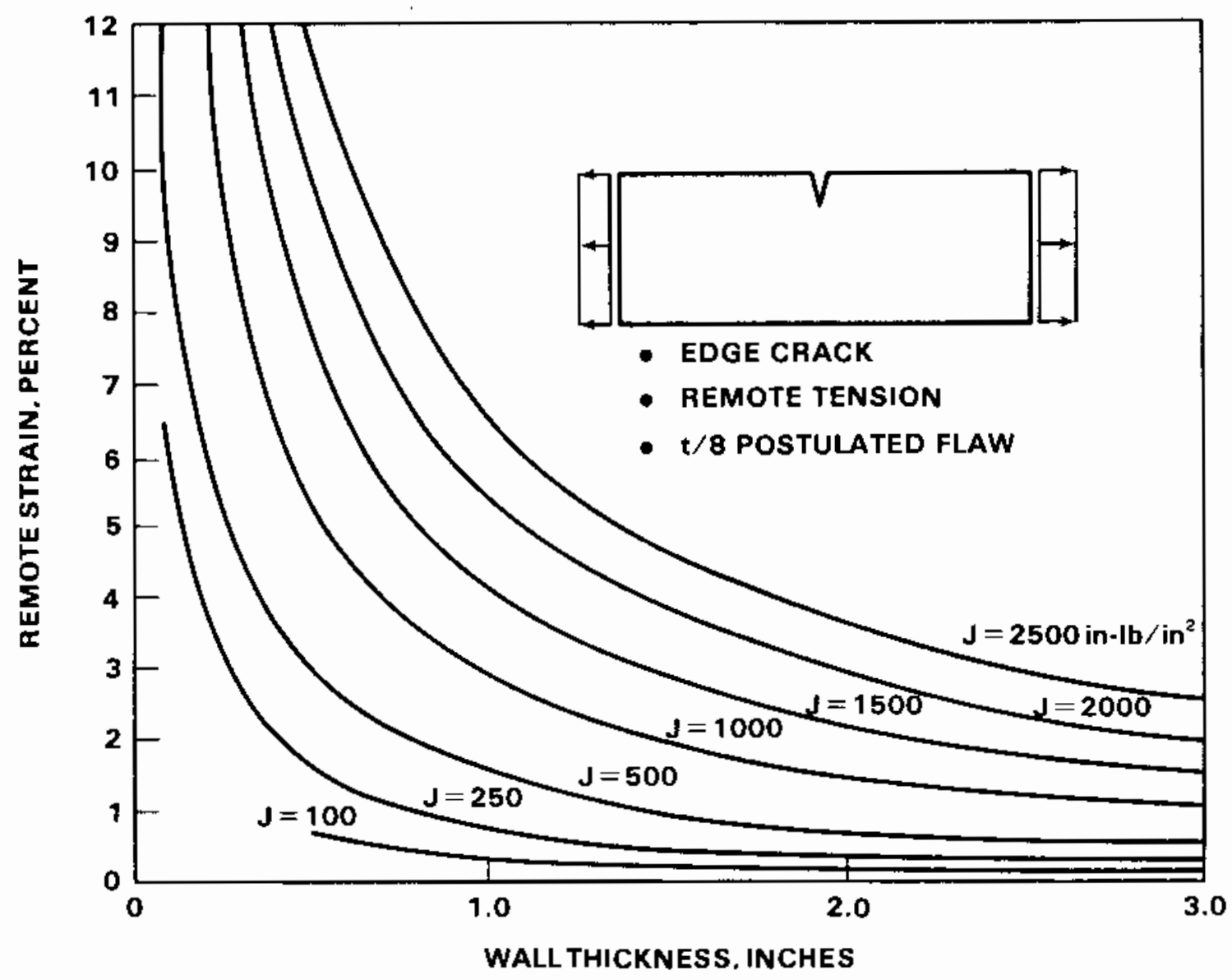

FIGURE 4.2. Plastic Fracture Solution for Applied J

impact tests. Nondestructive evaluations (NDE) were performed on the critical parts of the pipe specimens to detect cracks; these provided no evidence of cracks of sufficient size to affect the test results. There was evidence of small surface defects in post-test visual examinations. These defects were small and oriented parallel to the surface of the pipe and, as such, did not tend to grow through the wall of the pipe.

The NDE of the pipe impact specimens included both ultrasonic inspection and use of magnetic particles. On some specimens, outside surface indications 


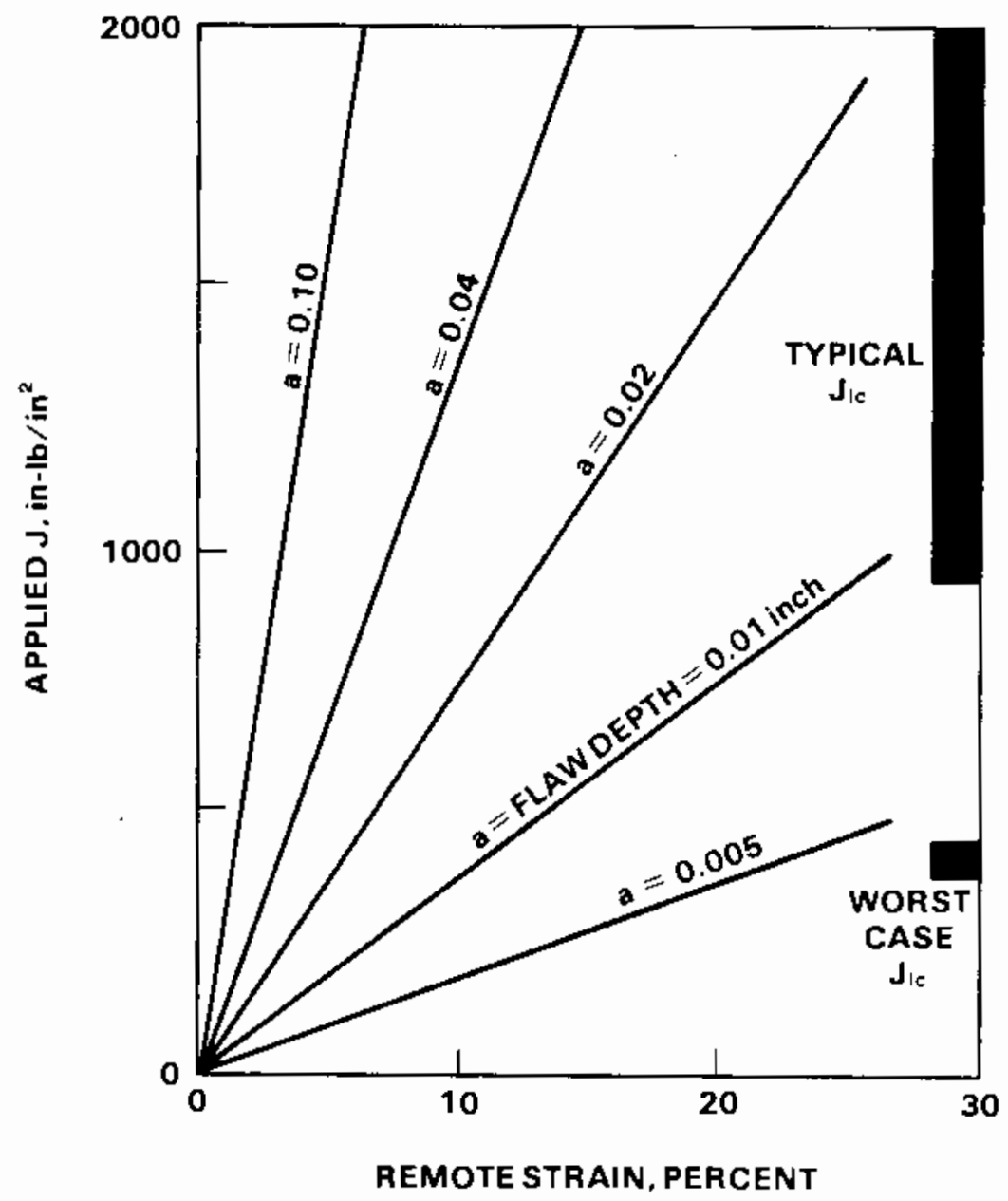

FIGURE 4.3. Al06 Plastic Fracture Prediction

of cracks were seen by both the ultrasonic and magnetic particle inspections. The cracks were sized for depth using an electrical resistivity gage, with the greatest measured depth being 0.050 inch. No known defects were revealed by NDE in the impacted or deformed portions of the test pipe specimens.

\subsection{PLASTIC STRAIN LIMITS}

The ductile rupture of nominally unflawed material has been the subject of extensive investigation in the field of metal forming technology (Hecker 
1973, 1978). The levels of strain associated with pipe rupture in the PNL tests support the use of this methodology to explain and predict the formation and propagation of cracks in the pipe specimens. Unlike fracture mechanics theory, these methods do not postulate the presence of existing flaws as the mechanism of fracture. They do, however, recognize that ductile fracture involves the growth and coalescence of material defects on the microstructural level.

In the simplest analysis, ductile rupture will be expected when the plastic strain (e.g., effective or von Mises strain) exceeds a critical value based on the elongation or reduction in area for a tensile test. More sophisticated predictions consider the effects of biaxial and triaxial states of stress and strain.

A review of the literature indicates two approaches to the multiaxial effect which give strain 1 imits as shown in Figure 4.4. The forming 1 imit curve is based on experiments that simulate sheet metal forming (e.g., deep drawing) operations (Hecker 1973). Strain states that lie outside the boundary of this curve would be expected to produce cracking, whereas strain states within this curve should not produce cracking. In the pipe impact tests, the axes of major and minor strain would correspond to surface strains (e.g., axial and hoop strains). The position of the forming limit curve of figure 4.4 is based on test data from deformation of sheet type specimens. For these tests the stress in the thickness direction is zero. As such, failure or cracking is associated with tensile instability (necking or thickness reduction). Such failures may not be representative of conditions in the pipe impact tests.

The other approach to strain limits considers ductility exhaustion and is more applicable to triaxial states of stress and deformation as experienced, for example, in extrusion operations (Norris et a1. 1978). The shaded zone in Figure 4.4 corresponds to various assumptions regarding the role of tensile stresses in enhancing the effect of plastic deformation on ductile failure. The upper or more optimistic bound assumes no role of tensile stresses and 


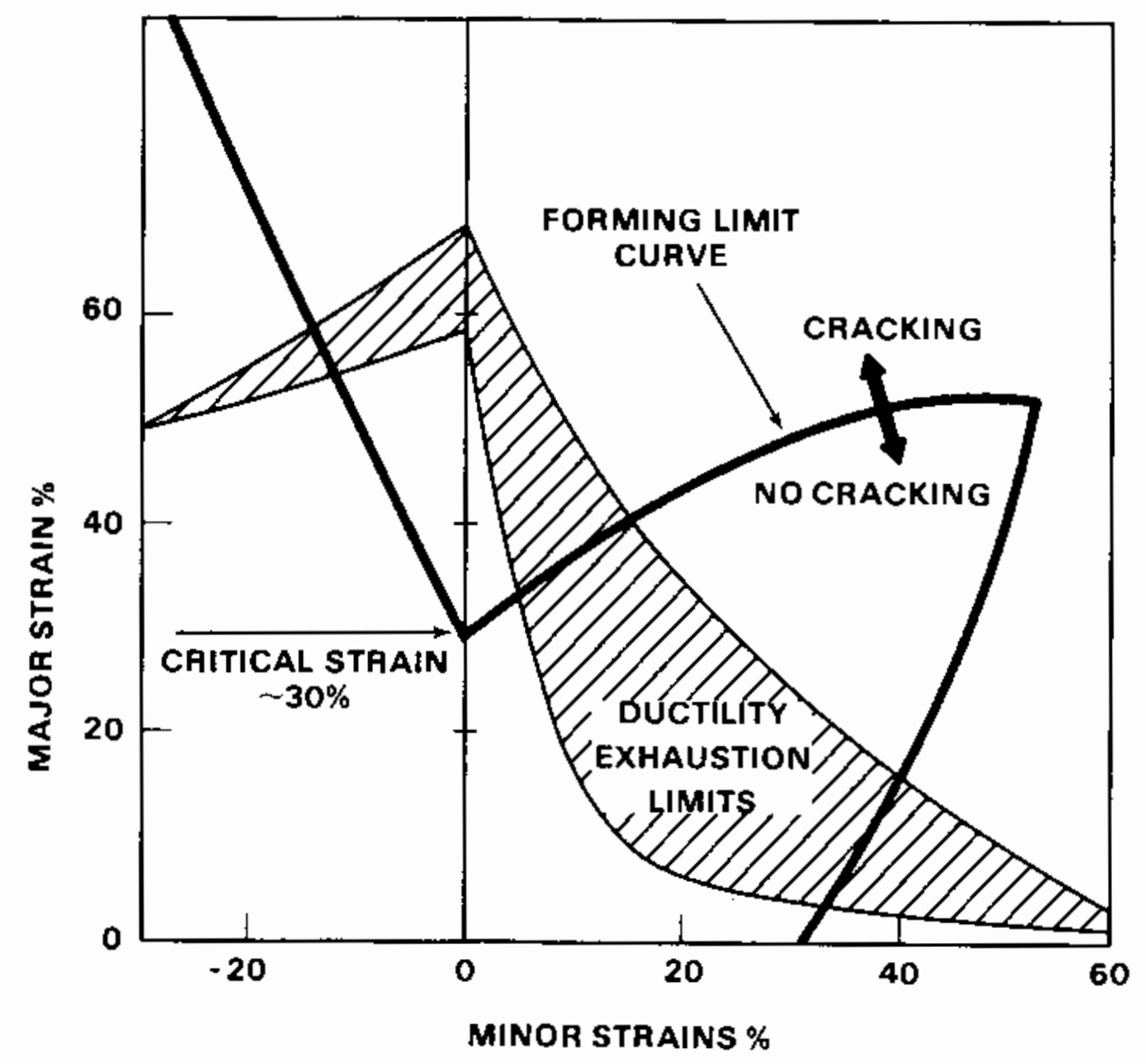

FIGURE 4.4. Strain Limits for Unflawed AI06 Predicted by Metal Forming Technology

bases the failure prediction solely on the level of plastic strain (failure occurs when the effective plastic strain equals the elongation measured in a uniaxial tensile test). The lower or more pessimistic bound shown in Figure 4.4 multiplies the plastic strain by the hydrostatic component of stress to calculate a measure of damage. Failure is predicted when this damage parameter equals the corresponding value for a uniaxial tensile test.

Figure 4.5 shows measured strains (strain circle data) for the outside surface of target pipe tested in Group 5b. While rupture did not occur in this test, the level of deformation in the target pipe was similar (perhaps some- 


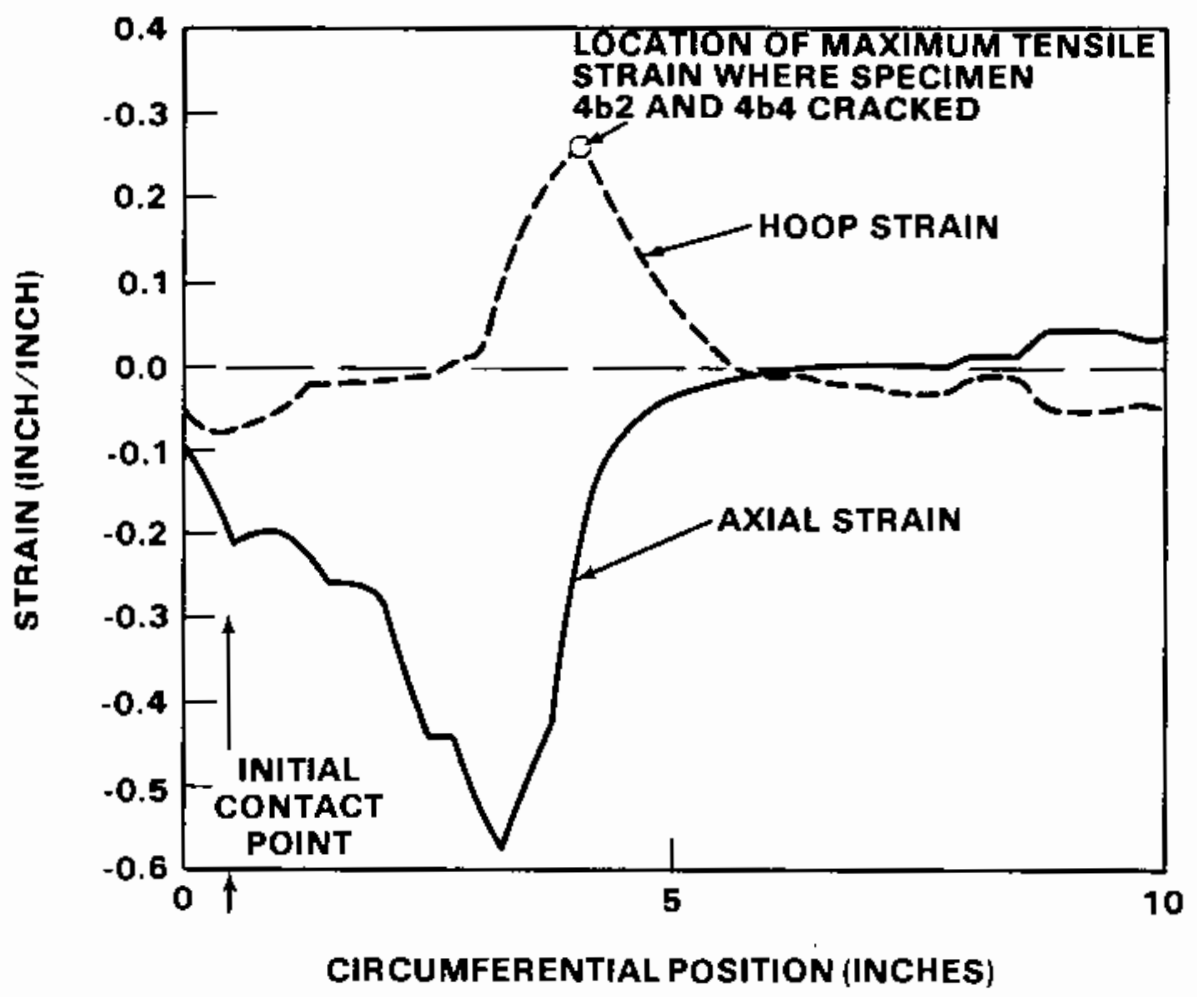

FIGURE 4.5. Measured Strains for PNL Pipe Impact Test 5b

what less) to that for tests $4 \mathrm{~b} .2$ and $4 \mathrm{~b} .4$, which exhibited through-wall cracking. Without strain data for the inside surface of the pipe one can only consider alternative possibilities that are consistent with the measured outside surface strains. It is clear, however, that the deformation modes near the point of cracking in tests $4 b .2$ and $4 b .4$, included a significant contribution from through-wall bending deformation. On this basis, the major strain was at least 0.25 (0D surface-measured value) and possibly as high as 0.55 (ID surface-estimated value). The circumferential orientation of the cracks in tests $4 \mathrm{~b} .2$ and $4 \mathrm{~b} .4$ strongly suggest the existence of high (but unmeasured) axial strains at the inside surface. If the associated minor strains are assumed to be in the possible range of \pm 0.55 , one can readily plot strain states in Figure 4.4 that are located in the regions where cracking is predicted. 
The application of strain limits from metal forming technology demonstrates that initial defects in the PNL pipe specimens probably had an insignificant effect on the pass/fajl outcome of the tests. Rather, the test results clearly showed that large plastic strains were associated with test-induced failures. Furthermore, the observed strain levels were consistent with expected strain limits for unflawed material.

\subsection{RUPTURE PROBABILITY FOR FLAWED PIPE}

All results of the PNL impact tests are intended to apply to unflawed piping; care was taken by pre-test NDE to exclude any specimens with known flaws. Nevertheless, it must be recognized that flaws do exist in real piping systems, although their rate of occurrence is generally believed to be very low. Impact of a pipe at the location of a flaw could rupture a pipe at impact velocities or energy levels that are much lower than those indicated by the PNL tests.

This discussion presents probabilistic arguments to justify the exclusion of flawed pipe specimens from the PNL test matrix. The main consideration is that the presence of a flaw is not required for a pipe to rupture at the impact velocities associated with pipe impact events. Additional considerations are the low occurrence rate for flaws and the high probability that the impact will not occur at the location of the flaw. Hence, the probability of impact occurring at a flaw is low. In addition, the corresponding probability of rupturing unflawed material is much greater.

The potential contribution of flaws to impact-induced pipe rupture can be estimated for the reference pipe geometry of figure 4.6. Calculations were based on the following considerations:

- The pipe has one weld per 10 diameters of pipe.

- The highly deformed impact region measures half a diameter by 180 degrees.

- Impact can occur anywhere on the pipe with equal probability (no preference for welds). 
- Flaws within the impact region grow through-wall at any impact energy.

- The probability of a flaw in each weld is 0.05 (Harris, Lim and Dedhia $1981)$.

- Flaws in welds are 50 times more likely than in base metal on a unit material volume basis (Thomas 1979).

- Half of the flaws are smaller than the estimated size that could influence the results of the impact tests - a long crack of 0.02-inch depth (Harris, Lim and Dedhia 1981).

- Only half of the flaws are unfavorably oriented or located relative to high tensile strains.

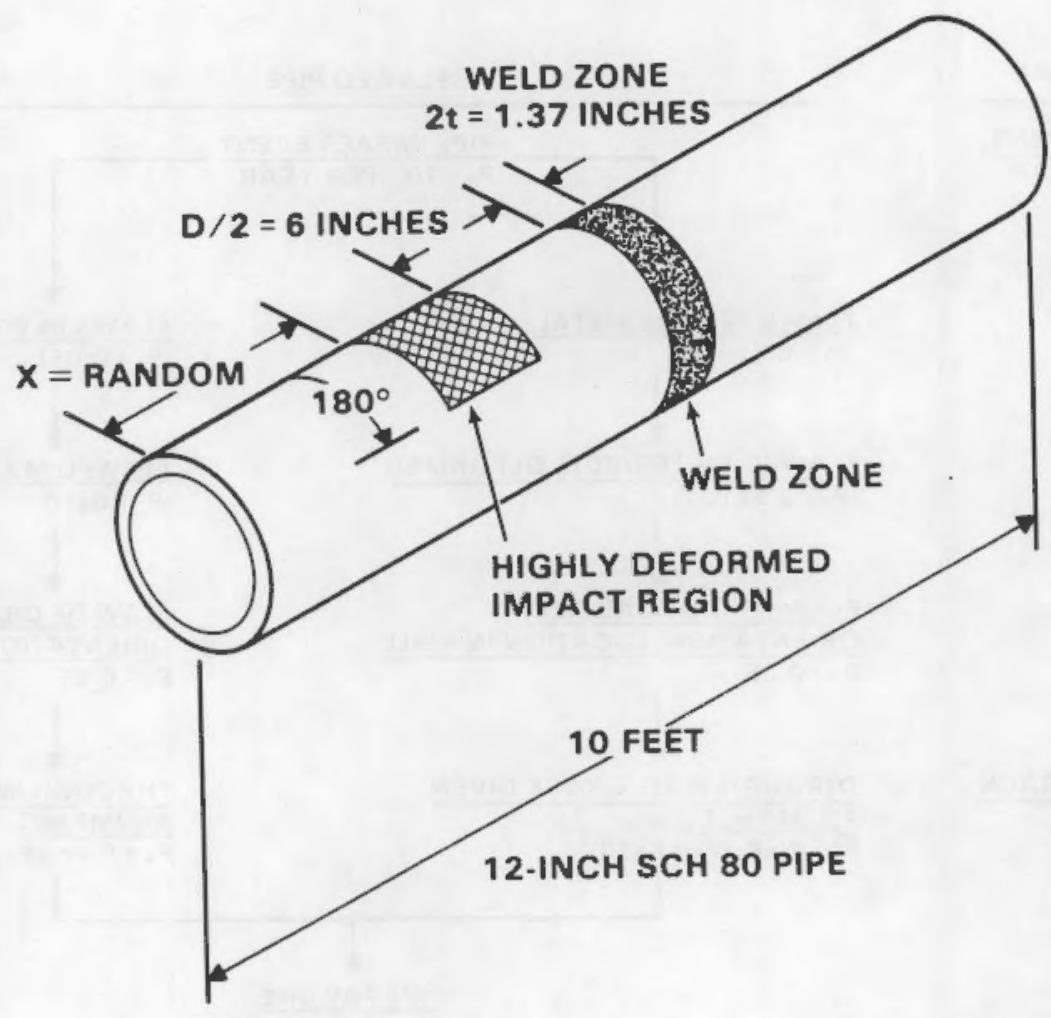

FIGURE 4.6. Reference Geometry for Rupture Probability Estimate 
- No pipe impact events have yet occurred in 3000 years of reactor operation. (This gives an event rate that is less than $3.7 / 3000=1.23 \times 10^{-3}$ events per year with a confidence level of $95 \%$.)

Failure probability estimates were then made following the logic of Figure 4.7. For flawed pipe, the failure probability was estimated for possible flaws in either the weld or base metal. It is of interest that flaws in the base metal contribute as much to the total failure probability as do weld flaws. While weld material will be more likely to have flaws (on a unit volume basis), this factor is offset by the much greater volume of base metal relative to welds. The overall estimate of flaw-induced pipe failures due to impact events was estimated as $10^{-6}$ pipe ruptures per year. The corresponding contribution of failure for unflawed pipe is not estimated in Figure 4.7, but
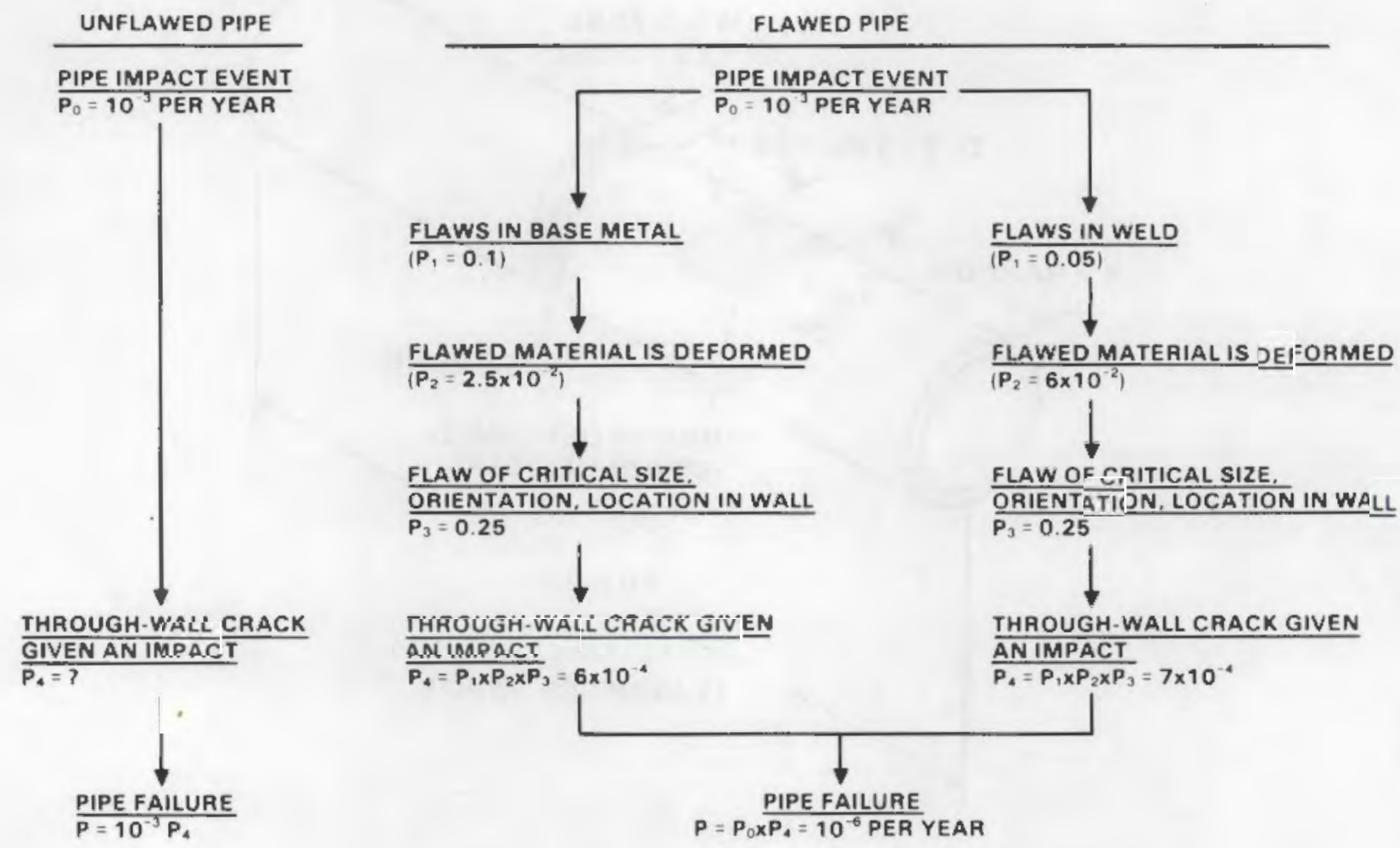

FIGURE 4.7. Summary of Failure Probability Estimates 
is dependent on considerations of impact velocities or relative pipe diameter, which will govern $P_{4}$ (probability of rupture given an impact event). However, the analysis in Section 4.5 indicates that $P_{4}$ will be significantly greater than $10^{-3}$.

The conciusions based on this evaluation of flaws and their contribution to potential pipe ruptures due to impact events can be summarized as follows:

- The probability of flaw-induced fracture is low (about $10^{-6}$ per year) and is similar to the estimated risk of vessel fracture.

- The contribution of flaws to rupture probability should be much less than the rupture probability for unflawed piping.

- The impact tests of unflawed pipes conducted at PNL address the major contribution to risk.

\subsection{RUPTURE PROBABILITY FOR UNFLAWED PIPE}

An objective of the PNL pipe impact tests was to establish the impact velocities or energies required to rupture piping. Although piping with flaws was specifically excluded from the test plan, several other factors of the test were designed to give worst-case conditions (i.e., normal impact, support conditions). This section relates the test conditions to conditions that will exist in the field for potential impact events. That is, given that a pipe impact event does occur, what is the probability or fraction of events that will result in rupture of the impacted pipe?

The analysis presented here is purely exploratory and illustrative in nature, but serves to point out the governing variables and to provide rough estimates of failure probability. The following factors can be listed as important contributors to pipe rupture, given the occurrence of an impact event.

1. If high velocities of the impacting pipe are to be achieved, the jet force must be normal to the accelerated pipe and the pipe motion must exceed a few pipe diameters before the pipe impacts an adjacent pipe. Furthermore, the support/hinge must be several diameters from the peak/ jet force, so that the pipe can attain a whipping action. 
2. The moving pipe must be sufficiently larger in diameter and/or have greater wall thickness to be capable of inflicting damage to the impacted pipe.

3. The impacting pipe must be sufficiently normal to the impacted pipe, and not be parallel or be simply deflected by a glancing impact.

Clearly then, not all impact events will result in significant damage to the impacted pipe.

Figure 4.8 illustrates the parameters that govern the impact velocity and energy associated with a pipe break/impact event. Simple derivations give the velocity and energy relationships as

$$
\begin{aligned}
V^{2} & =(3 / 2 p)(1-\beta) \hat{P}(D / t) \theta \\
E & =1 / 4 \pi(1-\beta) \hat{p} D^{2} L \theta \\
V & =i \text { impact velocity } \\
E & =\text { impact energy } \\
\hat{p} & =\text { effective pressure on end of pipe } \\
\beta & =\text { fraction of energy absorbed by plastic hinge } \\
\rho & =\text { density of pipe material } \\
D & =\text { pipe diameter } \\
L & =\text { iength of pipe to support or hinge } \\
t & =\text { wall thickness } \\
\theta & =\text { swing angle (radians). }
\end{aligned}
$$

Some realistic parameters that could be associated with the impact of a 6-inch Schedule 80 pipe impacting a 6 -inch Schedule 40 pipe (as in the PNL tests) are

$$
\begin{aligned}
& D=6 \mathrm{in} . \\
& t=0.43 \mathrm{in} . \\
& L=10 \mathrm{ft} \\
& \hat{P}=1500 \mathrm{psi} \\
& \beta=0.20 \\
& \rho=7.3 \times 10^{-4} \mathrm{ib}-\sec ^{2} / \mathrm{in}^{4}
\end{aligned}
$$




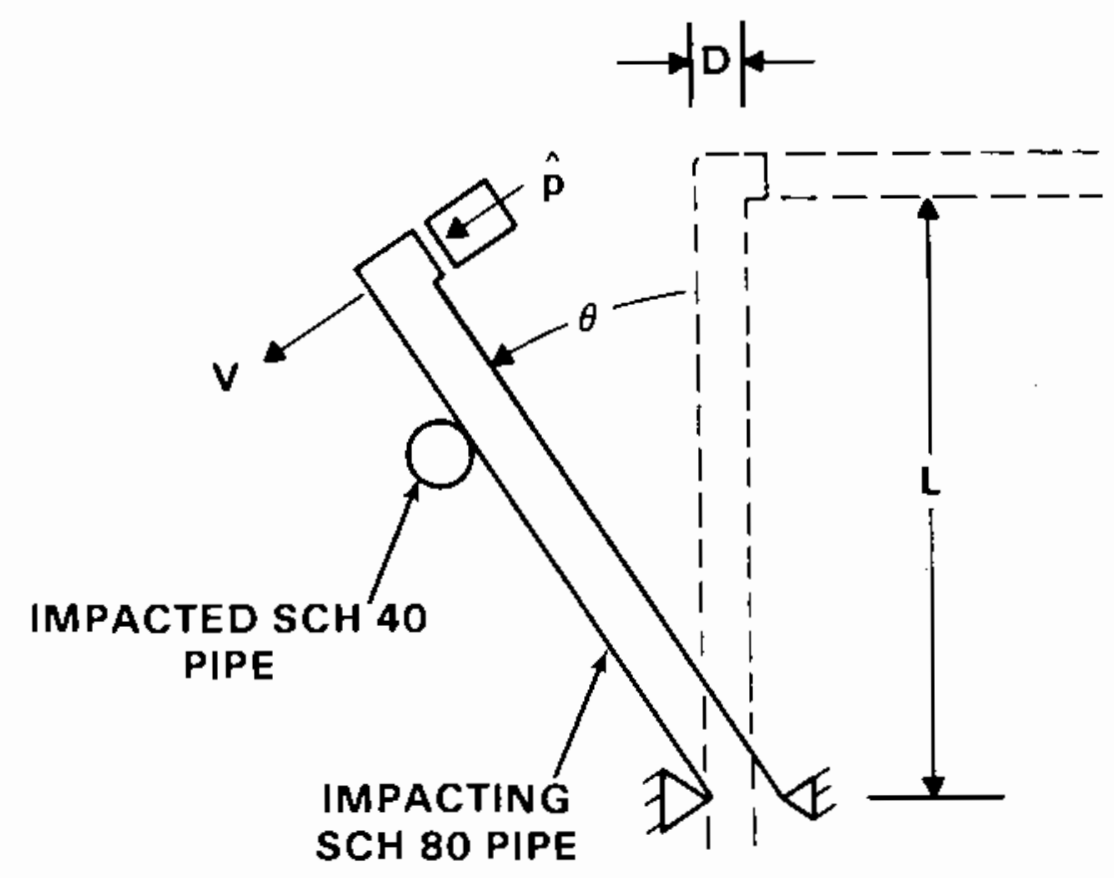

FIGURE 4.8. Configuration Used to Estimate Velocity/Energy Relationships

Figure 4.9 shows estimated impact velocities as a function of swing angle and tip motion as normalized by pipe diameter. Also shown is the velocity associated with rupture in the PNL tests. The results indicate that a tip motion of 2 to 4 diameters is sufficient to achieve a velocity that can rupture an adjacent pipe. This indicates that sufficient velocity can be readily achieved to rupture adjacent piping. Nevertheless, all impacts will not result in pipe failure, unless all or most governing parameters favor failure.

The probability of failure given an impact event was estimated by using judgment to attach numerical values to the individual probabilities governing rupture. Specificaliy, the probability of rupture was seen to be high if

- moving pipe has thicker wa11 $\left(P_{1}=0.25\right)$

- motion exceeds 3 to 4 diameters $\left(P_{2}=0.75\right)$

- jet force is normal to moving pipe $\left(P_{3}=0.5\right)$ 
TIP MOTION, $\delta / D$

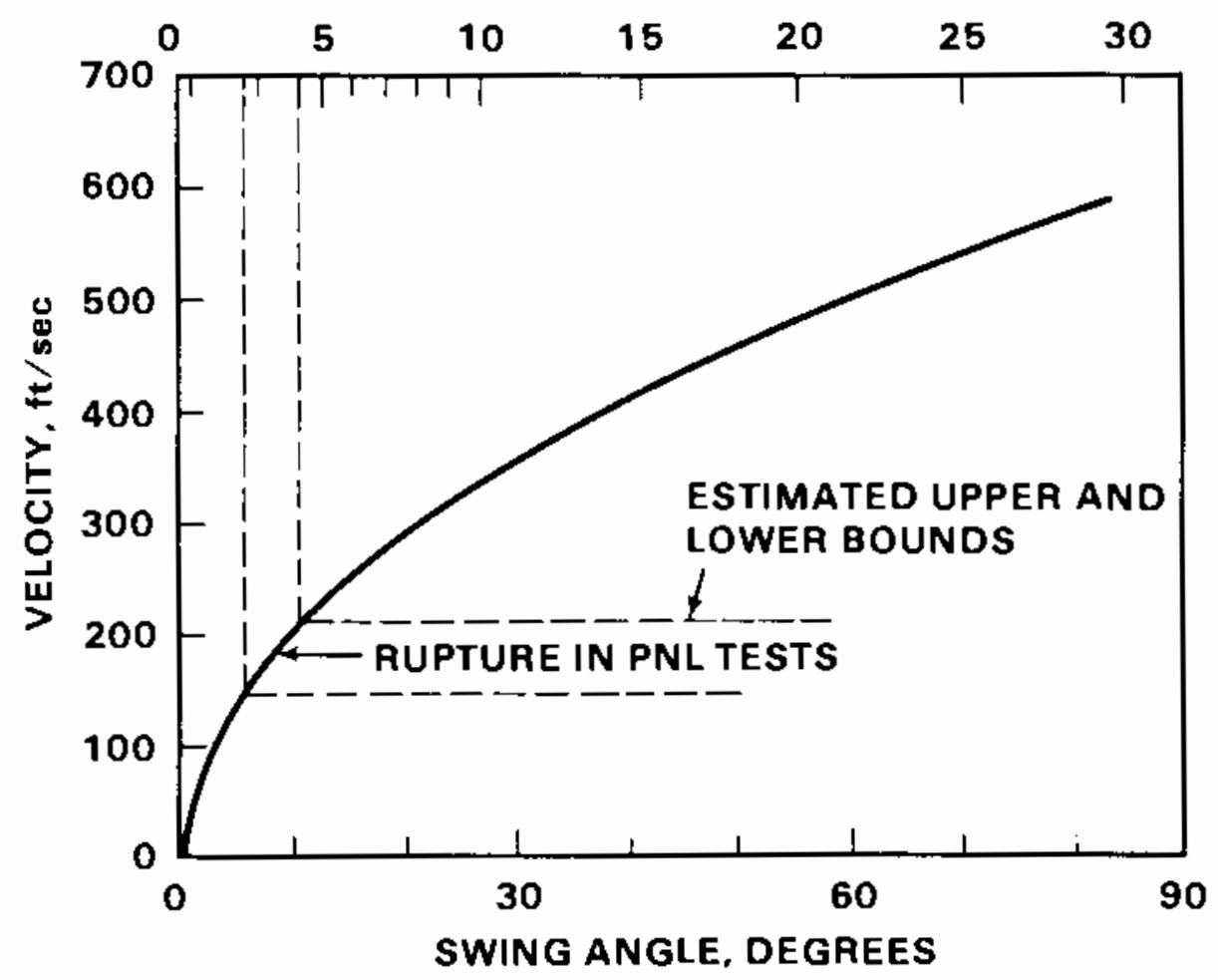

FIGURE 4.9. Estimated Velocities From Sample Calculation

- impacting pipes are normal $\left(P_{4}=0.25\right)$

- support/hinge is several diameters from break $\left(P_{5}=0.75\right)$.

Each of the individual probabilities is relatively high, but the probability that they all will have high or worst-case values in a given event is much lower. Specifically, the probability of a rupture, $P_{0}$, given an impact event can be estimated as $P_{0}=P_{1} \times P_{2} \times P_{3} \times P_{4} \times P_{5}=2 \times 10^{-2}$. This estimate assumes that all factors must be conducive to rupture, whereas rupture may occur in many cases if one parameter, particularly velocity, has an extreme value. In this regard, $P_{0}$ as estimated here can be viewed as a lower bound on failure probability. That is, more than one impact in $50\left(1 / 2 \times 10^{-2}\right)$ will result in a rupture. 
In estimating probabilities $P_{7}$ through $P_{5}$, a number of assumptions were made. For $P_{1}$ it was assumed that a typical plant has more small piping than larger pipes, but that the probability of a pipe breaking and being accelerated by a jet force is independent of diameter. In estimating $P_{2}$ it is recognized that mean pipe separations may exceed 3 to 4 diameters and $P_{2}$ could be greater than 0.75 . The probability $P_{3}$ was assigned a rather high value of 0.5 because one of the ends of the double-ended break may have an elbow that gives a jet force normal to the pipe. The probability $P_{4}$ was given a lower value of 0.25 because adjacent pipe will often have parallel routing. On the other hand, $P_{5}$ was assigned a higher value of 0.75 because at least one of the ends of a double-ended break will be remote from a support or hinge location.

The following general conclusions are supported by exploratory considerations of failure probabilities for impacts involving impact of unflawed piping:

- Impacts can occur at velocities higher than those of the PNL tests.

- The PNL test design includes many worst-case conditions.

- The probability of rupture may be as 10 as $2 \times 10^{-2}$ (given a pipe-onpipe impact event).

Furthermore, the analys is tends to support PNL's assumption that the probability of pipe ruptures due to pipe-to-pipe impact events will not be significantly affected by the presence of flaws in piping. Therefore, PNL's tests were properly focused on unflawed pipes. 
.

. 


\subsection{CONCLUSIONS AND RECOMMENDATIONS}

Based upon the experiments and analyses that have been conducted to date, a few preliminary conclusions can be made. One data point invalidated the current Standard Review Plan Section 3.6.2 criteria. In the Group 5b tests, impact by a large pipe (6-inch Sch 80) on a small pipe (3-inch Sch 160) did not cause rupture. However, because of the limitations on the number of size combinations and level of test kinetic energies, the criteria have not been evaluated for all possible scenarios. Results of the tests have shown that, in addition to pipe diameter and wall thickness, velocity and impact geometry could significantly affect the potential for rupture. Other parameters such as sectional modulus and support conditions may also be important. The results of the limited number of tests cannot by themselves determine the validity of the current criteria or serve as a basis from which to propose new criterja.

The initial results of the modeling efforts, although preliminary, are encouraging. Further work in this area is appropriate. Because the rupture of the impacted pipes is the primary consideration of the criteria, the results from any model that predicts bend angles and cross-sectional deformations represent only an intermediate step. A method is needed that uses these data to predict, within known limits, the likelihood of rupture. The failure model, if developed further, has the potential to achieve this.

Additional work on the Pipe-to-Pipe Impact Program has been proposed for the remainder of FY 1984. The main task proposed for FY 1984 consists of determining the range of parameters relevant to additional pipe-to-pipe impact scenarios, and developing the corresponding test matrix that reflects a better understanding of the phenomenon.

Work proposed for FY 1984 will include completing the additional tests and, if appropriate, recommending changes to the existing pipe-to-pipe impact licensing criteria. The associated value/impact evaluations will also be performed, and program results will be reported. 


\section{.}

, 


\section{REFERENCES}

Gudas, J. R., and B. C. Anderson. 1981. "J, $-R$ Curve Characteristics of Piping Materials and Welds." Paper presented at the U.S. Nuclear Regulatory Commission Water Reactor Safety Research Information Meeting, October 1981, Washington, O.C.

Harris, D. 0., E. Y. Lim and 0. D. Dedhia. 1981. Probabilistic Fracture Mechanics Analysis. Volume 5 of Probability of Pipe Fracture in the Primary Coolant Loop of a PWR Plant. NUREG/CR-2189 VOL. 5, U.S. Nuclear Regulatory Commission, Washington, D.C.

Hecker, S. S. 1973. "Formability of HSLA Steel Sheets." Metals Engineering Quarterly. 13:42.

Hecker, S. S. 1978. "Sheet Stretching Experiments." In Application of Numerical Methods to Forming Processes, eds. J. Armen and R. F. Jones. AMD-Vo7. 28, American Society of Mechanical Engineers, New York, New York.

Kumar, J., M. D. German and C. F. Shih. 1981. An Engineering Approach for Elastic-Plastic Fracture Analysis. EPRI NP-1931, Electric Power Research Institute, Palo Alto, California.

Langhaar, H. L. 1951. Dimensional Analys is and Theory of Models. John Wiley and Sons, New York, New York.

Meirovitch, L. 1967. Analytical Methods in Vibrations. The MacMillan Company, New York, New York.

Norris, D. M., J. E. Reough, B. Moran and D. F. Quinones. 1978. "A Plastic, Mean-Stress Criterion for Ouctile Fracture." ASME Journal of Engineering Materials and Technology. 100:279-286.

Robinson, R. A., W. J. Zielenbach and A. A. Lawrence. 1976. A Survey of Strain-Rate Effects for Some Common Structural Materials Used in Radioactive Material Packaging and Transportation Systems. BMI 1954, Battelle Columbus Laboratories, Columbus, Ohio.

Thomas, H. M. 1979. "In-Service Inspection is Over-Rated." International Nuclear Engineering Journal. $51(6): 43-46$. 


\section{APPENDIX A}

\section{CALCULATION OF PLASTIC BENDING MOMENTS}

FOR PARTIALLY CRUSHED PIPES 
APPENDIX A

\section{CALCULATION OF PLASTIC BENDING MOMENTS FOR}

\section{PARTIALLY CRUSHED PIPES}

For the pipe flexure model, values for the plastic moments of the impacting and target pipes are needed. The cross sections of the locations for which the plastic moments are needed (the impact location) are not circular but deformed due to the crushing event. Although plastic moments could be calculated based on undeformed circular geometry, it is felt that a closer approximation would be achieved with an assumed elliptical cross section.

Consider the deformed and undeformed cross sections shown in Figure A.1. For a given crush deformation ( $d$ - 2b), an expression is needed for the plastic moment of the crushed elliptical section. To this end, two assumptions were made:

- The wall thickness of the elliptical section at $\theta=0^{\circ}, 90^{\circ}, 180^{\circ}$, and $270^{\circ}$ is equal to that of the original circular section.

- The area of material (annular cross-sectional area) of the two sections is equal.

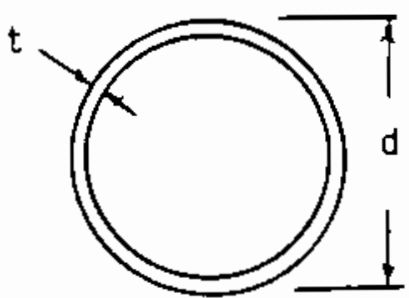

Origina? Section

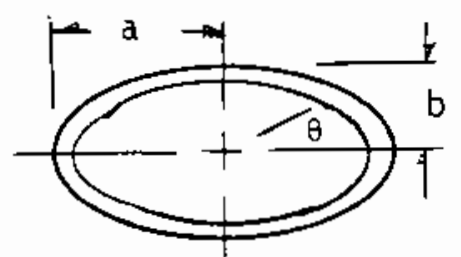

Crushed Section

FIGURE A.1. Assumed Elliptical Ovalization Geometry for Crushed Pipe Sections 
From these assumptions, the area of circular annulus = area of elliptical annulus, as shown by

$$
\begin{aligned}
\frac{\pi}{4}\left[d^{2}-(d-2 t)^{2}\right] & =\pi[a b-(a-t)(b-t)] \\
\frac{\pi}{4}\left(4 t d-4 t^{2}\right) & =\pi\left[(a+b) t-t^{2}\right] \\
d & =a+b \\
a & =d-b
\end{aligned}
$$

Thus, for a given initial diameter (d), wall thickness $(t)$, and crush deformation ( $d-2 b$ ), the major axis parameter (a) may be readily determined. The plastic moment about the horizontal axis for the elliptical section is now expressible as

$$
M_{p}=\frac{4}{3} \sigma_{y}\left[a b^{2}-(a-t)(b-t)^{2}\right]
$$


APPENDIX B

DERIVATION OF TARGET PIPE VOLUMETRIC COMPLIANCE 


\section{APPENDIX B}

\section{DERIVATION OF TARGET PIPE VOLUMETRIC COMPLIANCE}

In Section 3.0, the following expression was given for the force necessary to crush a fluid-filled pipe a given distance:

$$
\begin{aligned}
F(\delta) & =F_{\text {empty }}(\delta)+F_{p}(\delta) \\
F_{p}(\delta) & =\left(P_{0}+\frac{V}{C}\right) \frac{d V}{d \delta}
\end{aligned}
$$

$$
\text { Where } \begin{array}{ll}
F & =\text { total force } \\
F_{\text {empty }}= & \text { force for empty pipe } \\
F_{P} & =\text { additional force for fluid-filled pipe } \\
P_{0} & =\text { initial pressure in pipe (for } \delta=0) \\
V & =\text { volume displacement in the immediate vicinity of the } \\
& \text { concentrated load } \\
& =\text { crush displacement } \\
& =\text { pipe volumetric compliance } \\
C & \quad C=\frac{\pi}{4} L \\
d & =\text { pipe diameter } \\
t & =\text { pipe wall thickness } \\
E & =\text { Young's modulus } \\
V & =\text { Poisson's ratio } \\
L & =\text { pipe length } \\
B & =\text { bulk modulus of liquid contents }
\end{array}
$$

B. 1 
In arriving at this expression for $F_{p}(\delta)$, the following assumptions were made.

- The pipe is long relative to the region containing plastic deformations.

- The local volume displaced during crush is a unique function of, and independent of, fluid contents.

- The pipe remains elastic except for a small region in the impact vicinity.

- The crush event is quasi-static.

Consider the pipe crush situation shown in Figure B.1. From energy considerations, the force due to fluid pressure $F_{p}(\delta)$ is

$$
F_{p}(\delta)=P \frac{d V}{d \delta}
$$

where $P=P_{0}+\Delta P$

$$
\begin{aligned}
& P_{0}=\text { initial pressure of fluid } \\
& \Delta P=\text { pressure increase due to } V .
\end{aligned}
$$

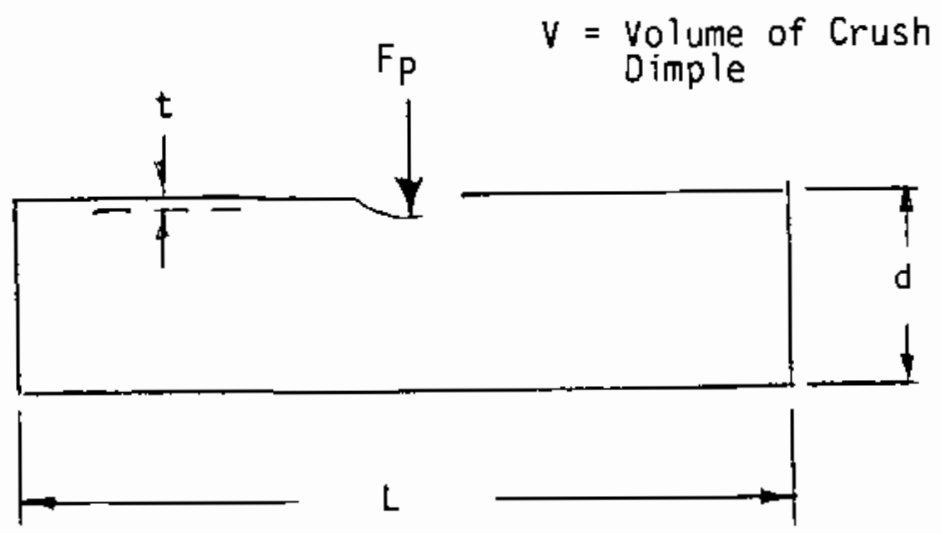

FIGURE B.1. Geometry and Terminology for Volumetric Compliance Analys is 
The crush volume is expressible as

$$
v=v_{f}+v_{p}
$$

where $V_{f}=$ contraction of fluid volume due to $\Delta P$

$V_{P}=$ increase in pipe volume due to $\Delta P$.

An expression for $V_{f}$ is

$$
V_{f}=\frac{\Delta P}{\beta} \frac{\pi d^{2} L}{4}
$$

where $B$ is the fluid bulk modulus.

$V_{p}$ must be computed by considering circumferential and axial stretching of the pipe wall due to $\Delta P$. The axial and circumferential stresses in the pipe wall, neglecting end effects, are

$$
\begin{aligned}
& \sigma_{z}=\frac{\Delta P_{d}}{\Delta t} \\
& \sigma_{\theta}=\frac{\Delta P_{d}}{2 t}
\end{aligned}
$$

Corresponding strains are

$$
\begin{aligned}
& \varepsilon_{z}=\frac{\sigma_{z}}{E}-\frac{\nu \sigma_{\theta}}{E}=\frac{\Delta P_{d}}{E t}\left(\frac{1}{4}-\frac{v}{2}\right) \\
& \varepsilon_{\theta}=\frac{\sigma_{\theta}}{E}-\frac{\nu \sigma_{z}}{E}=\frac{\Delta P_{d}}{E t}\left(\frac{1}{2}-\frac{v}{4}\right)
\end{aligned}
$$

$V_{p}$ is now expressibie as

$$
\begin{aligned}
& V_{p}=L\left(1+\varepsilon_{z}\right) \frac{\pi\left[d\left(1+\varepsilon_{\theta}\right)\right]^{2}}{4}-\frac{\pi d^{2}}{4} L \\
& V_{p}=\frac{\Delta P_{d} L}{4 E t} \pi d^{2}\left[\frac{5}{4}-v\right] \text { for smal } 1 \varepsilon_{z} \text { and } \varepsilon_{\theta}
\end{aligned}
$$


The crush volume now takes the form

$$
V=\Delta P \frac{\pi d^{2} L}{4}\left[\frac{d}{E t}\left(\frac{5}{4}-\nu\right)+\frac{1}{\beta}\right]
$$

Substituting into the expression for $F_{p}(\delta)$,

$$
\begin{aligned}
F_{P}(\delta) & =\left(P_{0}+\frac{V}{C}\right) \frac{d V}{d \delta} \\
C & =\frac{\pi d^{2} L}{4}\left[\frac{d}{E t}(5 / 4-v)+\frac{1}{\beta}\right]
\end{aligned}
$$

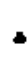

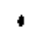

$*$

B. 4 


\section{DISTRIBUTION}

No. of

Copies

OFFSITE

10

Dr. G. H. Weidenhamer

Mechanical and Structural

Engineering Research Branch

U.S. Nuclear Regulatory Commission

Mail Stop 1130-SS

Washington, D.C. 20555

2 NRC Division of Technical Information and Document Control

Washington, D.C. 20555

2 DOE Technical Information Center

U.S. Department of Energy

P.0. Box 62

Oak Ridge, TN 37830

J. E. Richardson

U.S. Nuclear Regulatory Commission

Mail Stop 1130-5S

Washington, D.C. 20555

R. J. Bosnak

Mechanical Engineering Branch

Division of Engineering

U.S. Nuclear Regulatory Commission

Washington, D.C. 20555

Dr. S. N. Hou

Mechanical Engineering Branch

Division of Engineering

U.S. Nuclear Reguiatory Commission

Washington, D.C. 20555
No. of

Copies

ONSITE

15 Pacific Northwest Laboratory

J. M. Alzhe imer (2)

M.C.C. Bampton

D. R. Ells

J. R. Friley

L. R. Shotwe 1

F. A. Simonen

L. A. Strope

A. M. Sutey

Technical Information (4)

Publishing Coordination (2) 